Cochrane Database of Systematic Reviews

\title{
Valproate preparations for agitation in dementia (Review)
}

Baillon SF, Narayana U, Luxenberg JS, Clifton AV

Baillon SF, Narayana U, Luxenberg JS, Clifton AV.

Valproate preparations for agitation in dementia.

Cochrane Database of Systematic Reviews 2018, Issue 10. Art. No.: CD003945.

DOI: 10.1002/14651858.CD003945.pub4.

www.cochranelibrary.com 
TABLE OF CONTENTS

PLAIN LANGUAGE SUMMARY

SUMMARY OF FINDINGS

BACKGROUND

OBJECTIVES

METHODS

Figure 1.

RESULTS

Figure 2.

DISCUSSION

AUTHORS' CONCLUSIONS

ACKNOWLEDGEMENTS

REFERENCES

\section{CHARACTERISTICS OF STUDIES}

DATA AND ANALYSES

Analysis 1.1. Comparison 1 Valproate preparations versus placebo, Outcome 1 Brief Psychiatric Rating Scale (BPRS) total score. Change from baseline at 6 weeks (intention to treat (ITT)).

Analysis 1.2. Comparison 1 Valproate preparations versus placebo, Outcome 2 BPRS agitation factor. Change from baseline at 6 weeks (ITT).

Analysis 1.3. Comparison 1 Valproate preparations versus placebo, Outcome 3 Cohen-Mansfield Agitation Index. Total Score. Change from baseline at 6 weeks (ITT).

Analysis 1.4. Comparison 1 Valproate preparations versus placebo, Outcome 4 BPRS hostility factor. Change from baseline at 6 weeks (ITT).

Analysis 1.5. Comparison 1 Valproate preparations versus placebo, Outcome 5 Overt Aggression Scale total score. Change from baseline at 6 weeks (ITT).

Analysis 1.6. Comparison 1 Valproate preparations versus placebo, Outcome 6 Neuropsychiatric Inventory total score. Change from baseline at 6 weeks (ITT).

Analysis 1.7. Comparison 1 Valproate preparations versus placebo, Outcome 7 Neuropsychiatric Inventory Agitation/ Aggression subscore. Change from baseline at 6 weeks (ITT).

Analysis 1.8. Comparison 1 Valproate preparations versus placebo, Outcome 8 Mini-Mental State Examination total score. Change from baseline at 6 weeks (ITT).

Analysis 1.9. Comparison 1 Valproate preparations versus placebo, Outcome 9 Physical Self-Maintenance Scale total score. Change from baseline at 6 weeks (ITT).

Analysis 2.1. Comparison 2 Divalproex versus placebo, Outcome 1 Total number of participants with sedation at 6 weeks. ..... Analysis 2.2. Comparison 2 Divalproex versus placebo, Outcome 2 Total number of participants with nausea, vomiting, or diarrhoea at 6 weeks.

Analysis 2.3. Comparison 2 Divalproex versus placebo, Outcome 3 Total number of participants with a urinary tract infection by 6 weeks.

Analysis 2.4. Comparison 2 Divalproex versus placebo, Outcome 4 Total number of participants who had falls by 6 weeks. ..... Analysis 2.5. Comparison 2 Divalproex versus placebo, Outcome 5 Total number of participants with general disorders by 6 weeks.

Analysis 2.6. Comparison 2 Divalproex versus placebo, Outcome 6 Total number of participants with postural instability by 6 weeks.

Analysis 2.7. Comparison 2 Divalproex versus placebo, Outcome 7 Total number of participants with weakness by 6 weeks. ...

Analysis 2.8. Comparison 2 Divalproex versus placebo, Outcome 8 Total number of participants with cardiovascular problems by 6 weeks.

Analysis 2.9. Comparison 2 Divalproex versus placebo, Outcome 9 Total number of participants with oedema by 6 weeks. ...... Analysis 2.10. Comparison 2 Divalproex versus placebo, Outcome 10 Total number of participants with a fever by 6 weeks. .... Analysis 2.11. Comparison 2 Divalproex versus placebo, Outcome 11 Total number of participants with a respiratory problem by 6 weeks.

Analysis 2.12. Comparison 2 Divalproex versus placebo, Outcome 12 Total number of participants with ataxia at 6 weeks. ..... Analysis 2.13. Comparison 2 Divalproex versus placebo, Outcome 13 Total number of participants with a skin problem at 6 weeks. 
Analysis 2.14. Comparison 2 Divalproex versus placebo, Outcome 14 Total number of participants with trauma (other than falls) by 6 weeks.

Analysis 2.15. Comparison 2 Divalproex versus placebo, Outcome 15 Total number of participants with thrombocytopenia by 6 weeks.

Analysis 2.16. Comparison 2 Divalproex versus placebo, Outcome 16 Total number of participants with joint problems by 6 weeks.

Analysis 2.17. Comparison 2 Divalproex versus placebo, Outcome 17 Total number of participants with other infection by 6 weeks.

Analysis 2.18. Comparison 2 Divalproex versus placebo, Outcome 18 Total number of participants with hallucinations by 6 weeks.

Analysis 2.19. Comparison 2 Divalproex versus placebo, Outcome 19 Total number of participants with accidental injury by 6 weeks.

Analysis 2.20. Comparison 2 Divalproex versus placebo, Outcome 20 Total number of participants with anorexia by 6 weeks. ..

Analysis 2.21. Comparison 2 Divalproex versus placebo, Outcome 21 Total number of participants with weight loss by 6 weeks.

Analysis 2.22. Comparison 2 Divalproex versus placebo, Outcome 22 Total number of participants with dehydration by 6 weeks.

Analysis 2.23. Comparison 2 Divalproex versus placebo, Outcome 23 Total number of participants with metabolism and nutritional disorders by 6 weeks.

Analysis 2.24. Comparison 2 Divalproex versus placebo, Outcome 24 Total number of participants with psychiatric disorders by 6 weeks.

Analysis 2.25. Comparison 2 Divalproex versus placebo, Outcome 25 Total number of participants with other gastrointestinal problem by 6 weeks.

Analysis 2.26. Comparison 2 Divalproex versus placebo, Outcome 26 Total numbers of participants with nervous system disorders by 6 weeks.

Analysis 2.27. Comparison 2 Divalproex versus placebo, Outcome 27 Total number of participants with any adverse event by 6 weeks.

Analysis 2.28. Comparison 2 Divalproex versus placebo, Outcome 28 Total number of participants with serious adverse events by 6 weeks.

ADDITIONAL TABLES

APPENDICES

WHAT'S NEW

HISTORY

CONTRIBUTIONS OF AUTHORS

DECLARATIONS OF INTEREST

SOURCES OF SUPPORT

DIFFERENCES BETWEEN PROTOCOL AND REVIEW

INDEX TERMS 
[Intervention Review]

\title{
Valproate preparations for agitation in dementia
}

\author{
Sarah F Baillon 1,2 , Usha Narayana ${ }^{3}$, Jay S Luxenberg ${ }^{4}$, Andrew V Clifton 5
}

1Department of Health Sciences, University of Leicester, Leicester, UK. ${ }^{2}$ Research and Development Department, Leicestershire Partnership NHS Trust, Leicester, UK. ${ }^{3}$ Old Age Psychiatry, Leeds and York Partnerships NHS Foundation Trust, York, UK. ${ }^{4}$ On Lok, San

Francisco, California, USA. ${ }^{5}$ Faculty of Health and Life Sciences, De Montfort University, Leicester, UK

Contact: Andrew V Clifton, Faculty of Health and Life Sciences, De Montfort University, 3.10 Edith Murphy House, The Gateway, Leicester, LE19BH, UK. andrew.clifton@dmu.ac.uk.

Editorial group: Cochrane Dementia and Cognitive Improvement Group.

Publication status and date: New search for studies and content updated (no change to conclusions), published in Issue 10, 2018.

Citation: Baillon SF, Narayana U, Luxenberg JS, Clifton AV. Valproate preparations for agitation in dementia. Cochrane Database of Systematic Reviews 2018, Issue 10. Art. No.: CD003945. DOI: 10.1002/14651858.CD003945.pub4.

Copyright @ 2018 The Cochrane Collaboration. Published by John Wiley \& Sons, Ltd.

\section{A B S T R A C T}

\section{Background}

Agitation has been reported in up to $90 \%$ of people with dementia. Agitation in people with dementia worsens carer burden, increases the risk of injury, and adds to the need for institutionalisation. Valproate preparations have been used in an attempt to control agitation in dementia, but their safety and efficacy have been questioned.

\section{Objectives}

To determine the efficacy and adverse effects of valproate preparations used to treat agitation in people with dementia, including the impact on carers.

\section{Search methods}

We searched ALOIS - the Cochrane Dementia and Cognitive Improvement Group's Specialized Register on 7 December 2017 using the terms: valproic OR valproate OR divalproex. ALOIS contains records from all major health care databases (the Cochrane Library, MEDLINE, Embase, PsycINFO, CINAHL, LILACS) as well as from many trials databases and grey literature sources.

\section{Selection criteria}

Randomised, placebo-controlled trials that assessed valproate preparations for agitation in people with dementia.

\section{Data collection and analysis}

Two review authors independently screened the retrieved studies against the inclusion criteria and extracted data and assessed methodological quality of the included studies. If necessary, we contacted trial authors to ask for additional data, including relevant subscales, or for other missing information. We pooled data in meta-analyses where possible. This is an update of a Cochrane Review last published in 2009. We found no new studies for inclusion.

\section{Main results}

The review included five studies with 430 participants. Studies varied in the preparations of valproate, mean doses (480 mg/day to $1000 \mathrm{mg} /$ day), duration of treatment (three weeks to six weeks), and outcome measures used. The studies were generally well conducted although some methodological information was missing and one study was at high risk of attrition bias.

The quality of evidence related to our primary efficacy outcome of agitation varied from moderate to very low. We found moderate-quality evidence from two studies that measured behaviour with the total Brief Psychiatric Rating Scale (BPRS) score (range 0 to 108) and with the BPRS agitation factor (range 0 to 18). They found that there was probably little or no effect of valproate treatment over six weeks (total BPRS: 
mean difference (MD) 0.23 , 95\% confidence interval (CI) -2.14 to 2.59; 202 participants, 2 studies; $\mathrm{BPRS}$ agitation factor: $\mathrm{MD}-0.67,95 \% \mathrm{Cl}-$ 1.49 to $0.15 ; 202$ participants, 2 studies). Very low-quality evidence from three studies which measured agitation with the Cohen-Mansfield Agitation Index (CMAI) were consistent with a lack of effect of valproate treatment on agitation. There was variable quality evidence on other behaviour outcomes reported in single studies of no difference between groups or a benefit for the placebo group.

Three studies, which measured cognitive function using the Mini-Mental State Examination (MMSE), found little or no effect of valproate over six weeks, but we were uncertain about this result because the quality of the evidence was very low. Two studies that assessed functional ability using the Physical Self-Maintenance Scale (PSMS) (range 6 to 30) found that there was probably slightly worse function in the valproate-treated group, which was of uncertain clinical importance (MD 1.19, 95\% Cl 0.40 to 1.98; 203 participants, 2 studies; moderatequality evidence).

Analysis of adverse effects and serious adverse events (SAE) indicated a higher incidence in valproate-treated participants. A meta-analysis of three studies showed that there may have been a higher rate of adverse effects among valproate-treated participants than among controls (odds ratio (OR) 2.02, 95\% Cl 1.30 to 3.14; 381 participants, 3 studies, low-quality evidence). Pooled analysis of the number of SAE for the two studies that reported such data indicated that participants treated with valproate preparations were more likely to experience SAEs (OR 4.77, 95\% CI 1.00 to $22.74 ; 228$ participants, 2 studies), but the very low quality of the data made it difficult to draw any firm conclusions regarding SAEs. Individual adverse events that were more frequent in the valproate-treated group included sedation, gastrointestinal symptoms (nausea, vomiting, and diarrhoea), and urinary tract infections.

\section{Authors' conclusions}

This updated review corroborates earlier findings that valproate preparations are probably ineffective in treating agitation in people with dementia, but are associated with a higher rate of adverse effects, and possibly of SAEs. On the basis of this evidence, valproate therapy cannot be recommended for management of agitation in dementia. Further research may not be justified, particularly in light of the increased risk of adverse effects in this often frail group of people. Research would be better focused on effective non-pharmacological interventions for this patient group, or, for those situations where medication may be needed, further investigation of how to use other medications as effectively and safely as possible.

\section{PLAIN LANGUAGE SUMMARY}

\section{Valproate preparations for the treatment of agitated behaviour in people with dementia}

\section{Background}

Agitated behaviour is very common in the later stages of dementia. It can include verbal behaviours, such as shouting, and physical behaviours, such as wandering or physical aggression. It has been shown to worsen the stress experienced by family carers, increase the risk of injury, and increase the need for people with dementia to move into institutional care.

A type of medication that has been used to treat agitated behaviour in people who have dementia is valproate, which is available in several different preparations (valproic acid, divalproex sodium, sodium valproate, and valproate semi-sodium). These medications are not recommended in current guidelines (e.g. from the National Institute for Health and Care Excellence), but are sometimes still given to people with dementia to treat agitated behaviour.

\section{Purpose of this review}

We wanted to review the evidence about how effective and safe it is to give valproate preparations to people with dementia to treat agitation.

\section{Studies included in this review}

We searched medical databases up to December 2017 for studies that compared any preparation of valproate with a placebo (dummy tablet) to treat agitated behaviour in people diagnosed with dementia.

We included five studies with 479 participants who had various types of dementia and agitated behaviour. Most studies lasted for six weeks, although one was only three weeks long. The studies were generally well conducted, but the methods were not always fully reported and one study was at high risk of bias because of the high number of people who dropped out from the valproate-treated group.

\section{Key findings}

Studies measured agitated behaviour with various scales and the reliability of the evidence for the different scales ranged from moderate to very low. Overall, we found no evidence that valproate preparations improved behaviour, or specifically, agitated behaviour. We found that valproate preparations probably had little or no effect on participants' ability to perform daily activities. We could not be sure whether they had an effect on cognition (thinking and remembering) because the reliability of the evidence was very low. 
We found low-reliability evidence from three studies that participants taking valproate may be more likely than those taking placebo to experience harmful effects. We could not be as certain about differences in serious harms, such as serious illness or admission to hospital, but data from two studies suggested that these may be more common in the participants taking valproate. Some of the side effects associated with valproate were sleepiness, feeling sick, being sick, watery stools, and urinary tract infections.

\section{Conclusions}

We only identified five relatively small studies for inclusion in this review. They varied in their methods, type of medicine and its dose, duration of treatment, and scales used to make measurements. This limited our ability to pool data across studies. However, we could be moderately confident in the conclusion that valproate preparations do not improve agitated behaviour in dementia. They may also be associated with harmful effects. 
SUMMARY OF FINDINGS

\section{Summary of findings for the main comparison. Valproate preparations compared to placebo for agitation in dementia}

Valproate preparations compared to placebo for agitation in dementia

Patient or population: people with agitation in dementia

Setting:

Intervention: valproate preparations

Comparison: placebo

\begin{tabular}{|c|c|c|c|c|c|c|}
\hline \multirow[t]{2}{*}{ Outcomes } & \multicolumn{2}{|c|}{ Anticipated absolute effects ${ }^{\star}(95 \% \mathrm{Cl})$} & \multirow{2}{*}{$\begin{array}{l}\text { Relative effect } \\
(95 \% \mathrm{Cl})\end{array}$} & \multirow{2}{*}{$\begin{array}{l}\text { № of partici- } \\
\text { pants } \\
\text { (studies) }\end{array}$} & \multirow{2}{*}{$\begin{array}{l}\text { Certainty of } \\
\text { the evidence } \\
\text { (GRADE) }\end{array}$} & \multirow[t]{2}{*}{ Comments } \\
\hline & Risk with placebo & $\begin{array}{l}\text { Risk with val- } \\
\text { proate prepara- } \\
\text { tions }\end{array}$ & & & & \\
\hline $\begin{array}{l}\text { Agitation and aggression } \\
\text { assessed with: Brief Psychiatric Rating Scale } \\
\text { total score. Change from baseline at } 6 \text { weeks } \\
\text { (ITT) }\end{array}$ & $\begin{array}{l}\text { The mean change from } \\
\text { baseline for agitation } \\
\text { and aggression was - } \\
5.34 \text { points. }\end{array}$ & $\begin{array}{l}\text { MD } 0.23 \text { higher } \\
\text { (2.14 lower to } 2.59 \\
\text { higher) }\end{array}$ & - & $\begin{array}{l}202 \\
\text { (2 RCTs) }\end{array}$ & $\begin{array}{l}\oplus \oplus \oplus \odot \\
\text { Moderate } \\
a, b\end{array}$ & - \\
\hline \multicolumn{7}{|l|}{$\begin{array}{l}\text { Scale: } 0-108 \text { (higher score indicated higher } \\
\text { level of dysfunction) }\end{array}$} \\
\hline $\begin{array}{l}\text { Agitation and aggression } \\
\text { assessed with: BPRS agitation factor. Change } \\
\text { from baseline at } 6 \text { weeks (ITT) } \\
\text { Scale: } 0-18 \text { (higher score indicated higher lev- } \\
\text { el of dysfunction) }\end{array}$ & $\begin{array}{l}\text { The mean change from } \\
\text { baseline for agitation } \\
\text { and aggression was - } \\
1.88 \text { points. }\end{array}$ & $\begin{array}{l}\text { MD } 0.67 \text { lower } \\
\text { (1.49 lower to } 0.15 \\
\text { higher) }\end{array}$ & - & $\begin{array}{l}202 \\
(2 \mathrm{RCTs})\end{array}$ & $\begin{array}{l}\oplus \oplus \oplus \Theta \\
\text { Moderate } a, b\end{array}$ & - \\
\hline $\begin{array}{l}\text { Agitation and aggression } \\
\text { assessed with: Cohen-Mansfield Agitation } \\
\text { Index total score. Change from baseline at } 6 \\
\text { weeks (ITT) }\end{array}$ & $\begin{array}{l}\text { The mean change from } \\
\text { baseline for agitation } \\
\text { and aggression was - } \\
4.42 \text { points. }\end{array}$ & $\begin{array}{l}\text { MD } 1.84 \text { lower } \\
\text { (6.02 lower to } 2.34 \\
\text { higher) }\end{array}$ & - & $\begin{array}{l}217 \\
\text { (3 RCTs) }\end{array}$ & $\begin{array}{l}\oplus \ominus \ominus \ominus \\
\text { Very low } a, b, c, d\end{array}$ & - \\
\hline \multicolumn{7}{|l|}{$\begin{array}{l}\text { Scale: } 0-216 \text { (higher score indicated more agi- } \\
\text { tated behaviour) }\end{array}$} \\
\hline $\begin{array}{l}\text { Cognition } \\
\text { assessed with: Mini-Mental State Examina- } \\
\text { tion total score. Change from baseline at } 6\end{array}$ & $\begin{array}{l}\text { The mean change from } \\
\text { baseline for cognition } \\
\text { was } 0.46 \text { points. }\end{array}$ & $\begin{array}{l}\text { MD } 0.7 \text { lower } \\
\text { (1.61 lower to } 0.2 \\
\text { higher) }\end{array}$ & - & $\begin{array}{l}217 \\
\text { (3 RCTs) }\end{array}$ & $\begin{array}{l}\oplus \ominus \ominus \odot \\
\text { Very low } a, b, c, d\end{array}$ & - \\
\hline
\end{tabular}

weeks (ITT) 
Scale: 0-30 (lower score indicated greater cognitive impairment)

\section{Functional performance}

assessed with: Physical Self-Maintenance

Scale total score. Change from baseline at 6

weeks (ITT)

The mean change from

baseline for functional

performance was 0.06

MD 1.19 higher

(0.4 higher to 1.98

203

$\oplus \oplus \oplus \ominus$

higher)

Moderate $^{a}$

Scale: 6-30 (higher score indicated greater

impairment in ADL)

\section{Any adverse event by 6 weeks}

points.

$-$

Study population

OR 2.02

(1.30 to 3.14)

381

(3 RCTs)

$\oplus \oplus \ominus \ominus$

602 per 1000

753 per 1000

(663 to 826 )

Serious adverse events by 6 weeks

Study population

OR 4.77

228

$\oplus \ominus \ominus \ominus$

18 per 1000

79 per 1000

(18 to 291)

*The risk in the intervention group (and its $95 \%$ confidence interval) is based on the assumed risk in the comparison group and the relative effect of the intervention (and its $95 \% \mathrm{Cl}$ ).

ADL: activities of daily living; Cl: confidence interval; ITT: intention to treat; MD: mean difference; OR: odds ratio; RCT: randomised controlled trial.

\section{GRADE Working Group grades of evidence}

High quality: we are very confident that the true effect lies close to that of the estimate of the effect.

Moderate quality: we are moderately confident in the effect estimate: the true effect is likely to be close to the estimate of the effect, but there is a possibility that it is sub-

stantially different.

Low quality: our confidence in the effect estimate is limited: the true effect may be substantially different from the estimate of the effect.

Very low quality: we have very little confidence in the effect estimate: the true effect is likely to be substantially different from the estimate of effect.

aDowngraded one level for imprecision due to small number of participants.

$b$ Downgraded in light of imprecision due to confidence intervals including the potential for harm or benefit.

cDowngraded one level due to inconsistency (heterogeneity between studies).

$d$ Downgraded one level due to study limitations (risk of bias). 


\section{B A C K G R O U N D}

\section{Description of the condition}

Agitation is reported in up to $90 \%$ of people with dementia (Alzheimer's Society 2011a). A widely accepted definition of agitation is: "inappropriate verbal, vocal, or motor activity that is not explained by needs or confusion per se" (Billig 1991; CohenMansfield 1989). The descriptors of agitation include wandering, crying out, aggressiveness, repetitive movements, and uncooperative behaviour. Agitation in people with dementia worsens carer burden, increases the risk of injury, and adds to the need for institutionalisations (Livingstone 2014).

\section{Description of the intervention}

Current guidelines recommend that people with dementia who develop non-cognitive symptoms or behaviours that cause them distress or challenge those who provide their care should first have a comprehensive assessment to determine likely causative factors, such as physical illness, depression, pain, adverse effects of medication, personal or psychosocial factors, or aspects of their physical environment. Appropriate steps should then be taken to address those factors, and a period of 'watchful waiting' should be observed, if possible, as in many cases symptoms will improve or resolve over four to six weeks (Alzheimer's Society 2011a). The guidelines also suggest that consideration should be given to providing individualised interventions such as aromatherapy or multisensory stimulation as there is some evidence of their clinical effectiveness (Livingstone 2014; NICE 2006). In fact, research has shown that just 10 minutes of one-to-one time each day can reduce behavioural and psychological symptoms associated with dementia (BPSD) (Alzheimer's Society 2011b).

The National Institute for Health and Care Excellence (NICE) guideline on supporting people with dementia and their carers suggests that people with dementia who present with noncognitive symptoms or challenging behaviour should be offered pharmacological intervention in the first instance "only if they are severely distressed or there is an immediate risk of harm to the person or others" and that a thorough assessment of possible causes of the behaviour should be carried out as soon as possible (NICE 2016). Drug treatment for the control of violence, aggression, and extreme agitation should be implemented with the aim of avoiding sedation and the use of high doses or combinations of drugs, and with careful monitoring of the person's physical condition and any adverse effects (NICE 2006).

If drug treatment of agitation is considered necessary, then the drug classes recommended by NICE, in order, are antipsychotics, acetylcholinesterase inhibitors, and memantine. There is some evidence of modest benefits of antipsychotics in around $50 \%$ of people with dementia, but they are associated with adverse effects such as sedation, parkinsonism, gait disturbance, dehydration, falls, chest infection, accelerated cognitive decline, and stroke, and they are associated with increased mortality in the long term (Alzheimer's Society 2011b; Maher 2011). The increased risk of cerebrovascular adverse events and death in this patient group resulted in a Medicines and Healthcare products Regulatory Agency (MHRA) warning that no antipsychotic should be used for this indication in dementia (except risperidone in some circumstances) (MHRA 2012). Risperidone is the only antipsychotic licensed for people with dementia, and guidelines recommend treatment should be used for no longer than 12 weeks. The evidence of benefit of other types of antipsychotics is more limited, and use for BPSD is off-label. Acetylcholinesterase inhibitors and memantine are licensed for the treatment of cognitive symptoms in Alzheimer's disease and there is some evidence that these medications may positively impact on agitated behaviour, although there is no evidence that they specifically improve agitation (NICE 2006).

Other medications that have been used to treat agitated behaviour in people with dementia include benzodiazepines, hypnotics, antidepressants, and anticonvulsants. There is no evidence of benefit of benzodiazepines for this indication, and they carry increased risk of adverse effects (Bierman 2007). There is relatively little evidence relating to antidepressants for agitated behaviour in dementia; findings on efficacy are mixed and there is evidence of adverse effects (Porteinsson 2014; Seitz 2011). Among anticonvulsants, carbamazepine and valproate preparations have both been used widely.

\section{How the intervention might work}

Various valproate preparations are available: valproic acid, divalproex, sodium valproate, and valproate semi-sodium. Suggested mechanisms by which valproic acid may have an impact on agitation include enhancement of the intracerebral neurotransmitting agent, gamma-butyric acid (GABA), antimanic action, and mood stabilising effect (Lon 1995). Since 1996, a more readily tolerated compound of valproate, divalproex, has been used. This drug differs slightly from valproic acid in that peak blood flow levels occur later (three to six hours, compared with three hours), but the dosage and half-life of this drug are identical to those of valproic acid. Sodium valproate is licensed for the treatment of epilepsy in standard-release oral preparations, and in modified-released preparations for various indications according to the preparation. Sodium valproate or valproate semisodium is licensed for the treatment of manic episodes in bipolar disorder. None of the valproate preparations are licensed for the management of agitated behaviour in people with dementia; therefore, use of for this purpose is off-label.

Adverse effects associated with valproate preparations include falls, gait disturbances, sedation, tremor, muscular weakness, depressed mood, gastrointestinal disorders (nausea, vomiting, constipation, and diarrhoea), urinary tract infections (UTI), and thrombocytopenia. The current NICE advice on the use of valproate preparations for the management of aggression, agitation, and behavioural disturbances in dementia states that current evidence suggests that such medications are no more effective than placebo, and that adverse effects are also more common in people taking them (NICE 2015).

\section{Why it is important to do this review}

This is an update of a Cochrane Review first published in 2004, and previously updated in 2009.

One summary of evidence published by NICE suggests that valproate preparations are no more effective than placebo for agitation in dementia (NICE 2015). Despite this guidance, valproate preparations are still sometimes being used in this patient group, perhaps because other drug options are not always effective and may be associated with adverse effects. This update is intended to apply current Cochrane methods to synthesise the evidence 
concerning use of valproate for agitation in dementia, and to assess the quality of this evidence, in order to inform decision-making by carers, clinicians, researchers, and policy-makers.

\section{OB JECTIVES}

To determine the efficacy and adverse effects of valproate preparations used to treat agitation in people with dementia, including the impact on carers.

\section{METHODS}

\section{Criteria for considering studies for this review}

\section{Types of studies}

We included only randomised, placebo-controlled trials. We excluded interrupted time series trials. Where studies used a crossover design, we included only data from the first part of the study.

\section{Types of participants}

We included participants of either sex and of any age, both inpatients and outpatients (with or without carers). Dementia should have been diagnosed according to the classifications provided by Diagnostic and Statistical Manual of Mental Disorders, 4th edition (DSM-IV) (APA 1994), International Classification of Diseases, 10th edition (ICD-10) (WHO 1991), Diagnostic and Statistical Manual of Mental Disorders, 3rd edition (DSM-III) (APA 1980), or Diagnostic and Statistical Manual of Mental Disorders, 3rd revised edition (DSM-IIIR) (APA 1987). In the absence of these criteria, we also accepted other evidence of dementia such as the Mini-Mental State Examination (MMSE) (Folstein 1975), psychiatric evaluation, psychological evaluation, or a medical evaluation. We accepted definitions of agitation provided by individual investigators.

Because agitation is common in delirium, we had initially specified that all studies should have included clinical evaluation to rule out delirium and other treatable causes of agitation (e.g. pain, infection, drug effect, urinary or faecal retention) prior to entering people into the trial. However, reporting of baseline clinical evaluation was not always specific or detailed. Therefore, we took a pragmatic approach to avoid risking the loss of relevant evidence and included studies despite this information not being explicitly reported.

\section{Types of interventions}

We required at least one week of treatment with valproate preparations, of any dosage given by mouth, compared with placebo. People receiving stable therapy with other psychoactive medications, including cholinesterase inhibitors, memantine, and antidepressants, could be included if this was permitted in the study protocol.

\section{Types of outcome measures}

\section{Primary outcomes}

- Agitation, or one or more aspects of agitation as measured by a scale that specifically measured agitation, either exclusively or as one of its components. The scales included but were not limited to:

- Cohen-Mansfield Agitation Inventory (CMAl; CohenMansfield 1986);
- Social Dysfunction and Agitation Scale (SDAS; Wistedt 1990);

- Clinical Global Impression Scale for Aggression (CGI; Guy 1976);

- "Nurse Observation" scale (Colenda 1991);

- Behavior Observation Scale of Intramural Psychogeriatric Patients (GIP; Verstraten 1988);

- Brief Psychiatric Rating Scale (BPRS; Overall 1962; Overall 1988);

- Overt Aggression Scale (OAS; Yudofsky 1986).

\section{Secondary outcomes}

- Cognition.

- Functional performance.

- Overall clinical impression.

- Effect on carers (carers' psychological morbidity or burden).

- Incidence and severity of adverse effects.

- Dropouts, including dropouts due to adverse events.

\section{Search methods for identification of studies}

\section{Electronic searches}

We searched ALOIS (www.medicine.ox.ac.uk/alois), which is the Cochrane Dementia and Cognitive Improvement Group's (CDCIG) Specialized Register on 2 October 2014. The search terms used were: valproic OR valproate OR divalproex.

The Information Specialists for the CDCIG maintain ALOIS, which contains studies that fall within the areas of dementia prevention, dementia treatment and management, and cognitive enhancement in healthy older populations. The studies are identified through:

- monthly searches of a number of major healthcare databases: MEDLINE, Embase, CINAHL, PsycINFO, and Lilacs;

- monthly searches of a number of trial registers: ISRCTN; UMIN (Japan's Trial Register); the World Health Organization (WHO) portal (which covers ClinicalTrials.gov; ISRCTN; the Chinese Clinical Trials Register; the German Clinical Trials Register; the Iranian Registry of Clinical Trials and the Netherlands National Trials Register, plus others);

- quarterly searches of the Central Register of Controlled Trials (CENTRAL);

- six-monthly searches of a number of grey literature sources: ISI Web of Knowledge Conference Proceedings; Index to Theses and Australasian Digital Theses.

To view a list of all sources searched for ALOIS see About ALOIS on the ALOIS website (www.medicine.ox.ac.uk/alois).

Details of the search strategies used for the retrieval of reports of trials from the healthcare databases, CENTRAL, and conference proceedings can be viewed in the 'methods used in reviews' section within the editorial information about the Dementia and Cognitive Improvement Group.

\section{Searching other resources}

We performed additional searches in many of the sources listed above to cover the timeframe from the last searches performed for ALOIS to ensure that the search for the review was as up-to-date 
and as comprehensive as possible. The search strategies used can be seen in Appendix 1.

We carried out the most recent search for this review on 7 December 2017. Previous searches were done in October 2016, July 2010, and February 2008.

\section{Data collection and analysis}

\section{Selection of studies}

The Information Specialist of the CDCIG removed duplicates of the same references. Two review authors (ETL and JL) independently examined titles and abstracts against the prespecified inclusion criteria to exclude clearly ineligible studies. We examined any potentially eligible trial in full text. Two review authors (ETL and $\mathrm{JL}$ ) independently evaluated full texts according to the eligibility criteria. We compared selections of trials and the review authors agreed the final list of studies. We explained final decisions for the exclusion of articles that we retrieved in full text in the Characteristics of excluded studies table.

\section{Data extraction and management}

Two review authors (ETL and JL) extracted data from each study using a data collection form that was piloted by the team. For the purpose of this updated review, the data were entered into Review
Manager 5 (Review Manager 2014). Two review authors (AC and SFB) checked the data for accuracy. We also extracted data about ongoing studies, including study name, methods, participants, interventions, outcomes, starting date, contact information, and notes.

\section{Assessment of risk of bias in included studies}

Two review authors (SFB and AC) independently assessed the risk of bias in accordance with Cochrane's tool for assessing methodological quality and risk of bias (Higgins 2011). This tool assesses how the randomisation sequence was generated, how allocation was concealed, the integrity of blinding (participants, raters, and personnel), the completeness of outcome data, selective reporting, and other biases. Where inadequate details of randomisation and other characteristics of the trials were provided, we contacted authors of the studies to obtain further information.

We described the risk of bias of all included studies in the Characteristics of included studies table and narratively. In addition, we provided an overall judgement of included studies in a 'Risk of bias' summary (see Figure 1). Where the two review authors disagreed on 'Risk of bias' decisions, the final rating was made by consensus discussion involving the third member of the review team. 
Figure 1. Risk of bias summary: review authors' judgements about each risk of bias item for each included study.

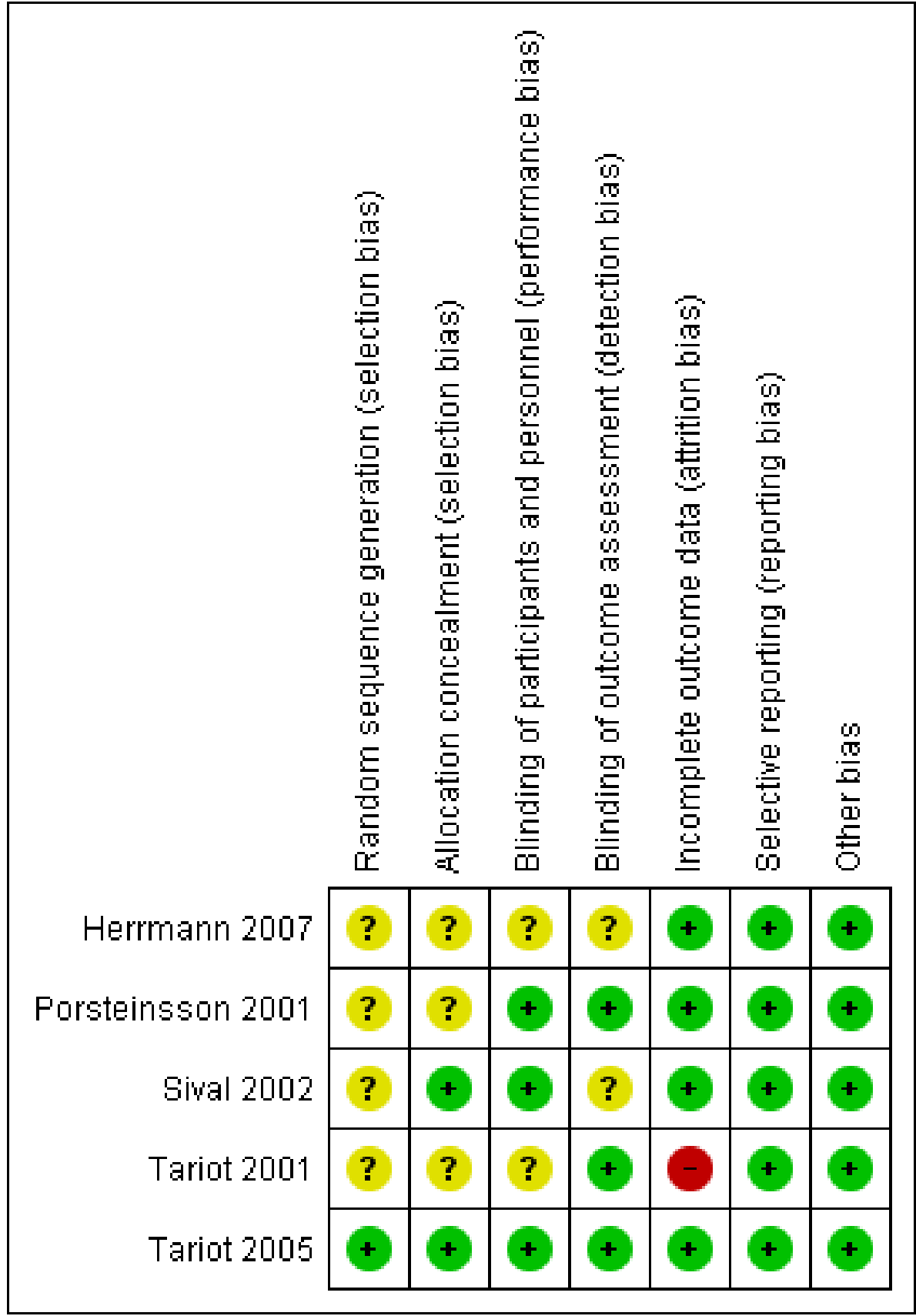

\section{Measures of treatment effect}

We used the mean difference (MD) to measure the treatment effect. If the same outcome was assessed using different scales, then we used the standardised mean difference (SMD). We reported $95 \%$ confidence intervals $(\mathrm{Cl})$. We reported results of dichotomous outcomes as odds ratios (OR) with $95 \% \mathrm{Cl}$.

\section{Unit of analysis issues}

We considered only participant-level outcomes. We analysed change in outcome measure from pre- to post-treatment. For crossover trials, we used data for the first period only (if available) because of the possibility of carry-over effects.

\section{Dealing with missing data}

To allow an intention-to-treat analysis, we sought data irrespective of compliance, whether or not the participant was subsequently deemed ineligible, or otherwise excluded from treatment or followup. If intention-to-treat data were not available in the publications, we extracted 'on-treatment' data or the data of participants who completed the trial and indicated it as such. We did not use data from titration phases prior to the randomised phase to assess safety or efficacy. 


\section{Assessment of heterogeneity}

We considered clinical heterogeneity between trials (participants, interventions, and outcomes) when deciding whether or not to synthesise data. Where we performed a meta-analysis, we used a standard $\mathrm{Chi}^{2}$ test to check for heterogeneity. We also assessed the impact of heterogeneity on the meta-analysis using the $1^{2}$ statistic.

\section{Assessment of reporting biases}

We tried to minimise the impact of publication bias by searching for both published and unpublished trials. We compared conference abstracts and registered trials with published data. We contacted the responsible organisation or the researcher for more information when we found studies in trial registries that appeared to have been completed but not published (see Description of studies). We found too few studies to allow assessment of possible publication bias using funnel plots and Egger's test for asymmetry (Egger 1997).

\section{Data synthesis}

Where data were suitable for a meta-analysis, we presented the effect estimate from a fixed-effect model.

\section{Subgroup analysis and investigation of heterogeneity}

Due to the low number of included studies, subgroup analysis was not possible. Therefore, participants were combined into the category of 'dementia' regardless of subtype.

\section{Sensitivity analysis}

We did not conduct any sensitivity analyses.

\section{'Summary of findings' table}

We used the GRADE approach to assess the quality of the supporting evidence behind each estimate of treatment effect. We presented key outcomes in Summary of findings for the main comparison, including, for each outcome, a summary of the amount of data, the magnitude of the effect size, and the overall quality of the evidence (Schünemann 2011). The measures included were: change in agitation and aggression, cognition, functional performance, and incidence and severity of adverse effects.

\section{RE S U L T S}

\section{Description of studies}

\section{Results of the search}

The initial search for eligible RCTs was completed in August 2005. This identified three studies for inclusion in the review (Porsteinsson 2001; Sival 2002; Tariot 2001). An updated search on 7 February 2008 retrieved two new studies (Herrmann 2007; Tariot 2005). Further updated searches on 30 July 2010, and 4 November 2016 identified no new studies for either inclusion or exclusion in the review. The most recent search was performed in December 2017.

After removal of duplicates and first assessment by the Information Specialist of the CDCIG based on a screening of titles and abstracts, these searches resulted in a total of 41 records being passed to the authors for further scrutiny.

See Figure 2 for the flow of studies for this review. 
Figure 2. Study flow diagram.

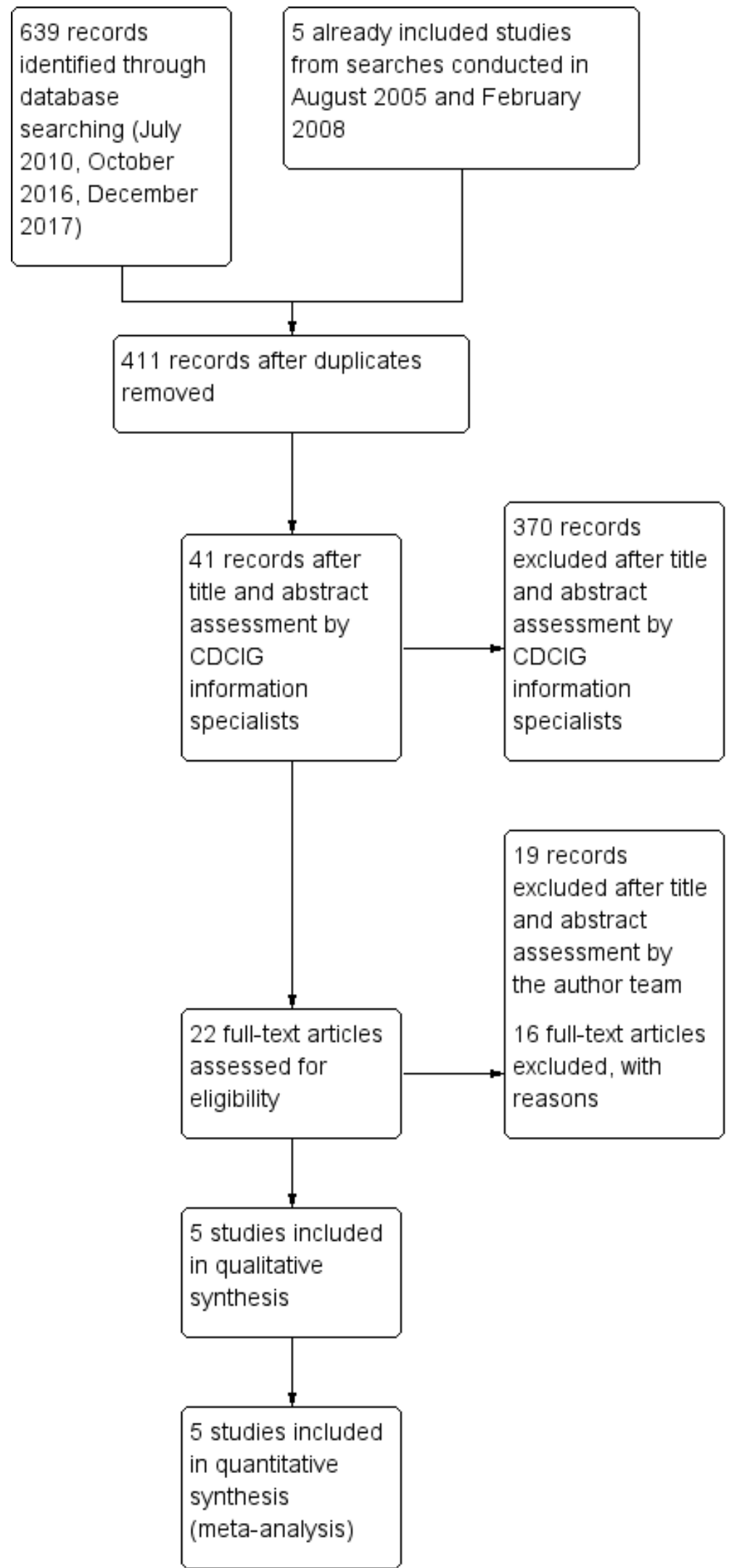




\section{Included studies}

We identified five studies eligible for inclusion (Herrmann 2007; Porsteinsson 2001; Sival 2002; Tariot 2001; Tariot 2005). A detailed description of each study is given in the Characteristics of included studies table.

\section{Design}

Two studies were placebo-controlled crossover studies (Herrmann 2007; Sival 2002). In Sival 2002, there were two three-week treatment periods separated by a one-week washout period. In Herrmann 2007, the treatment periods lasted six weeks and there was a two-week washout period between treatments. The remaining three studies were parallel-group, placebo-controlled RCTs with six-week treatment periods (Porsteinsson 2001; Tariot 2001; Tariot 2005).

\section{Sample size}

The two crossover studies were the smallest with 14 (Herrmann 2007) and 43 (Sival 2002) participants. Porsteinsson 2001 had 56 participants, Tariot 2001 had 173, and Tariot 2005 had 153.

\section{Setting}

One study was conducted in Europe (Sival 2002), and another in Canada (Herrmann 2007). Three were multisite studies in the US (Porsteinsson 2001; Tariot 2001; Tariot 2005). All studies involved people who were institutionalised. In Sival 2002, the participants were from a short-stay ward at a psychiatric hospital; in the other studies, participants were resident in long-term care facilities.

\section{Participants}

See Table 1 for a description of the participants' characteristics at baseline in all studies.

All studies included participants with dementia, mostly with moderate-to-severe dementia. All studies used one or more standard methods to diagnose dementia, including Alzheimer's disease, vascular dementia, and mixed dementia (DSM-IV (APA 1994); National Institute of Neurological and Communicative Disorders and Stroke-Alzheimer's Disease and Related Disorders Association (NINCDS-ADRDA; McKhann 1984)).

Sival 2002 used the Clinical Dementia Rating Scale (Hughes 1982), in which 2/42 participants were classified as "light," 24/42 participants as "moderate," and 14/42 participants as "severe." This same study used the MMSE (Folstein 1975), but 14 participants could not be scored because of low level of function. All other studies also used the MMSE. Mean scores at baseline were 7.4 (Tariot 2001), 6.8 (Porsteinsson 2001), 4.5 (Herrmann 2007), and 10.8 (range 4 to 24) (Tariot 2005).

Inclusion criteria relating to degree of agitated behaviour varied between studies, but all studies required included participants to exhibit minimum levels of agitation according to standardised measures (Neuropsychiatric Inventory (NPI), BPRS, Social Dysfunction and Aggression Scale-9).

- Herrmann 2007 required participants to display "significant BPSD" as indicated by a score of 8 or greater on the NPI.

- Porsteinsson 2001 required participants to have exhibited agitated behaviour for a minimum of two weeks "with sufficient intensity" to result in a BPRS score of three or more on items relating to tension, hostility, unco-operativeness, or excitement.

- Sival 2002 used Patel's criteria for aggressive behaviour (Patel 1993), and also required participants to score 3 or greater on at least one item of the Social Dysfunction and Aggression Scale-9.

- Tariot 2001 included participants who exhibited "manic symptoms" according to the Bech-Rafaelsen Mania Scale (BRMS) and six items of the BPRS. Participants were required to score 15 or greater on the BRMS and 3 or greater on two or more of the items of the BPRS relating to tension, grandiosity, hostility, suspiciousness, unco-operativeness, and excitement, with a total score of 15 or more.

- Tariot 2005 required participants to have at least a two-week history of agitation with a total score greater than 2 on the BPRS items relating to tension, hostility, unco-operativeness, or excitement.

\section{Interventions}

\section{Divalproex sodium}

One study treated participants with divalproex sodium delayedrelease tablets or placebo (Tariot 2001). Dosage started at $125 \mathrm{mg}$ twice daily and was titrated to $20 \mathrm{mg} / \mathrm{kg} /$ day to $30 \mathrm{mg} / \mathrm{kg} /$ day, to be reduced if intolerable adverse effects appeared. The median dose for treated participants at the end of six weeks was $1000 \mathrm{mg} /$ day. One study treated participants with rapid-acting divalproex sodium at an initial dose of $375 \mathrm{mg} /$ day which was titrated upwards to a mean dose of $826 \mathrm{mg} /$ day (Porsteinsson 2001). In this trial, a non-blinded supervising physician, who had no contact with the blinded researchers, altered drug dosage by $125 \mathrm{mg} /$ day, depending on written reports by the researchers of response and adverse effects. In Tariot 2005, participants commenced sprinkle formulation divalproex sodium $125 \mathrm{mg}$ twice daily for three days, which was increased in $125 \mathrm{mg}$ increments every three days to $750 \mathrm{mg} /$ day or up to a maximum dose $1000 \mathrm{mg} /$ day. Researchers decreased the dose by $125 \mathrm{mg} /$ day if a participant experienced adverse effects. The mean dose at the end of the treatment period was $800 \mathrm{mg} /$ day.

\section{Sodium valproate}

In Sival 2002, study participants received sodium valproate 240 mg twice daily for three weeks. Participants in Herrmann 2007 received valproate $125 \mathrm{mg}$ liquid suspension twice daily, increased to $500 \mathrm{mg}$ twice daily over the first two weeks. The dose could then be increased to a maximum of $1500 \mathrm{mg} /$ day or decreased based on efficacy and tolerability as determined by a blinded study physician.

All studies permitted short-term use of short-acting psychotropics. Porsteinsson 2001 used chloral hydrate. Tariot 2001 permitted short-term use of lorazepam, oxazepam, or chloral hydrate as needed. Sival 2002 allowed oxazepam for severe anxiety or insomnia. Tariot 2005 permitted zolpidem or lorazepam (or both) for severe agitation or sleep-induction. Herrmann 2007 permitted loxapine as a rescue medication.

\section{Outcomes}

All included studies aimed to assess the effect of valproate treatments on agitation, aggression, mania, and overall function of people with dementia. 
The instruments used to measure the outcomes in each study are given in Table 2.

\section{Agitation and aggression}

The included studies used several different scales to assess change in agitated and aggressive behaviour.

Four studies used the CMAI scale to measure agitation and aggression (Herrmann 2007; Porsteinsson 2001; Tariot 2001; Tariot 2005). It was not clear which version of the CMAI was used, although three gave the same source reference for the scale (Herrmann 2007; Porsteinsson 2001; Tariot 2005). Tariot 2005 stated that they used a 36 -item version of CMAI, whereas the most commonly used version is the 29-item version. Information obtained from the author suggested that they actually used the 29-item version of the scale. Herrmann 2007 and Porsteinsson 2001 did not state specifically which version of the CMAI they used in their studies. We attempted to contact these authors to clarify the scale version and scoring used. Tariot 2001 used a different version of the scale specifically designed for nursing home residents (Cohen-Mansfield 1989).

Three studies used the BPRS to assess disturbed behaviour (Porsteinsson 2001; Tariot 2001; Tariot 2005), and two studies also used the agitation and hostility subscales of the BPRS as outcome measures (Porsteinsson 2001; Tariot 2005). All three studies used the 18-item scale but two studies rated items 0 to 6 (Tariot 2001; Tariot 2005), whereas one study rated items 1 to 7 (Porsteinsson 2001). While this would lead to disparity in total scores in each study, analysis of change in score in each study were still comparable. Information relating to the scoring of the agitation and hostility subscales of the BPRS was not available from the authors of the studies which used them, and could not be found through a further literature search.

Tariot 2001 used the BRMS to assess manic symptoms. Porsteinsson 2001 used the OAS to measure aggression. Herrmann 2007 used the NPI and its agitation subscale at their primary outcome measure. Sival 2002 used the Social Dysfunction and Aggression-9 Scale (SDAS-9), and the "Nurse Observation" scale, to measure incidence of aggression; the CGI to rate clinical impression of aggressive behaviour; and GIP to measure other types of disturbed behaviour.

- The CMAI examines 29 types of agitated behaviour, including pacing, verbal or physical aggression, screaming, and restlessness. The frequency of these behaviours is measured on a 29-item scale with each item rated from 0 (never occurs) to 6 (occurs several times an hour) and scores for physical and verbal aggression and overall aggression may be aggregated.

- The BPRS measures physical and verbal aggression, hallucinatory behaviour, and abnormal thought content. The scale comprises 18 items each scored on a 7-point scale with a higher score indicating higher level of dysfunction.

- The CGI uses a 7-point scale with scores ranging from 1 (no aggressive behaviour) to 7 (severely aggressive behaviour). It is also used to measure overall response to treatment.

- The BRMS is an 11-item observer-based scale that rates the severity of manic symptoms on a 5-point scale (Bech 1978).

- The OAS quantifies aggressive verbal and physical behaviours and includes the number, specific nature, and intervention response.
- The NPI is a 12-item scale, designed to assess the severity and frequency of behavioural symptoms in people with dementia (Cummings 1994).

- The SDAS-9 measures several aspects of behaviour to do with patient interaction with other people, and physical and verbal aggression. The scale is a 9-point observation scale covering outward aggressive behaviour, with total sores ranging from 0 to 36).

- The "Nurse Observation" scale assesses the incidence of aggressive behaviour at the moment the behaviour occurs.

- The GIP consists of 14 observational scales to describe agitated and aggressive behaviour.

\section{Cognition}

Herrmann 2007; Porsteinsson 2001; and Tariot 2005 assessed cognitive functioning using the MMSE.

\section{Functional performance}

Porsteinsson 2001 and Tariot 2005 assessed participants' functional performance using the Physical Self-Maintenance Scale (PSMS) (Lawton 1969).

\section{Overall clinical impression}

Three studies included a rating of global clinical response of the participants using the CGI, a 7-point scale with scores ranging from "very much improved" to "very much worse" (Porsteinsson 2001; Tariot 2001; Tariot 2005). Tariot 2001 reported this as mean change and Tariot 2005 as number of participants showing improvement. Porsteinsson 2001 reported CGI separately for therapeutic effect and adverse effects using a different Likert type scale for each.

\section{Adverse effects}

All five studies examined the tolerability, adverse effects, and safety of valproate preparations.

- Four studies used check-lists of adverse effects (e.g. drowsiness, nausea, vomiting, diarrhoea, confusion, disturbance in speech, disturbance of co-ordination, tremor, seizures, oedema, fever thrombocytopenia), which were reviewed at regular intervals by interviewing participants and nursing staff; and by reviewing chart entries (Herrmann 2007; Porsteinsson 2001; Sival 2002; Tariot 2005).

- Tariot 2001 measured adverse events based on the Coding Symbols for Thesaurus of Adverse Reaction Terms (COSTART 1989).

\section{Effect on carers (carers psychological morbidity)}

None of the included studies assessed any aspect of carer burden or well-being.

\section{Excluded studies}

We excluded most studies on the basis of the study design (e.g. not RCTs). The studies that were excluded, with reasons for exclusion, are listed in the Characteristics of excluded studies table.

\section{Risk of bias in included studies}

See Figure 1. 


\section{Allocation}

All studies included in this review indicated that participants were randomly allocated to treatments groups. However, four studies did not report the process of random sequence generation and we considered them to be at unclear risk of bias in this domain (Herrmann 2007; Porsteinsson 2001; Sival 2002; Tariot 2001). For three of these studies, there was also no specific information about allocation concealment, but Sival 2002 stated that the "code was not available to the investigators" and so we rated its risk of bias due to allocation concealment to be low. Tariot 2005 had a low risk of allocation bias.

\section{Blinding}

Two studies failed to state explicitly whether all staff involved in the study were blind to the treatment allocation of the participants (unclear risk of bias; Herrmann 2007; Tariot 2001), and two failed to state whether research staff completing the outcome measures were blinded (unclear risk of bias; Herrmann 2007; Sival 2002).

In Porsteinsson 2001, although the physicians having direct responsibility for participant care and researchers completing study assessments were blinded, a non-blinded physician, who had no direct contact with these physicians, adjusted divalproex sodium dosage based on reports from the blinded raters. Similarly, in Sival 2002, a pharmacist and independent physician reviewed out-of-range laboratory results, including valproate levels. These staff had no contact with participants, investigators, the ward team or participant's relatives so we considered that the risk of introducing bias due to unblinding was low.

Tariot 2001 was described as a double-blind study but total serum valproate levels were measured weekly and monitored by nursing staff. It was not stated whether these nursing staff were involved in the study, so we judged this to pose an unclear risk of performance bias.

\section{Incomplete outcome data}

In Tariot 2001, 54\% of the valproate-treated participants dropped out compared with $29 \%$ of control participants; $22 \%$ of all participants dropped out because of adverse effects, and the study had to be discontinued prematurely. Further, since participants had been on therapy for varying periods of time when the study was terminated, interpretation of the effects of treatment was difficult. We considered this study at high risk of attrition bias.

Porsteinsson 2001 included data in the analysis from participants who dropped out of the study, and gave the reasons for the participants dropping out (two from the divalproex group, and four from the placebo group; low risk of attrition bias).

In Tariot 2005, 11/75 participants in the divalproex group and $14 / 78$ participants in the placebo group dropped out of treatment early, but the reasons for discontinuation were not given. However, all participants who discontinued prematurely completed final assessments which were included in the analysis, so we considered the risk of attrition bias to be low.

In Herrmann 2007, two participants dropped out during each treatment phase but reasons for this were not stated. The study authors stated that they conducted an intention-to-treat analysis, but data for all participants was not included in the results table. We included only the results from the first part of the study in this review and obtained first-phase data from the study authors for all participants; for this reason, we considered the risk of attrition bias to be low.

In Sival 2002, three participants dropped out of the study due to adverse events in either the placebo or washout periods and these data were included in the analysis. One participant was excluded from the analysis due to protocol violation (low risk of attrition bias).

\section{Selective reporting}

We found no published protocols for the included studies. However, for all included studies, the results of the primary and secondary outcome measures that were specified in the methods sections of the papers were reported, as well as the frequency of adverse events. Therefore, we judged all the studies to be at low risk of selective reporting bias.

\section{Other potential sources of bias}

Sival 2002 had a cross-over design. No results from the first phase of the study were available. The statistical analysis did not take account of the paired nature of the data ("the t-test for independent samples is used to analyse the two-period cross-over trial").

We noted that three of the included studies were supported by grants from Abbott laboratories - a company which may have had a vested interest in the efficacy of the treatment - but we did not rate this as a source of bias (Porsteinsson 2001; Tariot 2001; Tariot 2005).

\section{Effects of interventions}

See: Summary of findings for the main comparison Valproate preparations compared to placebo for agitation in dementia

The included studies varied in the type of valproic acid preparation, dosage, and duration of therapy. The methods of evaluating the participants also varied between the studies, with use of different scales to assess agitation and aggression, and response to therapy. Tariot 2001 was discontinued due to the disproportionate number of dropouts in the treatment group (54\%) as well as a high proportion in the placebo group (29\%), with the results that not all participants received treatment for the full study period. Many of these dropouts occurred in the first three weeks (11/47 participants). Due to the high risk of attrition bias caused by the high dropout rate, we decided to exclude the data from the pooled analysis in this review. Sival 2002 was a cross-over design and firstphase data were not available from the published paper, or from the authors, and so data from this study was also not included in our analyses.

\section{Agitation and aggression}

We were able to pool data on agitation/aggression measured with the BPRS from two studies and the CMAI from three studies.

A meta-analysis of agitated behaviour, assessed with total BPRS scores in two studies, showed that there was probably no difference between valproate and placebo group in total BPRS after six weeks of treatment (MD $0.23,95 \% \mathrm{Cl}-2.14$ to 2.59; 202 participants, 2 studies; Analysis 1.1; moderate-quality evidence, downgraded due to imprecision) (Porsteinsson 2001; Tariot 2005). A pooled analysis of agitation measured with the agitation factor of the BPRS confirmed that there was probably no effect of treatment 
specifically on agitation (MD $-0.67,95 \% \mathrm{Cl}-1.49$ to $0.15 ; 202$ participants, 2 studies; Analysis 1.2; moderate-quality evidence, downgraded due to imprecision). The quality of evidence on agitation measured with the CMAI was lower, but meta-analysis of three studies that reported the change in total CMAI score between baseline and six weeks also suggested no effect on agitated behaviour (MD $-1.84,95 \% \mathrm{Cl}-6.02$ to $2.34,217$ participants, 3 studies; $12=52 \%$; Analysis 1.3 ; very low-quality evidence, downgraded due to risk of bias, inconsistency, and imprecision) (Herrmann 2007; Porsteinsson 2001; Tariot 2005). Herrmann 2007 and Porsteinsson 2001 did not state specifically which version of the CMAl they used in their studies, we made the assumption that they used the standard 29-item scale. Information from Tariot 2005 indicated that they also used the 29 item scale despite the paper stating they used a 36 item version of the scale. In light of the uncertainty regarding which version Tariot 2005 used, we repeated the pooled analysis of change in total CMAI score after excluding data from Tariot 2005 (MD 1.96, 95\% Cl-6.18 to 10.10; 70 participants, 2 studies; very low-quality evidence, downgraded due to risk of bias, inconsistency, and imprecision).

Single studies only reported the other outcome measures. Porsteinsson 2001 found that there was probably little or no effect of divalproex on the hostility factor of the BPRS (MD $0.10,95 \% \mathrm{Cl}$ 1.12 to 1.32 ; 55 participants, 1 study; Analysis 1.4; moderate-quality evidence, downgraded due to imprecision) or the Overt aggression total score (MD $0.10,95 \% \mathrm{Cl}-3.42$ to $3.62 ; 55$ participants, 1 study; Analysis 1.5; moderate-quality evidence, downgraded due to imprecision). Herrmann 2007 used the NPI. This showed a clinically important difference in behavioural symptoms as measured by the NPI total score, favouring the placebo group, but there was a great deal of uncertainty about this result (MD 15.28, 95\% Cl -5.19 to 35.75 ; 14 participants, 1 study; Analysis 1.6; very low-quality evidence, downgraded one level due to risk of bias and two levels due to imprecision). There was similarly a high level of uncertainty about the result on the NPI agitation/aggression subscale, which showed no clear evidence of a difference between groups (MD 1.43, $95 \% \mathrm{Cl}-2.48$ to 5.34 ; 14 participants, 1 study; Analysis 1.7; very lowquality evidence, downgraded one level due to risk of bias and two levels due to imprecision).

\section{Cognition}

Three studies assessed cognitive functioning using the MMSE (Herrmann 2007; Porsteinsson 2001; Tariot 2005). The quality of this evidence was very low. but pooled analysis of the data indicated that there may have been little or no effect of valproate on the change in MMSE score over the six-week treatment period (MD $0.70,95 \% \mathrm{Cl}-1.61$ to $0.20 ; 217$ participants, 3 studies; Analysis 1.8; very low-quality evidence, downgraded due to risk of bias, inconsistency, and imprecision).

\section{Functional performance}

Porsteinsson 2001 and Tariot 2005 assessed functional ability using the PSMS. Pooled analysis of the change in total PSMS score indicated that there was probably little or no effect of valproate on this outcome (MD 1.19, 95\% Cl 0.40 to 1.98; 203 participants, 2 studies; Analysis 1.9; moderate-quality evidence, downgraded due to imprecision).

\section{Overall clinical impression}

Three studies included a measure of global clinical change, but we excluded data from Tariot 2001 due to the very high risk of attrition bias. Tariot 2005 used the CGI as an index of clinical efficacy, measuring change in participants' overall clinical condition on a 7point scale ( 0 marked improvement to 6 marked worsening). The number of participants showing improvement was reported not to differ significantly between the two groups. Porsteinsson 2001 used the CGI to rate "therapeutic effect" on a 4-point scale, and the presence and clinical significance of adverse effects on a 7point scale (from very much improved to very much worse). They reported no difference between groups in CGI ratings. Because of the different ways in which the CGI was used was used in these two studies, we were unable to pool data.

\section{Incidence and severity of adverse effects}

Meta-analysis of three studies, all of which used divalproex sodium, found there may have been a higher rate of adverse effects among participants treated with divalproex sodium than among participants in the control group (OR 2.02, 95\% Cl 1.30 to 3.14; 381 participants, 3 studies; Analysis 2.27; low-quality evidence, downgraded due to imprecision and inconsistency) (Porsteinsson 2001; Tariot 2001; Tariot 2005). A fourth study reported that the mean incidence of adverse effects was low during three weeks of observation in both sodium valproate $(0.17)$ and placebo (0.02) groups, but the study provided no description of the types of adverse reactions or actual numbers of adverse events experienced, so we could not include this study in the meta-analysis (Sival 2002). Data on adverse effects during the first treatment phase of Herrmann 2007 were not available in the published data or from the authors, but over the course of both treatment phases, 12 participants experienced at least one adverse event while taking valproate compared to eight participants while taking placebo. The mean number of adverse events from valproate was significantly greater than with placebo.

The descriptions of adverse effects which study authors used varied making pooled analysis of all adverse effects difficult. However, pooled analysis of adverse effects that were reported in more than one study indicated that sedation (OR 2.66, 95\% Cl 1.44 to 4.92; 228 participants, 2 studies; Analysis 2.1; moderatequality evidence, downgraded due to imprecision), 'nausea, vomiting and diarrhoea' (OR 6.92, 95\% Cl 2.13 to 22.49; 381 participants, 3 studies; Analysis 2.2; moderate-quality evidence, downgraded due to imprecision), and UTIs (OR 3.07, 95\% Cl 1.05 to 8.97 ; 228 participants, 2 studies; Analysis 2.3; moderate-quality evidence, downgraded due to imprecision) were more frequently reported among valproate-treated participants than placebotreated participants. Falls, respiratory, skin or joint problems, and infections (other than UTI) were no more frequent in valproatetreated than in placebo-treated participants.

One study reported thrombocytopenia in 6/87 participants in the valproate group and $0 / 85$ participants in the placebo group (Tariot 2001). One study reported thrombocytopenia in $2 / 14$ participants during the treatment phase and none in the placebo phase (Herrmann 2007). In Porsteinsson 2001, 2/28 participants in the divalproex group had developed a significant decrease in platelet count, but not to the level of thrombocytopenia. Sival 2002 monitored blood counts, but reported no instances of a drop in platelet count. 


\section{Serious adverse events}

The included studies varied in the reporting of serious adverse events (SAE) during their treatment period. Sival 2002 did not report the incidence of SAE during their study. Herrmann 2007 did not report numbers of participants who experienced SAE clearly, but the study stated that two participants in the treatment phase had falls that rated as SAEs. There was no indication given about whether these falls were considered related to the study medication and it was not clear whether these were the only SAEs to occur. Tariot 2005 also did not report specifically on numbers of SAEs although there was one death in the drugtreatment group which was not considered related to the study drug. The authors stated that most adverse events were rated as mild to moderate in severity and were judged as not related to the study drug. Porsteinsson 2001 reported four SAEs, one in the placebo group (worsening of chronic renal failure) and three in the divalproex group (one with seizure, cerebrovascular accident, and pneumonia; one with seizure; and one with small bowel obstruction). Tariot 2001 reported one SAE due to hyponatraemia in the divalproex group, which was thought probably to be related to the study drug. Six other participants experienced SAEs, five in the divalproex group and one in the placebo group. These SAEs were four hospitalisations (for cellulitis, dehydration, pneumonia, myocardial infarction, and constipation) and one cerebrovascular accident; all were considered to be unrelated to the study drug.

Pooled analysis of the number of SAEs for the two studies which did report data indicated that participants treated with valproate were more likely to experience SAEs (OR 4.77, 95\% CI 1.00 to 22.74; 228 participants, 2 studies; Analysis 2.28; very low-quality evidence, downgraded due to risk of bias, inconsistency, and imprecision) (Porsteinsson 2001; Tariot 2001).

\section{Dropouts}

All included studies reported that there were participants who dropped out during the study period. For most studies, the number of dropouts were not disproportionate between the treatment and the placebo groups (Porsteinsson 2001: 7\% divalproex versus 14\% placebo; Sival 2002: $0 \%$ valproate versus $5 \%$ placebo; Tariot 2005: $15 \%$ divalproex versus 18\% placebo; Herrmann 2007: $7 \%$ valproate versus $7 \%$ placebo). However, in the study by Tariot 2001, a disproportionate number of participants in the treatment group dropped out of the study (54\% divalproex versus $29 \%$ placebo), with $22 \%$ from the treatment group compared to only $4 \%$ of the placebo group withdrawing due to adverse events. These adverse events were predominantly related to somnolence but also included hyponatraemia, accidents, and weight loss. Due to this disproportionate level of withdrawal in the divalproex group, the study was terminated early.

\section{DISCUSSION}

\section{Summary of main results}

We found no evidence of a beneficial effect of valproate on our primary outcome of agitation or closely related behavioural outcomes, measured using several outcome scales. Neither did we find evidence of any important effect on any of our secondary efficacy outcomes. However, participants taking valproate may have been at higher risk of adverse effects, including SAEs. These findings are described in Summary of findings for the main comparison.
Specifically, our results showed that there was probably little or no effect on agitated and aggressive behaviours as measured by the BPRS. There was very low-quality evidence using other scales, but results were consistent with this finding. Pooled analysis also indicated probably slightly worse function in the valproate-treated group, on functional ability assessed with the PSMS, of uncertain clinical importance. We found very low-quality evidence of no effect on cognition assessed with the MMSE.

Pooled analysis of the numbers of participants who experienced any adverse effect was limited to three of the included studies (Porsteinsson 2001; Tariot 2001; Tariot 2005), but indicated that participants treated with valproate preparations may have been more likely to experience adverse effects than participants taking placebo. Likewise, participants treated with valproate preparations were more likely to experience SAEs, although the quality of this evidence was very low (data from two studies; Porsteinsson 2001; Tariot 2001). Individual adverse effects which were found in one or more studies to be more frequent in the valproate-treated group were sedation, gastrointestinal symptoms, and UTI.

\section{Overall completeness and applicability of evidence}

The small number of included studies, some of which involved small numbers of participants, limited the evidence available. This was further limited since one study closed prematurely and that separate first-phase data were not available from the cross-over trials for inclusion in the review analysis (Herrmann 2007 for some data; Sival 2002).

Because of the limited number of participants, it was not possible to analyse secondary objectives such as the effect of valproate therapy on individual manifestations of agitation (e.g. crying out, wandering) or the influence of age, gender, or degree and type of dementia on the response to therapy. The small number of included studies also meant it was not possible to analyse how the response to valproate preparations was influenced by dose and duration of treatment.

The premature termination of one study, in which 47 (54\%) treated participants dropped out before the protocol could be completed, severely limited the confidence that could be placed on the conclusion of the study authors that divalproex sodium improved agitation of people with dementia (Tariot 2001). Because so many of the participants did not complete the study treatment period, we did not include data from this study in the pooled efficacy analyses.

\section{Quality of the evidence}

We only identified five studies for inclusion in this review and most varied in the outcome measures used to assess impact of treatment with valproate preparations on agitated behaviour thus making comparisons of study outcomes difficult. We found the quality of evidence for most outcomes measures used to be of low or very low quality primarily due to risk of bias, imprecision, and inconsistency in the included studies (because of poorly described methodology, small sample sizes, and heterogeneity of sample groups and treatments used).

Methodological and clinical diversity limited opportunities for pooling data. Specifically, variations in method, type of medication, dosage, duration of treatment, and use of different outcome measures in these studies made it difficult to apply meta-analysis. For example, it was difficult to compare directly studies that 
employed short-acting sodium valproate (Sival 2002) or longeracting divalproex sodium (Porsteinsson 2001; Tariot 2001), and in which the dosage varied more than two-fold (Sival 2002, mean dose 480 mg/day; Tariot 2001, median dose 1000 mg/day; Porsteinsson 2001, mean dose $875 \mathrm{mg} /$ day).

We did not include data from Sival 2002 because we could not obtain first period data as our protocol required. We considered that there was a risk of carryover effects. We also considered that there was a unit of analysis error in the analysis reported in the paper, which failed to account for the cross-over design.

\section{Potential biases in the review process}

It is possible that pooling of clinically diverse studies may have concealed important benefits or harms.

\section{Agreements and disagreements with other studies or reviews}

The conclusions of this updated review were in keeping with the NICE evidence summary on the use of valproate preparations for agitation and aggression in dementia which stated that such medications were no more effective than placebo, and that adverse effects were more common in people taking them (NICE 2015).

\section{AUTHORS' CONCLUSIONS}

\section{Implications for practice}

Robust randomised controlled trial evidence regarding valproate preparations for aggression in people who have dementia is limited, and we identified only five studies for inclusion in this review. Evidence from the five trials, including limited pooled analysis of data, did not support the use of valproate preparations to manage agitation in people with dementia, and demonstrated increased frequency of several types of adverse effect, including serious adverse effects.

From the information available, valproate preparations cannot be recommended for the treatment of people with dementia with agitation.

\section{Implications for research}

The quality of evidence in this review ranged from moderate to very low on a range of different outcome measures and overall did not indicate any benefit of valproate for the treatment of agitation in people with dementia. As the limited evidence that was available showed no signal of benefit, further investigation may not be justified, particularly in light of the increased risk of adverse effects in this often frail group of people. Research would be better focused on effective non-pharmacological interventions for this patient group, or, for those situations where the behaviours present immediate risk, further evaluation of how other medications, such as antipsychotics, can be used most effectively and safely.

\section{ACKNOWLEDGEMENTS}

For the review of 2004, to Dymphna Hermans for conducting an exhaustive search of the literature; to Jacqueline Birks, for helpful analysis of the statistics data; to consumer editor: Ann Ludvic, to Sarah Sampler for co-ordination of the report of 2004 and to author Edmund Lonergan.

For the update of 2009, to Vittoria Lutje for the literature search, to Helen Collins for guidance in statistical analysis of the results, and for editorial assistance.

For 2017 to 2018 update, to Anna Noel-Storr for the updated literature search and to Jenny McCleery for editorial assistance. 


\section{R E F E R E N C E S}

\section{References to studies included in this review}

Herrmann 2007 \{published data only\}

Herrmann N, Lanctot KL, Rothenberg LS, Eryavec G. A placebocontrolled trial of valproate for agitation and aggression in Alzheimer's disease. Dementia and Geriatric Cognitive Disorders 2007;23:116-9.

\section{Porsteinsson 2001 \{published data only\}}

Porsteinsson AP, Tariot PN, Erb R, Cox C, Smith E, Jakimovich L, et al. Placebo controlled study of divalproex sodium for agitation in dementia. American Journal of Geriatric Psychiatry 2001;9(1):58-66.

\section{Sival 2002 \{published data only\}}

Sival RC, Haffmans PM, Jansen PA, Duursma SA. Sodium valproate in the treatment of aggressive behavior in patients with dementia - a randomised placebo controlled clinical trial. International Journal of Psychiatry 2002;17(6):579-85.

\section{Tariot 2001 \{published data only\}}

Tariot PN, Schneider LS, Mintzer JE, Cutler AJ, Cunningham MR, Thomas MS, et al. Safety and tolerability of divalproex sodium in the treatment of signs and symptoms of mania in elderly patients with dementia: results of a double-blind, placebocontrolled trial. Current Therapeutic Research 2001;62(1):51-67.

\section{Tariot 2005 \{published data only\}}

Tariot PN, Raman R, Jakimovich L, Schneider L, Porsteinsson A, Thomas $\mathrm{R}$, et al. Divalproex sodium in nursing home residents with possible or probable Alzheimer disease complicated by agitation: a randomized, controlled trial. American Geriatric Psychiatry 2005;13:942-9.

\section{References to studies excluded from this review}

\section{Forester 2007 \{published data only\}}

Forester B, Vanelli M, Hyde J, Perez R, Ahokpossi C, Scribney W, et al. Report on an open label prospective study of divalproex sodium on the behavioral and psychological symptoms of dementia as monotherapy and in combination with second generation antipsychotic medication. American Journal of Geriatric Pharmacotherapy 2007;5:209-17.

\section{Goldberg 1999 \{published data only\}}

Goldberg RJ. The use of adjunctive divalproex for neuroleptic unresponsive behavioral disturbances in nursing home residents with dementia. Annals of Long-Term Care 1999;7:63-6.

\section{Gupta 1998 \{published data only\}}

Gupta S, O'Connell RO, Parekh A, Krotz B, Stockwell D. Efficacy of valproate for agitation and aggression in dementia: CAS reports. International Journal of Geriatric Psychopharmacology 1998;1:244-8.

\section{Haas 1997 \{published data only\}}

Haas S, Vincent K, Holt J, Lippmann S. Divalproex: a possible treatment alternative for demented elderly aggressive patients. Annals of Clinical Psychiatry 1997;9(3):145-7.
Horne 1995 \{published data only\}

Horne M, Lindley SE. Divalproex sodium in the treatment of aggressive behavior and dysphoria in patients with organic brain syndromes. Journal of Clinical Psychiatry 1995;56(9):430-1.

Kasckow 1997 \{published data only\}

Kasckow JW, McElroy SL, Cameron RL, Mahler LL, Fudala SJ. A pilot study on the use of divalproex sodium in the treatment of behavioral agitation in elderly patients with dementia: assessment with the BEHAVED-AD and CGI rating scales. Current Therapeutic Research 1997;58(12):351-4.

\section{Lott 1995 \{published data only\}}

Lott AD, McElroy SL, Keys MA. Valproate in the treatment of behavioral agitation in elderly patients with dementia. Journal of Neuropsychiatry Clinical Neuroscience 1995;7(3):314-9.

Mazure 1992 \{published data only\}

Mazure CM, Druss BG, Cellar JS. Valproate treatment of older patients with organic mental syndromes and behavioral dyscontrol. Journal of American Geriatric Society 1992;40(9):914-6.

Mellow 1993 \{published data only\}

Mellow AM, Solano-Lopez C, Davis S. Sodium valproate in the treatment of behavioral disturbances in dementia. Journal of Geriatric Psychiatry and Neurology 1993;6(4):205-9.

\section{Narayan 1997 \{published data only\}}

Narayan M, Nelson JC. Treatment of dementia with behavioral disturbance using divalproex or a combination of divalproex and a neuroleptic. Journal of Clinical Psychiatry 1997;58(8):351-4.

\section{Niedermier 1998 \{published data only\}}

Niedermier JA, Nasrallah HA. Clinical correlates of response to valproate in geriatric inpatients. Annals of Clinical Psychiatry 1998;10(4):165-8

\section{Porsteinsson 1997 \{published data only\}}

Porsteinsson AP, Tariot PN, Erb R, Gaile S. An open trial of valproate for agitation in geriatric neuropsychiatric disorders. American Journal Geriatric Psychiatry 1997;5(4):344-51.

\section{Sandborn 1995 \{published data only\}}

Sandborn WD, Bendfeldt F, Hamdy R. Valproic acid for physically aggressive behavior in geriatric patients. American Journal of Geriatric Psychiatry 1995;3(3):239-42.

Sival 1994 \{published data only\}

Sival RC, Haffman PM, Van Gent PP, van Nieuwkerk JF, Jansen PA. The effects of sodium valproate on disturbed behavior in dementia. Journal of American Geriatric Society 1994;42(8):906-7.

Takahashi 1996 \{published data only\}

Takahashi M, Akagi M. Case report of sodium valproate treatment of aggression associated with Alzheimer's disease [in Japanese]. No to Shinkei [Brain and Nerve] 1996;48(8):757-60. 
Tariot 2002 \{published data only\}

Tariot P, Porsteinsson AP, Jakimovich LJ, Kowalski N, Holt C. Open valproate treatment following a double-blind trial for agitation. 8th International Conference of Alzheimer's Disease and Related Disorders; 2002 July 20-25; Stockholm, Sweden. 2002:26.

\section{Additional references}

\section{Alzheimer's Society 2011a}

Alzheimer's Society. Optimising Treatment and Care for People with Behavioural and Psychological Symptoms of Dementia: a Best Practice Guide for Health and Social Care Professionals. London: Alzheimer's Society, 2011.

\section{Alzheimer's Society 2011b}

Alzheimer's Society. Reducing the Use of Anti-psychotic Drugs: a Guide to the Treatment and Care of Behavioural and Psychological Symptoms of Dementia. London: Alzheimer's Society, 2011.

\section{APA 1980}

American Psychiatric Association. Diagnostic and Statistical Manual of Mental Disorders. 3rd Edition. Washington (DC): American Psychiatric Association, 1980.

\section{APA 1987}

American Psychiatric Association. Diagnostic and Statistical Manual of Mental Disorders. 3rd Edition. Washington (DC): American Psychiatric Publishing, 1987.

\section{APA 1994}

American Psychiatric Association. Diagnostic and Statistical Manual of Mental Disorders. 4th Edition. Washington (DC): American Psychiatric Publishing, 1994.

\section{Bech 1978}

Bech P, Rafaelson OJ, Krampt P, Bolwig TG. The mania rating scale: scale construction and inter-observer agreement. Neuropharmacology 1978;17:430-1.

\section{Bierman 2007}

Bierman EJ, Comijs HC, Gundy CM, Sonnenberg C, Jonker C, Beekman AT. The effect of chronic benzodiazepine use on cognitive functioning in older persons: good, bad or indifferent?. International Journal of Geriatric Psychiatry 2007;22:1194-200.

\section{Billig 1991}

Billig N, Cohen-Mansfield J, Lipson S. Pharmaceutical treatment of agitation in a nursing home. Journal of the American Geriatrics Society 1991;39:1002-5.

\section{Cohen-Mansfield 1986}

Cohen-Mansfield J, Billig N. Agitated behaviours in the elderly. 1. A conceptual review. Journal of the American Geriatrics Society 1986;34:711-21.

\section{Cohen-Mansfield 1989}

Cohen-Mansfield J, Werner P, Marx MS. An observational study of agitation in agitated nursing home residents. International Psychogeriatrics 1989;1:153-65.

\section{Colenda 1991}

Colenda CC, Hamer RM. Antecedents and interventions for aggressive behavior of patients at a geropsychiatric state hospital. Hospital and Community Psychiatry 1991;42:287-92.

\section{COSTART 1989}

COSTART: Coding Symbols Thesaurus for Adverse Reaction Terms. US Food and Drug Administration. 3. Rockville (MD): US Food and Drug Administration: Center for Drugs and Biologics, Division of Drug and Biological Products Experience, 1989.

\section{Cummings 1994}

Cummings JL, Mega M, Gray K, Rosenberg-Thompson S, Carusi DA, Gornbein J. The Neuropsychiatric Inventory: comprehensive assessment of psychopathology in dementia. Neurology 1994;44:2308-14.

\section{Egger 1997}

Egger M, Smith G D, Schneider M, Minder C. Bias in metaanalysis detected by a simple, graphical test. BMJ 1997:315:629. [https://doi.org/10.1136/bmj.315.7109.629 ]

\section{Folstein 1975}

Folstein MF, Folstein SE, McHugh PR. A practical method for grading the cognitive state of patients for the clinician. Journal of Psychiatric Research 1975;12:189-98.

\section{Guy 1976}

Guy W. ECDEU Assessment Manual for Psychopharmacology. USA Department of Health, Education and Welfare Publication (ADM) 76-338. 2nd Edition. Washington (DC): US Government Printing Office, 1976:218-22.

\section{Higgins 2011}

Higgins JP, Green S, editor(s). Cochrane Handbook for Systematic Reviews of Interventions Version 5.1.0 (updated March 2011). The Cochrane Collaboration, 2011. Available from handbook.cochrane.org.

\section{Hughes 1982}

Hughes CP, Berg L, Danziger WL, Cohen LA, Martin RL. A new clinical scale for the staging of dementia. British Journal of Psychiatry 1982;140:566-72.

\section{Lawton 1969}

Lawton MP, Brody EM. Assessment of older people: selfmaintaining and instrumental activities of daily living. Gerontologist 1969;9:179-86.

\section{Livingstone 2014}

Livingston G, Kelly L, Lewis-Holmes E, Baio G, Morris S, Patel N, et al. Non-pharmacological interventions for agitation in dementia: systematic review of randomised controlled trials. British Journal of Psychiatry 2014;205(6):436-42. 


\section{Lon 1995}

Lon AD, McElroy SL, Keys MA. Valproate in the treatment of behavioral agitation in elderly patients with dementia. Journal of Neuropsychiatry and Clinical Neurosurgery 1995;7:314-9.

\section{Maher 2011}

Maher AR, Maglione M, Bagley S, Suttorp M, Hu JH, Ewing B, et al. Efficacy and comparative effectiveness of atypical antipsychotic medications for off-label uses in adults: a systematic review and meta-analysis. Journal of the American Medical Association 2011;306:1359-69.

\section{McKhann 1984}

McKhann G, Brackman D, Folstein M, Katzman R, Price D, Stadlan EM. Clinical diagnosis of Alzheimer's disease: report of the NINCDS-ADRDA workgroup under the auspices of the Department of Health and Human Services Task Force on Alzheimer's Disease. Neurology 1984;34:939-44.

\section{MHRA 2012}

Medicines and Healthcare products Regulatory Agency. Antipsychotics: initiative to reduce prescribing to older people with dementia. Drug Safety Update 2012;5(10):H1.

\section{NICE 2006}

National Institute for Health and Care Excellence. Dementia: Supporting People with Dementia and their Carers in Health and Social Care. Clinical guideline CG42. London: National Institute of Health and Care Excellence, 2006.

\section{NICE 2015}

National Institute for Health and Care Excellence. Management of Aggression, Agitation and Behavioural Disturbances in Dementia: Valproate Preparations. London: National Institute for Health and Care Excellence, 2015.

\section{NICE 2016}

National Institute for Health and Care Excellence. Dementia: Supporting People with Dementia and their Carers in Health and Social Care. Updated Clinical guideline CG42. London: National Institute for Health and Care Excellence, 2016.

\section{Overall 1962}

Overall JE, Gorham DR. The Brief Psychiatric Rating Scale. Psychology Reports 1962;10:799-812.

\section{Overall 1988}

Overall J, Gorham D. Introduction: the Brief Psychiatric Rating Scale (BPRS): recent developments in ascertainment and scaling. Psychopharmacology Bulletin 1988;24:97-8.

\section{Patel 1993}

Patel V, Hope T. Aggressive behavior in elderly people with dementia: a review. International Journal of Geriatric Psychiatry 1993;8:457-72.

\section{Porteinsson 2014}

Porsteinsson AP, Drye LT, Pollock BG, Devanand DP, Frangakis C, Ismail Z, et al. Effect of citalopram on agitation in Alzheimer disease: the CitAD randomized clinical trial. Journal of the American Medical Association 2014;311:682-91.

\section{Review Manager 2014 [Computer program]}

Nordic Cochrane Centre, The Cochrane Collaboration. Review Manager (RevMan). Version 5.3. Copenhagen: Nordic Cochrane Centre, The Cochrane Collaboration, 2014.

\section{Schünemann 2011}

Schünemann HJ, Oxman AD, Higgins JP, Vist GE, Glasziou P, Guyatt GH. Chapter 11: Presenting results and 'Summary of findings' tables. In: Higgins JP, Green S, editor(s). Cochrane Handbook for Systematic Reviews of Interventions Version 5.1.0 (updated March 2011). The Cochrane Collaboration, 2011. Available from handbook.cochrane.org.

\section{Seitz 2011}

Seitz D, Adunuri N, Gill SS, Gruneir A, Herrmann N, Rochon P. Antidepressants for agitation and psychosis in dementia. Cochrane Database of Systematic Reviews 2011, Issue 2. [DOI: 10.1002/14651858.CD008191.pub2]

\section{Verstraten 1988}

Verstraten PF. The GIP: an observational ward behavior scale. Psychopharmacology Bulletin 1988;24:717-9.

\section{WHO 1991}

World Health Organization. ICD-10. Tenth Revision of the International Classification of Diseases. Mental and Behavioural Disorders. Clinical Descriptions and Diagnostic Guidelines. 10th Edition. Geneva: World Health Organization, 1991.

\section{Wistedt 1990}

Wistedt B, Rasmussen A, Pedersen L, Malm U, TräskmanBendz L, Wakelin J, et al. The development of an observerscale for measuring social dysfunction and aggression. Pharmacopsychiatry 1990;23:249-52.

\section{Yudofsky 1986}

Yudofsky SC, Silver JM, Jackson W, Endicott J, Williams D. The Overt Aggression Scale for the objective rating of verbal and physical aggression. American Journal of Psychiatry 1986;143:35-9.

\section{References to other published versions of this review}

\section{Lonergan 2004}

Lonergan $\mathrm{E}$, Luxenberg J. Valproate preparations for agitation in dementia. Cochrane Database of Systematic Reviews 2004, Issue 2. [DOI: 10.1002/14651858.CD003945.pub2]

\section{Lonergan 2009}

Lonergan E, Luxenberg J. Valproate preparations for agitation in dementia. Cochrane Database of Systematic Reviews 2009, Issue 3. [DOI: 10.1002/14651858.CD003945.pub3] 
CHARACTERISTICS OF STUDIES

Characteristics of included studies [ordered by study ID]

Herrmann 2007

Methods Randomised, double-blind, placebo-controlled trial. Cross-over design, of 6-week treatment with valproate/placebo, with 2-week washout interval.

Participants

Setting: residents of 2 long-term care facilities associated with university-affiliated general hospitals in Canada.

Diagnosis: AD

Inclusion criteria: DSM-IV criteria for primary degenerative dementia, and NINCDS-ADRDA criteria for probable $A D$ of $\geq 1$ year's duration; aged $>55$ years; MMSE score $<15$ (i.e. moderate-to-severe cognitive impairment); NPI total score $\geq 8$.

Exclusion criteria: significant medical or neurological conditions that could account for cognitive impairment; Hachinski Ischemic Scale score 3; neuroimaging inconsistent with diagnosis of AD; presence of premorbid or current psychiatric diagnoses. No stated clinical evaluation to exclude acute medical illness such as delirium.

Total number of participants: 14 (12 participants completed, 1 dropout during each treatment phase. 2 additional participants discontinued placebo early but competed all study assessments.)

Baseline characteristics

- Age: mean 85.6 years (SD 4.5)

- Women: $43 \%$

- MMSE: mean 4.5 (SD 4.6)

- NPI total score: mean 33.4 (SD 23.6)

- NPI agitation/aggression score: mean 6.4 (SD 3.5)

- CMAl total score: mean 53.4 (SD 15.7)

- Number of participants with antidepressant drugs at screening (\%): 2 withdrawn from antidepressants before study

- Use of cholinesterase inhibitors: not reported

- Use of memantine: not reported

Titration of valproate, with a mean daily dose of $1134.6 \mathrm{mg}$ (SD 400.1).

Participants underwent a placebo washout of all psychotropic drugs before randomisation.

Outcomes Primary:

- Agitation measured with NPI agitation subscale score mean change at 6 weeks

Secondary:

- BPSD measured by NPI total score, change at 6 weeks

- Agitation measured with CMAI, change at 6 weeks

- Safety and tolerability 
Herrmann 2007 (Continued)

\title{
Bias Authors' judgement Support for judgement
}

Random sequence genera- Unclear risk Quote: "patients were randomised...." (p. 117)

tion (selection bias)

Insufficient information about the sequence generation process to permit judgement of low risk or high risk.

Allocation concealment Unclear risk Insufficient information to permit judgement of low risk or high risk.
(selection bias)

(selection bias)

Unclear risk Initial 1 week of single-blind placebo washout, then "double-blind crossover design" (p. 117).

and personnel (perfor-

Quote: "patients randomised to receive valproate liquid suspension or an

All outcomes identical placebo."

\begin{tabular}{lll}
\hline Blinding of outcome as- & Unclear risk & Insufficient information. No explanation given regarding who completed out- \\
sessment (detection bias) & come measures. Given that the study was described as double-blind, it was \\
All outcomes & likely that the rater was blind to treatment allocation but this is not stated ex- \\
& plicitly.
\end{tabular}

Incomplete outcome data Low risk 2/16 participants dropped out prior to randomisation and were not included (attrition bias) in analysis. 1 dropped out during each treatment phase (reasons not stated). All outcomes $\quad 2$ additional participants discontinued treatment with placebo early (reasons not stated), but completed all study assessments. Study authors stated that intention-to-treat analysis was completed using last observation carried forward, but incomplete data reported in results table.

\begin{tabular}{ll}
\hline $\begin{array}{l}\text { Selective reporting (re- } \\
\text { porting bias) }\end{array}$ & Low risk \\
& $\begin{array}{l}\text { Results of the primary and secondary outcome measures specified in methods } \\
\text { was available to determine the prespecified outcome measures. }\end{array}$
\end{tabular}

Other bias Low risk No other potential source of bias identified.

\section{Porsteinsson 2001}

$\begin{array}{ll}\text { Methods } & \begin{array}{l}\text { Multicentre, randomised, double-blind, placebo-controlled study of 6-week treatment placebo/dival- } \\ \text { proex sodium }\end{array}\end{array}$

Participants

\author{
Setting: 7 long-term care facilities in New York \\ Diagnosis: $A D$, VaD, or mixed dementia \\ Inclusion criteria: probable or possible AD (by DSM-IV and NINCDS-ADRDA criteria or VaD (by DSM-IV) \\ or mixed dementia (by DSM-IV); aged > 60 years; agitation for a minimum of 2 weeks; BPRS score $\geq 3$ on \\ items rating tension, hostility, unco-operativeness, or excitement. \\ Exclusion criteria: acute medical illness as reflected by history, examination, and laboratory testing. \\ Acute medical illness excluded. \\ Best efforts exerted to identify and implement non-pharmacological interventions for the agitation pri- \\ or to study consideration. \\ Total number of participants: 56 (1 dropped out between randomisation and treatment because of agi- \\ tation, but was included in the analysis). \\ Baseline characteristics \\ - Mean age: placebo: 84.7 (SD 6.0) years; divalproex: 85.3 (SD 8.1)
}


Porsteinsson 2001 (Continued)

- Women: placebo: 22/28 (79\%); divalproex: $17 / 28(61 \%)$

- Diagnosis: placebo: AD 75\%, VaD 18\%, mixed 7\%; divalproex: AD 68\%, VaD 18\%, mixed $14 \%$

- Number of participants on psychotropic drugs at screening (\%): placebo: $79 \%$; divalproex: $68 \%$

- Use of cholinesterase inhibitors: not reported

- Use of memantine: not reported

Interventions

Divalproex sodium: titrated to mean dose of $826 \mathrm{mg} /$ day; 6-week course

Placebo

Choral hydrate $250-500 \mathrm{mg}$ given on an as-needed basis.

Psychotropic medication was withdrawn before randomisation.

Primary:
- BPRS total score, change over 6 weeks
- BPRS agitation factor, change over 6 weeks
- BPRS hostility factor, change over 6 weeks
- CGI, change over 6 weeks
Secondary:
- Overt Aggression Scale score, change over 6 weeks
- CERAD BRSD weighted, change over 6 weeks
- CMAl total score, change over 6 weeks
- Shysical Self-maintenance score, change over 6 weeks

Notes

A physician monitor who did not have access to participants or study personnel determined the optimal dose of divalproex based on written reports from the blinded raters.

\section{Risk of bias}

\begin{tabular}{lll}
\hline Bias & Authors' judgement & Support for judgement \\
\hline $\begin{array}{l}\text { Random sequence genera- } \\
\text { tion (selection bias) }\end{array}$ & Unclear risk & $\begin{array}{l}\text { Randomisation was blocked by site, but no specific information regarding se- } \\
\text { quence generation process given to permit judgement of low risk or high risk. }\end{array}$ \\
\hline $\begin{array}{l}\text { Allocation concealment } \\
\text { (selection bias) }\end{array}$ & Unclear risk & $\begin{array}{l}\text { No information given. Insufficient information to permit judgement of low risk } \\
\text { or high risk. }\end{array}$ \\
\hline $\begin{array}{l}\text { Blinding of participants } \\
\text { and personnel (perfor- } \\
\text { mance bias) }\end{array}$ & Low risk & $\begin{array}{l}\text { All participants were blinded to treatment condition with the exception of a } \\
\text { physician-monitor and a pharmacist, neither of whom had contact with the } \\
\text { participant, care team, family, or laboratory personnel. The participant's opti- } \\
\text { mal dose was determined by the non-blinded physician on the basis of written } \\
\text { reports of adverse effects from the blinded raters, written reports describing } \\
\text { change in baseline behavioural target symptoms received from blinded raters, } \\
\text { and confidential laboratory data. }\end{array}$
\end{tabular}

Blinding of outcome as- Low risk Outcome measures were completed by blinded raters.

sessment (detection bias)

All outcomes

Incomplete outcome data Low risk

(attrition bias)

All outcomes

\begin{abstract}
1 participant was dropped between randomisation and treatment because of agitation, this participant was included in analysis. 2 participants dropped out from the divalproex group, due to bowel obstruction, and due to respiratory and urinary tract infections, delirium, and seizures. 4 participants dropped out from the placebo group, due to increased agitation. Data from participants
\end{abstract}

Valproate preparations for agitation in dementia (Review) 
Porsteinsson 2001 (Continued)

who dropped out were included in analysis. Efficacy data were analysed according to intention-to-treat principles, using last observation carried forward for subjects who dropped out after randomisation.

Sival 2002

\begin{tabular}{ll}
\hline Methods & Randomised, double-blind, placebo-controlled, cross-over design study of sodium valproate \\
\hline Participants & Setting: psychogeriatric short-stay ward at a psychiatric teaching hospital in the Netherlands. \\
& Diagnosis: dementia (by DSM-IV and NINCDS-ADRDA criteria) \\
& Inclusion criteria: people with aggressive behaviour and senile dementia according to the criteria of the \\
& DSM-IV and NINCDS-ADRDA and who met Patel's criteria and also had a score of 3 on $\geq 1$ of the items of \\
the SDAS-9. Aggressive behaviour was defined according to Patel's description (Patel 1993): aggressive & behaviour is an overt act, involving the delivery of noxious stimuli to (but not necessarily aimed at) an- \\
other object, organism, or self, which is clearly not accidental.
\end{tabular}

Results of the primary and secondary outcome measures specified in methods were reported, as well as frequency of adverse events, but no study protocol was available to determine the prespecified outcome measures.

$\begin{array}{ll}\text { Other bias } \quad \text { Low risk } & \begin{array}{l}\text { Study supported by "an unrestricted investigator-initiated grant from Abbott } \\ \text { Laboratories. Divalproex Sodium was donated by Abbott Park Laboratories." }\end{array}\end{array}$

\begin{abstract}
Exclusion criteria: another diagnosis besides dementia at Axis 1 of the DSM-IV; epilepsy or epileptic activity according to EEG; myocardial infarction $<3$ months prior to the study, cardiac arrhythmia requiring acute medical treatment; liver insufficiency, renal failure, myelodysplasia, and blood dyscrasias; using sodium valproate previously; alcohol or substance abuse, or both; using depot antipsychotics or fluoxetine within 30 days before the start of the trial. No stated clinical evaluation to exclude acute medical illness such as delirium.
\end{abstract}

Total number of participants: 43 (1 participant excluded due to protocol violation, and 3 participants dropped out)

Baseline characteristics

- Age: mean80.4 years (SD 6.8)

- Women: $59.5 \%$

- Diagnosis: AD 54.8\%, VaD 9.5\%, dementia in PD 2.4\%, mixed 31\%, other dementia $2.4 \%$

- MMSE: 11.4 (SD 5.0)

- CDR: light $4.8 \%$, moderate $57.1 \%$, severe $38.1 \%$

- Number of participants on psychotropic drugs at screening (\%): not reported

- Use of cholinesterase inhibitors: not reported

- Use of memantine: not reported

Interventions Sodium valproate $240 \mathrm{mg}$ twice daily. Oxazepam $10-30 \mathrm{mg} /$ day given if required for severe anxiety. Baseline extended by 1 week where SDAS-9 score was not $>2$

Psychotropic medication was withdrawn before randomisation.

Baseline period (1 week), placebo period ( 3 weeks), washout period with placebo (1 week), and treatment period with sodium valproate ( 3 weeks) - sequence of the treatment periods was assigned at random.

Outcomes

Primary:

- SDAS-9, mean change at end of each treatment period 
Sival 2002 (Continued)

- CGI scale, mean change at end of each treatment period

Secondary:

- GIP scale, mean change at end of each treatment period

- Safety and tolerability

Notes Participants who withdrew from the study were excluded from analysis.

\section{Risk of bias}

\begin{tabular}{lll}
\hline Bias & Authors' judgement & Support for judgement \\
\hline $\begin{array}{l}\text { Random sequence genera- } \\
\text { tion (selection bias) }\end{array}$ & Unclear risk & $\begin{array}{l}\text { Quote: "the sequence of the treatment periods was assigned at random. The } \\
\text { code was not accessible for the investigators" (p. 581). }\end{array}$ \\
& $\begin{array}{l}\text { No specific information regarding sequence generation process given to per- } \\
\text { mit judgement of low risk or high risk. }\end{array}$
\end{tabular}

Allocation concealment Low risk Quote: "The code was not accessible for the investigators" (p. 581).

(selection bias)

$\begin{array}{ll}\begin{array}{l}\text { Blinding of participants } \\ \text { and personnel (perfor- }\end{array} & \text { Double-blind study design. Used a placebo suspension, identical to the active } \\ \text { mance bias) } & \text { medication in appearance, quantity, smell, and taste. Participants and inves- } \\ \text { All outcomes } & \text { tigators blinded to treatment allocation. A pharmacist and an independent } \\ & \text { physician dealt with laboratory values, including peak valproate levels, out- } \\ & \text { side the normal range. They had no contact with the participants, investiga- } \\ & \text { tors, the ward team, or participant's relatives. }\end{array}$

\begin{tabular}{lll}
\hline Blinding of outcome as- & Unclear risk & Double-blind study. Outcome assessments made by geriatrician and research \\
sessment (detection bias) & nurse, but not explicitly stated if they were blind to treatment allocation.
\end{tabular}

All outcomes

Incomplete outcome data Low risk
(attrition bias)

(attrition bias)

Participants were considered dropouts and excluded from analysis in case of severe adverse reactions or in case of violation of the protocol. 1/43 participants left out of analysis due to protocol violation, and there were 2 dropouts during placebo period, and 1 dropout during washout period (reasons given and not associated with valproate treatment) and not included in analysis.

\begin{tabular}{lll}
\hline $\begin{array}{l}\text { Selective reporting (re- } \\
\text { porting bias) }\end{array}$ & Low risk & $\begin{array}{l}\text { Results of the primary and secondary outcome measures specified in methods } \\
\text { were reported, as well as frequency of adverse events, but no study protocol } \\
\text { was available to determine the prespecified outcome measures. }\end{array}$ \\
\hline Other bias & Low risk & No other potential source of bias identified. \\
\hline
\end{tabular}

Tariot 2001

\begin{tabular}{ll}
\hline Methods & 6-week randomised, double-blind, placebo-controlled, parallel-group, multicentre study \\
\hline Participants & Setting: nursing home residents in USA \\
& Diagnosis: probable or possible AD type or VaD \\
& Inclusion criteria: residents of long-term care facilities, aged $\geq 65$ years; diagnosis that met DSM-IV cri- \\
& teria for DAT or VaD, or both; exhibited manic symptoms. Manic symptoms defined using the Bech- \\
& Rafaelsen Mania Scale and 6 items of the BPRS. Participants were required to have a BRMS total score \\
& $\geq 15 ;$ BPRS score $\geq 3$ on $\geq 2$ of the following items: tension, grandiosity, hostility, suspiciousness, un-
\end{tabular}


Tariot 2001 (Continued)

co-operativeness, and excitement; and BPRS total score $\geq 15$; people had to be able to take oral medications; expected to remain in the same facility throughout the study.

Exclusion criteria: dementia other than DAT or VaD, or both; delirium; seizure disorders; uncontrolled gastrointestinal, renal, hepatic, endocrine, cardiovascular, pulmonary, immunological, or haematological disease; history of alcohol abuse or substance abuse; history of, or current, hepatitis A, B, or C infection or pancreatitis; and platelet count $<100 \times 109 / \mathrm{L}$ prior to randomisation; acute systemic medical disorders that could confound interpretation of results or affect compliance; medical conditions requiring the continuous use of medication that would interfere with the assessment of safety or efficacy of divalproex sodium; delirium.

Total number of participants: 173 (87 divalproex, 85 placebo). 1 participant excluded after randomisation as they could not swallow the study medication.

Baseline characteristics

- Mean age: divalproex: 83.1 (SD 6.7) years, placebo: 83.6 (SD 7.5) years

- Women: divalproex: $66 \%$, placebo: $64 \%$

- MMSE: divalproex: 7.1 (SD 0.75), placebo: 7.7 (SD 0.77)

- Number of participants on psychotropic drugs at screening (\%): not reported

- Use of cholinesterase inhibitors: allowed, if on stable dose

- Use of memantine: not reported

Interventions

Divalproex sodium: starting dose $125 \mathrm{mg}$ twice daily, titrated in increments of $125 \mathrm{mg} /$ day to target dose of $20-30 \mathrm{mg} / \mathrm{kg}$. Median dose $1000 \mathrm{mg} /$ day.

Psychotropic medication was withdrawn at least 7 days before randomisation. Lorazepam, oxazepam, or chloral hydrate were permitted as needed.

Outcomes

Primary:

- BRMS (11-item observer-based scale that rates the severity of manic symptoms), change at end point

- CMAl, change at end point

- CMAI verbally agitated behaviour subscale, change at end point

- CMAl aggressive behaviour subscale, change at end point

- CMAI physically non-aggressive behaviour subscale, change at end point

- BPRS, change at end point

- $\mathrm{CGI}$, change at end point

Secondary:

- Safety and tolerability

Notes

Study terminated prematurely due to a high number of dropouts in the active treatment group compared to placebo. $54 \%$ of divalproex sodium-treated participants dropped out compared to $29 \%$ of placebo-treated participants.

\section{Risk of bias}

\begin{tabular}{lll}
\hline Bias & Authors' judgement & Support for judgement \\
\hline $\begin{array}{l}\text { Random sequence genera- } \\
\text { tion (selection bias) }\end{array}$ & Unclear risk & $\begin{array}{l}\text { Quote: "Following screening/washout period patients were randomly assigned } \\
\text { in a 1:1 ratio" (p. 54). Insufficient information about the sequence generation } \\
\text { process to permit judgement of low risk or high risk. }\end{array}$ \\
\hline $\begin{array}{l}\text { Allocation concealment } \\
\text { (selection bias) }\end{array}$ & Unclear risk & $\begin{array}{l}\text { No information given. Insufficient information to permit judgement of low risk } \\
\text { or high risk. }\end{array}$ \\
\hline
\end{tabular}


Tariot 2001 (Continued)

Blinding of participants and personnel (perfor-

Unclear risk mance bias)

All outcomes
Described as a double-blind study but explicit statement that all staff were blinded to allocation not made except for the fact that the clinicians completing the outcome assessment measures were blinded. Total serum valproate levels were measured weekly and monitored by nursing staff - it was not stated whether these nursing staff were involved with the study/blinded.
Blinding of outcome as- Low risk sessment (detection bias)

All outcomes
Clinician who completed the outcome assessment measures were blinded.

\begin{tabular}{|c|c|c|}
\hline $\begin{array}{l}\text { Incomplete outcome data } \\
\text { (attrition bias) } \\
\text { All outcomes }\end{array}$ & High risk & $\begin{array}{l}\text { Based on an interim analysis indicating a disproportionate number of } \\
\text { dropouts (due to adverse events) in the active-treatment group versus the } \\
\text { placebo group, the trial was suspended ( } 47 / 87 \text { participants in divalproex group } \\
\text { and } 25 / 85 \text { participants in placebo group withdrew prematurely. } 22 \% \text { of partic- } \\
\text { ipants in divalproex group vs } 4 \% \text { in participants in placebo group due to ad- } \\
\text { verse effects. Intention-to-treat analysis carried out using last observation car- } \\
\text { ried forward method. For those participants who discontinued early, final as- } \\
\text { sessment carried out on the last day they were in the study. The previous as- } \\
\text { sessment was used as an estimate of the missing assessment. }\end{array}$ \\
\hline
\end{tabular}

\begin{tabular}{ll}
\hline $\begin{array}{l}\text { Selective reporting (re- } \\
\text { porting bias) }\end{array}$ & Low risk \\
& $\begin{array}{l}\text { were reported, as well as frequency of adverse events, but no study protocol } \\
\text { was available to determine the prespecified outcome measures. }\end{array}$
\end{tabular}

Other bias Low risk This study was supported by a grant from Abbott Laboratories.

\title{
Tariot 2005
}

Methods
study

Participants

\author{
Setting: nursing home residents in USA \\ Diagnosis: $A D$ \\ Inclusion criteria: diagnosis of probable or possible AD according to the NINCDS-ADRDA criteria; MMSE \\ score 4-24; aged > 49 years; residing in a nursing home; and having at least a 2-week history of agita- \\ tion associated with a total score $>14$ on the 18-item BPRS and score $>2$ on items assessing tension, \\ hostility, unco-operativeness, or excitement at screening and baseline. People were ambulatory or am- \\ bulatory-aided, and in stable medical condition.
}

Exclusion criteria: clinically significant active medical conditions, other psychiatric or CNS disorders; modified Hachinski Ischemia Score. Excluded "clinically significant active medical conditions, other psychiatric or CNS disorders."

Total number of participants: 153 (75 divalproex sodium, 78 placebo)

Baseline characteristics

- Mean age: placebo: 83.9 (SD 5.9) years, divalproex: 84.2 (SD 6.6) years

- Women: placebo: $73 \%$, divalproex: 63\%

- MMSE: placebo: 10.8 (SD 5.4), divalproex: 10.5 (SD 4.9)

- BPRS agitation score, mean: placebo: 8.2 (SD 3.3), divalproex: 8.3 (SD 3.0)

- BPRS total score, mean: placebo: 33.4 (SD 10.0), divalproex: 35.0 (SD 9.1)

- CMAl total score, mean: placebo: 36.4 (SD 15.8), divalproex: 35.6 (SD 16.4)

- PSMS score, mean: placebo: 17.8 (SD 5.0), divalproex: 17.5 (SD 5.2)

- Number of participants on psychotropic drugs at screening (\%): not reported 
Tariot 2005 (Continued)

- Use of cholinesterase inhibitors: permitted

- Use of memantine: not reported

Interventions

Divalproex sodium delayed-release tablets or placebo given for 6 weeks. Dosage titrated to 500-1000 $\mathrm{mg} /$ day.

All psychoactive drugs stopped 7 days prior to randomisation.

Psychotropic medication was withdrawn at least 7 days before randomisation. Zolpidem or lorazepam (or both) were permitted for severe agitation or sleep-induction as needed.

Primary:
- BPRS, change in agitation factor (items relating to anxiety, tension, and excitement)
Secondary:
- ADCS
- CGIC (index of clinical efficacy), change between baseline and 3 and 6 weeks
- CMAl, change between baseline and 3 and 6 weeks
- PSMS, change between baseline and 6 weeks
- MMSE, change between baseline and 6 weeks
- Frequency of rescue medication
- Safety and tolerability

Notes

Study represents the extension of an earlier pilot study that investigated the safety and tolerability of divalproex (Porsteinsson 2001). The authors concluded that diarrhoea and decreased platelet counts were more common among divalproex-treated participants and that divalproex sodium offered no advantage, compared with placebo, in the management of people with dementia with agitation and should not be used as a first-line treatment for this condition.

\section{Risk of bias}

\begin{tabular}{lll}
\hline Bias & Authors' judgement & Support for judgement \\
\hline $\begin{array}{l}\text { Random sequence genera- } \\
\text { tion (selection bias) }\end{array}$ & Low risk & $\begin{array}{l}\text { Quote: "Participants were assigned to one of two treatment groups in per- } \\
\text { muted blocks of 4, in accordance with a randomisation list created and main- } \\
\text { tained by the ADCS data management centre. Investigators sequentially as- } \\
\text { signed a randomisation number to each participant. No individual randomisa- } \\
\text { tion code was revealed during the trial" (p. 2). }\end{array}$ \\
\end{tabular}

\begin{tabular}{lll}
\hline $\begin{array}{l}\text { Allocation concealment } \\
\text { (selection bias) }\end{array}$ & Low risk & $\begin{array}{l}\text { The randomisation list was created and maintained by the ADCS data manage- } \\
\text { ment centre. No individual randomisation code was revealed during the trial. }\end{array}$ \\
\hline $\begin{array}{l}\text { Blinding of participants } \\
\begin{array}{l}\text { and personnel (perfor- } \\
\text { mance bias) }\end{array}\end{array}$ & Low risk & $\begin{array}{l}\text { Participants were assigned to double-blind treatment. All investigators blind- } \\
\text { ed to treatment allocation. Drug and placebo tablets were visually identical. } \\
\text { All outcomes }\end{array}$
\end{tabular}

\begin{tabular}{lll}
\hline $\begin{array}{l}\text { Blinding of outcome as- } \\
\text { sessment (detection bias) } \\
\text { All outcomes }\end{array}$ & Low risk & $\begin{array}{l}\text { All investigators blinded, study authors stated that no individual randomisa- } \\
\text { tion code was broken. }\end{array}$ \\
\hline $\begin{array}{l}\text { Incomplete outcome data } \\
\text { (attrition bias) }\end{array}$ & Low risk & $\begin{array}{l}11 / 75 \text { participants in divalproex group and 14/78 participants in placebo group } \\
\text { discontinued treatment early (specific reasons for discontinuation not given). } \\
\text { Participants who discontinued prematurely were seen for a final evaluation. } \\
\text { Primary analysis performed according to intention-to-treat principle. }\end{array}$ \\
\hline
\end{tabular}


Tariot 2005 (Continued)

Selective reporting (re- Low risk $\quad$ Results of the primary and secondary outcome measures specified in methods porting bias) were reported, as well as frequency of adverse events, but no study protocol was available to determine the prespecified outcome measures.

Other bias Low risk
Quote: "Laboratories Inc provided unrestricted supplemental and material support for this study."

AD: Alzheimer's disease; ADCS: Alzheimer's Disease Cooperative Study Activities; BPRS: Brief Psychiatric Rating Scale; BPSD: behavioural and psychological symptoms associated with dementia; CDR: Clinical Dementia Rating; CERAD: Consortium to Establish a Registry for Alzheimer's Disease; CMAl: Cohen-Mansfield Agitation Index; CNS: central nervous system; DAT: dementia of the Alzheimer type; DSM-IV: Diagnostic and Statistical Manual of Mental Disorders, 4th edition; EEG: electroencephalograph; GIP: Behavior Observation Scale of Intramural Psychogeriatric Patients; MMSE: Mini-Mental State Examination; NINCDS-ADRDA: National Institute of Neurological and Communicative Disorders and Stroke-Alzheimer's Disease and Related Disorders Association; NPI: Neuropsychiatric Inventory; PD: Parkinson's disease; SD: standard deviation; SDAS-9: 9-item Social Dysfunction and Agitation Scale; VaD: vascular dementia.

Characteristics of excluded studies [ordered by study ID]

\begin{tabular}{|c|c|}
\hline Study & Reason for exclusion \\
\hline Forester 2007 & Not randomised, no concealed allocation \\
\hline Goldberg 1999 & Not randomised placebo controlled \\
\hline Gupta 1998 & Not randomised placebo controlled \\
\hline Haas 1997 & Not randomised placebo controlled \\
\hline Horne 1995 & Not randomised placebo controlled \\
\hline Kasckow 1997 & Not randomised placebo controlled \\
\hline Lott 1995 & Not randomised placebo controlled \\
\hline Mazure 1992 & Not randomised placebo controlled \\
\hline Mellow 1993 & Not randomised placebo controlled \\
\hline Narayan 1997 & Not randomised placebo controlled \\
\hline Niedermier 1998 & Not randomised placebo controlled \\
\hline Porsteinsson 1997 & Not randomised placebo controlled \\
\hline Sandborn 1995 & Not randomised placebo controlled \\
\hline Sival 1994 & Not randomised placebo controlled \\
\hline Takahashi 1996 & Not randomised placebo controlled \\
\hline Tariot 2002 & Not randomised placebo controlled \\
\hline
\end{tabular}




\section{DATA AND ANALYSES}

Comparison 1. Valproate preparations versus placebo

\begin{tabular}{|c|c|c|c|c|}
\hline Outcome or subgroup title & No. of studies & $\begin{array}{l}\text { No. of partici- } \\
\text { pants }\end{array}$ & Statistical method & Effect size \\
\hline $\begin{array}{l}1 \text { Brief Psychiatric Rating Scale (BPRS) total } \\
\text { score. Change from baseline at } 6 \text { weeks (in- } \\
\text { tention to treat (ITT)) }\end{array}$ & 2 & 203 & $\begin{array}{l}\text { Mean Difference (IV, } \\
\text { Fixed, } 95 \% \mathrm{CI} \text { ) }\end{array}$ & $0.23[-2.14,2.59]$ \\
\hline $\begin{array}{l}2 \text { BPRS agitation factor. Change from baseline } \\
\text { at } 6 \text { weeks (ITT) }\end{array}$ & 2 & 203 & $\begin{array}{l}\text { Mean Difference (IV, } \\
\text { Fixed, } 95 \% \mathrm{CI})\end{array}$ & $-0.67[-1.49,0.15]$ \\
\hline $\begin{array}{l}3 \text { Cohen-Mansfield Agitation Index. Total } \\
\text { Score. Change from baseline at } 6 \text { weeks (ITT) }\end{array}$ & 3 & 217 & $\begin{array}{l}\text { Mean Difference (IV, } \\
\text { Fixed, } 95 \% \mathrm{CI} \text { ) }\end{array}$ & $-1.84[-6.02,2.34]$ \\
\hline $\begin{array}{l}4 \text { BPRS hostility factor. Change from baseline } \\
\text { at } 6 \text { weeks (ITT) }\end{array}$ & 1 & 55 & $\begin{array}{l}\text { Mean Difference (IV, } \\
\text { Fixed, } 95 \% \mathrm{CI} \text { ) }\end{array}$ & $0.10[-1.12,1.32]$ \\
\hline $\begin{array}{l}5 \text { Overt Aggression Scale total score. Change } \\
\text { from baseline at } 6 \text { weeks (ITT) }\end{array}$ & 1 & 55 & $\begin{array}{l}\text { Mean Difference (IV, } \\
\text { Fixed, } 95 \% \mathrm{CI} \text { ) }\end{array}$ & $0.10[-3.42,3.62]$ \\
\hline $\begin{array}{l}6 \text { Neuropsychiatric Inventory total score. } \\
\text { Change from baseline at } 6 \text { weeks (ITT) }\end{array}$ & 1 & 14 & $\begin{array}{l}\text { Mean Difference (IV, } \\
\text { Fixed, } 95 \% \mathrm{CI} \text { ) }\end{array}$ & $\begin{array}{l}15.28[-5.19 \\
35.75]\end{array}$ \\
\hline $\begin{array}{l}7 \text { Neuropsychiatric Inventory Agitation/Ag- } \\
\text { gression subscore. Change from baseline at } 6 \\
\text { weeks (ITT) }\end{array}$ & 1 & 14 & $\begin{array}{l}\text { Mean Difference (IV, } \\
\text { Fixed, } 95 \% \mathrm{CI})\end{array}$ & $1.43[-2.48,5.34]$ \\
\hline $\begin{array}{l}8 \text { Mini-Mental State Examination total score. } \\
\text { Change from baseline at } 6 \text { weeks (ITT) }\end{array}$ & 3 & 217 & $\begin{array}{l}\text { Mean Difference (IV, } \\
\text { Fixed, } 95 \% \mathrm{CI} \text { ) }\end{array}$ & $-0.70[-1.61,0.20]$ \\
\hline $\begin{array}{l}9 \text { Physical Self-Maintenance Scale total score. } \\
\text { Change from baseline at } 6 \text { weeks (ITT) }\end{array}$ & 2 & 203 & $\begin{array}{l}\text { Mean Difference (IV, } \\
\text { Fixed, } 95 \% \mathrm{CI} \text { ) }\end{array}$ & $1.19[0.40,1.98]$ \\
\hline
\end{tabular}

\section{Analysis 1.1. Comparison 1 Valproate preparations versus placebo, Outcome 1 Brief Psychiatric Rating Scale (BPRS) total score. Change from baseline at 6 weeks (intention to treat (ITT)).}

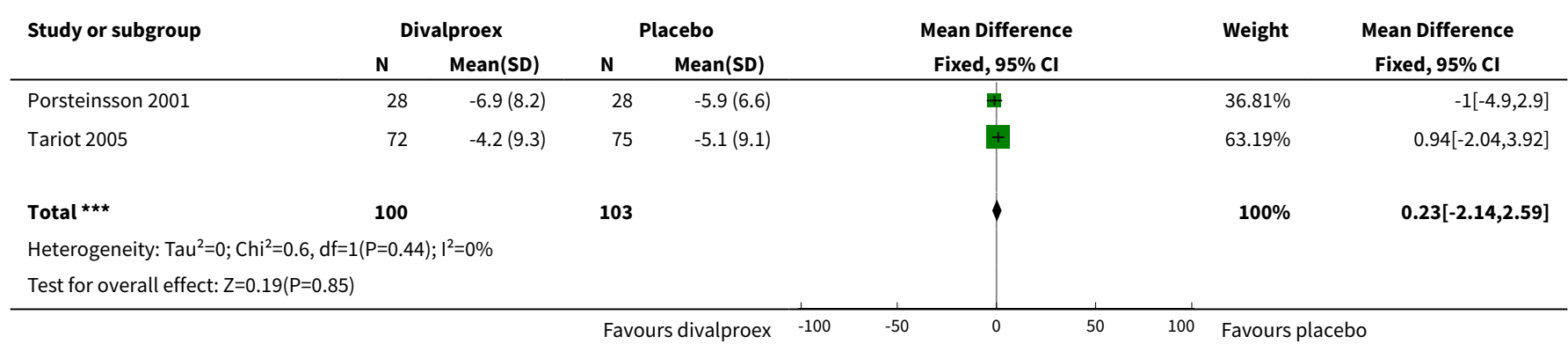


Analysis 1.2. Comparison 1 Valproate preparations versus placebo, Outcome 2 BPRS agitation factor. Change from baseline at 6 weeks (ITT).

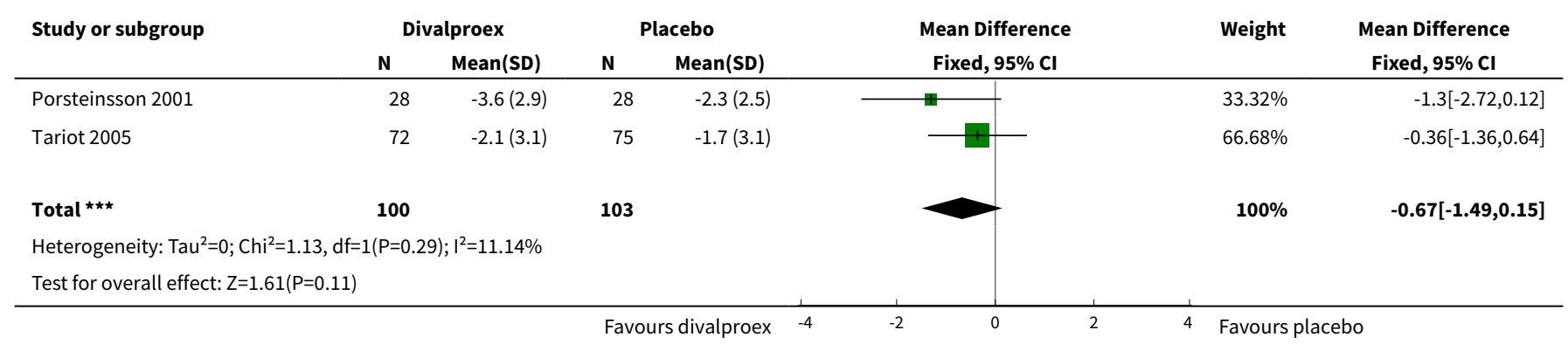

Analysis 1.3. Comparison 1 Valproate preparations versus placebo, Outcome 3 Cohen-Mansfield Agitation Index. Total Score. Change from baseline at 6 weeks (ITT).

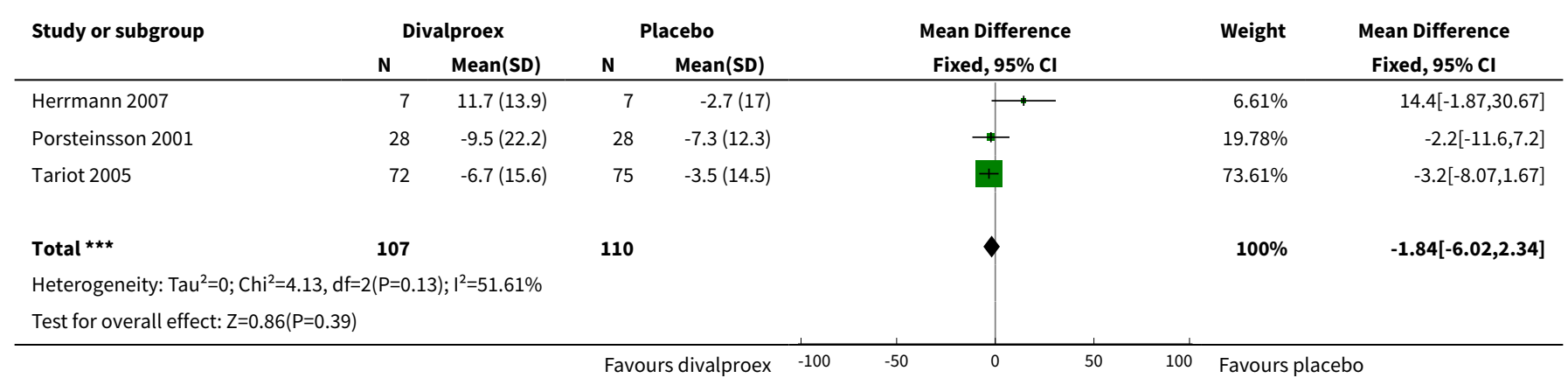

Analysis 1.4. Comparison 1 Valproate preparations versus placebo, Outcome 4 BPRS hostility factor. Change from baseline at 6 weeks (ITT).

\begin{tabular}{|c|c|c|c|c|c|c|c|}
\hline \multirow[t]{2}{*}{ Study or subgroup } & \multicolumn{2}{|c|}{ Divalproex } & \multicolumn{2}{|c|}{ Placebo } & \multirow{2}{*}{$\begin{array}{c}\text { Mean Difference } \\
\text { Fixed, } 95 \% \mathrm{Cl}\end{array}$} & \multirow[t]{2}{*}{ Weight } & \multirow{2}{*}{$\begin{array}{c}\text { Mean Difference } \\
\text { Fixed, } 95 \% \mathrm{Cl}\end{array}$} \\
\hline & $\mathbf{N}$ & Mean(SD) & $\mathbf{N}$ & $\operatorname{Mean}(S D)$ & & & \\
\hline Porsteinsson 2001 & 28 & $-1.5(2.5)$ & 27 & $-1.6(2.1)$ & - & $100 \%$ & $0.1[-1.12,1.32]$ \\
\hline 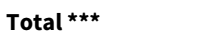 & 28 & & 27 & & & $100 \%$ & $0.1[-1.12,1.32]$ \\
\hline \multicolumn{8}{|c|}{ Heterogeneity: Tau $^{2}=0 ; \mathrm{Chi}^{2}=0, \mathrm{df}=0(\mathrm{P}<0.0001) ; \mathrm{I}^{2}=100 \%$} \\
\hline \multicolumn{8}{|c|}{ Test for overall effect: $\mathrm{Z}=0.16(\mathrm{P}=0.87)$} \\
\hline & & & Favo & s divalproex & $\begin{array}{ll}-5 & -2.5\end{array}$ & Favours & \\
\hline
\end{tabular}

Analysis 1.5. Comparison 1 Valproate preparations versus placebo, Outcome 5 Overt Aggression Scale total score. Change from baseline at 6 weeks (ITT).

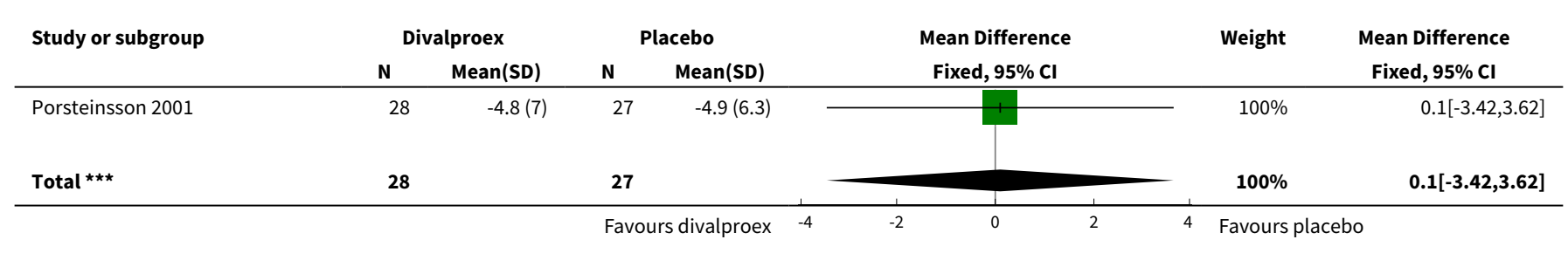




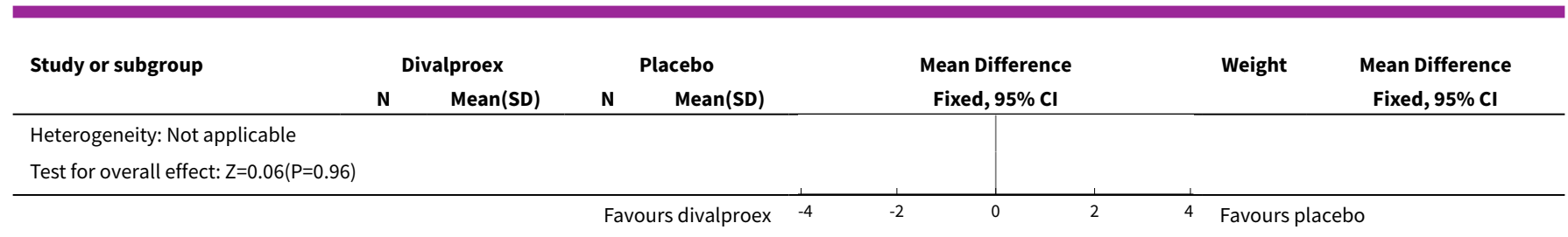

Analysis 1.6. Comparison 1 Valproate preparations versus placebo, Outcome 6 Neuropsychiatric Inventory total score. Change from baseline at 6 weeks (ITT).

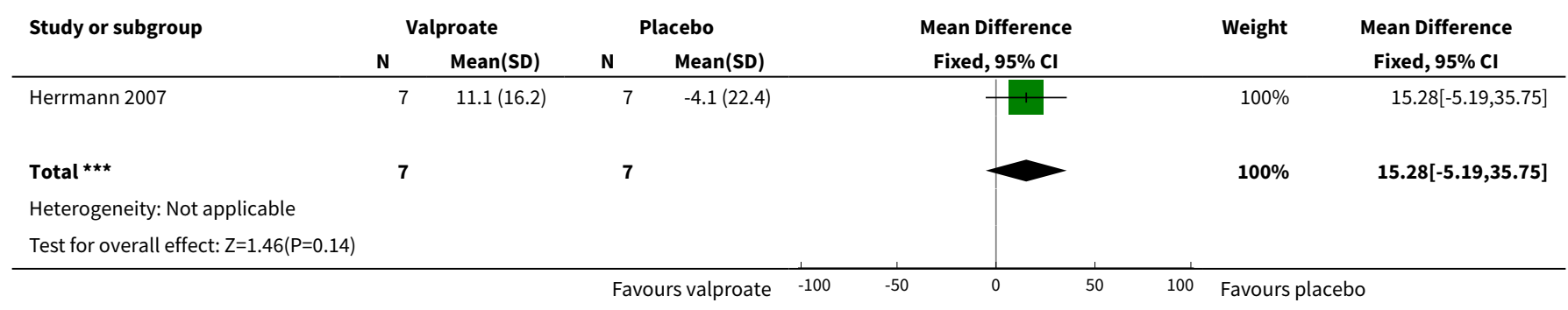

Analysis 1.7. Comparison 1 Valproate preparations versus placebo, Outcome 7 Neuropsychiatric Inventory Agitation/Aggression subscore. Change from baseline at 6 weeks (ITT).

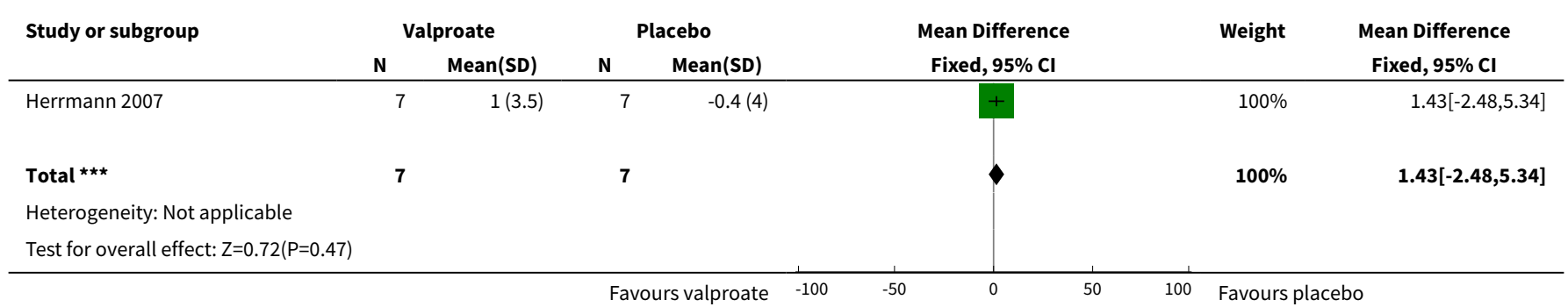

Analysis 1.8. Comparison 1 Valproate preparations versus placebo, Outcome 8 Mini-Mental State Examination total score. Change from baseline at 6 weeks (ITT).

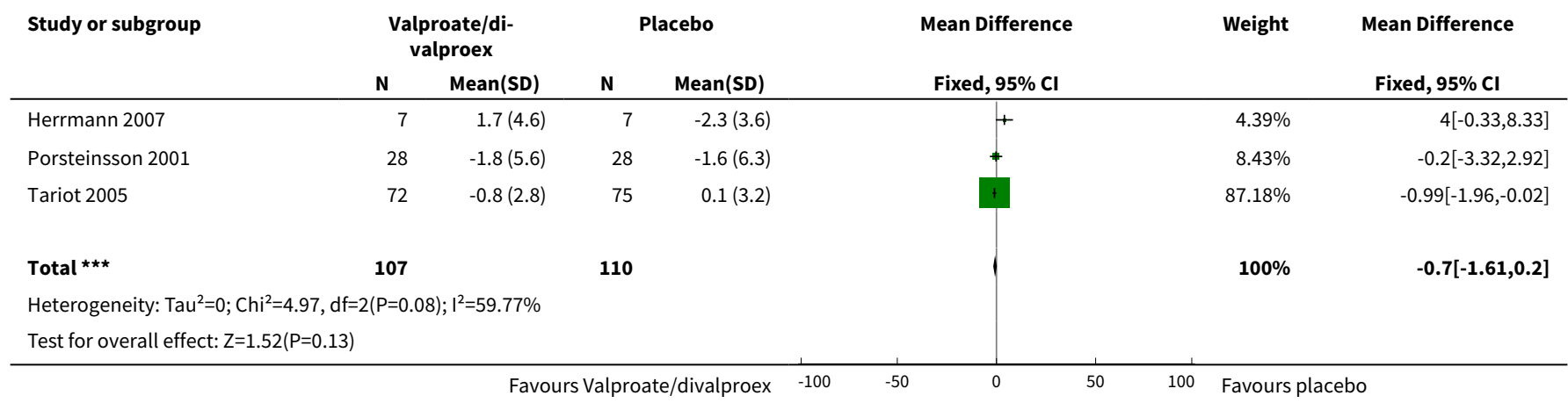


Analysis 1.9. Comparison 1 Valproate preparations versus placebo, Outcome 9 Physical Self-Maintenance Scale total score. Change from baseline at 6 weeks (ITT).

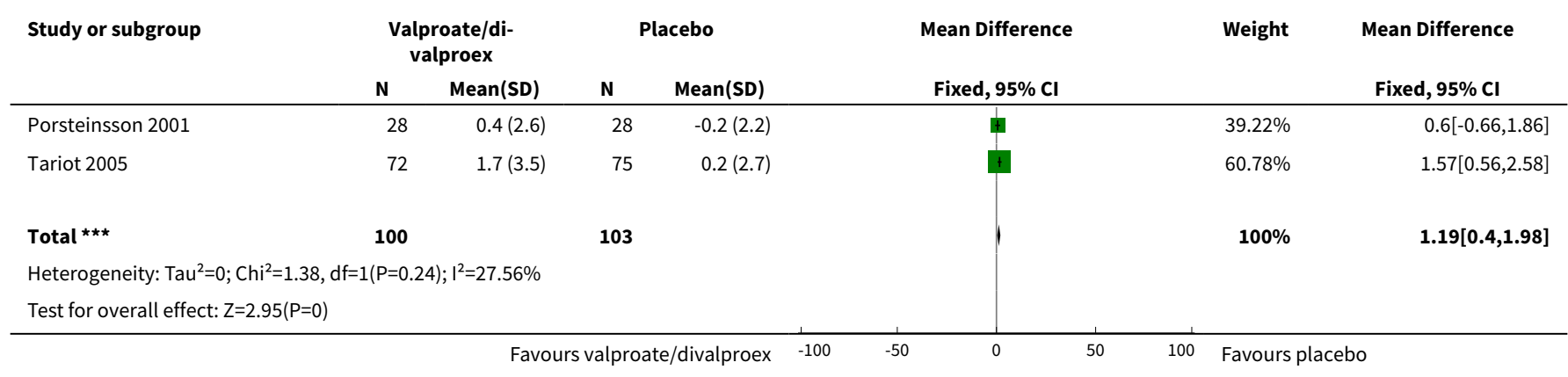

\section{Comparison 2. Divalproex versus placebo}

\begin{tabular}{|c|c|c|c|c|}
\hline Outcome or subgroup title & No. of studies & $\begin{array}{l}\text { No. of partici- } \\
\text { pants }\end{array}$ & Statistical method & Effect size \\
\hline $\begin{array}{l}1 \text { Total number of participants with sedation } \\
\text { at } 6 \text { weeks }\end{array}$ & 2 & 228 & $\begin{array}{l}\text { Odds Ratio (M-H, Fixed, } \\
95 \% \mathrm{Cl})\end{array}$ & $2.66[1.44,4.92]$ \\
\hline $\begin{array}{l}2 \text { Total number of participants with nausea, } \\
\text { vomiting, or diarrhoea at } 6 \text { weeks }\end{array}$ & 3 & 381 & $\begin{array}{l}\text { Odds Ratio (M-H, Fixed, } \\
95 \% \mathrm{Cl})\end{array}$ & $6.92[2.13,22.49]$ \\
\hline $\begin{array}{l}3 \text { Total number of participants with a uri- } \\
\text { nary tract infection by } 6 \text { weeks }\end{array}$ & 2 & 228 & $\begin{array}{l}\text { Odds Ratio }(\mathrm{M}-\mathrm{H}, \text { Fixed, } \\
95 \% \mathrm{Cl})\end{array}$ & $3.07[1.05,8.97]$ \\
\hline $\begin{array}{l}4 \text { Total number of participants who had falls } \\
\text { by } 6 \text { weeks }\end{array}$ & 2 & 209 & $\begin{array}{l}\text { Odds Ratio (M-H, Fixed, } \\
95 \% \mathrm{Cl})\end{array}$ & $1.40[0.71,2.79]$ \\
\hline $\begin{array}{l}5 \text { Total number of participants with general } \\
\text { disorders by } 6 \text { weeks }\end{array}$ & 1 & 153 & $\begin{array}{l}\text { Odds Ratio (M-H, Fixed, } \\
95 \% \mathrm{Cl})\end{array}$ & $2.14[1.05,4.36]$ \\
\hline $\begin{array}{l}6 \text { Total number of participants with postural } \\
\text { instability by } 6 \text { weeks }\end{array}$ & 1 & 56 & $\begin{array}{l}\text { Odds Ratio (M-H, Fixed, } \\
95 \% \mathrm{Cl})\end{array}$ & $4.5[0.47,43.09]$ \\
\hline $\begin{array}{l}7 \text { Total number of participants with weak- } \\
\text { ness by } 6 \text { weeks }\end{array}$ & 1 & 56 & $\begin{array}{l}\text { Odds Ratio (M-H, Fixed, } \\
95 \% \mathrm{Cl})\end{array}$ & $\begin{array}{l}10.47[0.54 \\
204.32]\end{array}$ \\
\hline $\begin{array}{l}8 \text { Total number of participants with cardio- } \\
\text { vascular problems by } 6 \text { weeks }\end{array}$ & 1 & 56 & $\begin{array}{l}\text { Odds Ratio (M-H, Fixed, } \\
95 \% \mathrm{Cl})\end{array}$ & $2.08[0.18,24.31]$ \\
\hline $\begin{array}{l}9 \text { Total number of participants with oedema } \\
\text { by } 6 \text { weeks }\end{array}$ & 1 & 56 & $\begin{array}{l}\text { Odds Ratio (M-H, Fixed, } \\
95 \% \mathrm{Cl})\end{array}$ & $\begin{array}{l}7.82[0.39 \\
158.87]\end{array}$ \\
\hline $\begin{array}{l}10 \text { Total number of participants with a fever } \\
\text { by } 6 \text { weeks }\end{array}$ & 1 & 56 & $\begin{array}{l}\text { Odds Ratio (M-H, Fixed, } \\
95 \% \mathrm{Cl})\end{array}$ & $\begin{array}{l}7.82[0.39 \\
158.87]\end{array}$ \\
\hline $\begin{array}{l}11 \text { Total number of participants with a respi- } \\
\text { ratory problem by } 6 \text { weeks }\end{array}$ & 2 & 209 & $\begin{array}{l}\text { Odds Ratio (M-H, Fixed, } \\
95 \% \mathrm{Cl})\end{array}$ & $0.90[0.33,2.46]$ \\
\hline $\begin{array}{l}12 \text { Total number of participants with ataxia } \\
\text { at } 6 \text { weeks }\end{array}$ & 1 & 56 & $\begin{array}{l}\text { Odds Ratio (M-H, Fixed, } \\
95 \% \mathrm{Cl})\end{array}$ & $1.39[0.28,6.87]$ \\
\hline
\end{tabular}




\begin{tabular}{|c|c|c|c|c|}
\hline Outcome or subgroup title & No. of studies & $\begin{array}{l}\text { No. of partici- } \\
\text { pants }\end{array}$ & Statistical method & Effect size \\
\hline $\begin{array}{l}13 \text { Total number of participants with a skin } \\
\text { problem at } 6 \text { weeks }\end{array}$ & 3 & 381 & $\begin{array}{l}\text { Odds Ratio (M-H, Fixed, } \\
95 \% \mathrm{Cl})\end{array}$ & $1.03[0.55,1.91]$ \\
\hline $\begin{array}{l}14 \text { Total number of participants with trauma } \\
\text { (other than falls) by } 6 \text { weeks }\end{array}$ & 1 & 56 & $\begin{array}{l}\text { Odds Ratio (M-H, Fixed, } \\
95 \% \mathrm{Cl})\end{array}$ & $0.64[0.10,4.17]$ \\
\hline $\begin{array}{l}15 \text { Total number of participants with throm- } \\
\text { bocytopenia by } 6 \text { weeks }\end{array}$ & 1 & 172 & $\begin{array}{l}\text { Odds Ratio (M-H, Fixed, } \\
95 \% \mathrm{Cl})\end{array}$ & $\begin{array}{l}13.64[0.76 \\
245.98]\end{array}$ \\
\hline $\begin{array}{l}16 \text { Total number of participants with joint } \\
\text { problems by } 6 \text { weeks }\end{array}$ & 2 & 209 & $\begin{array}{l}\text { Odds Ratio (M-H, Fixed, } \\
95 \% \mathrm{Cl})\end{array}$ & $0.85[0.35,2.05]$ \\
\hline $\begin{array}{l}17 \text { Total number of participants with other } \\
\text { infection by } 6 \text { weeks }\end{array}$ & 3 & 381 & $\begin{array}{l}\text { Odds Ratio (M-H, Fixed, } \\
95 \% \mathrm{Cl})\end{array}$ & $1.31[0.70,2.45]$ \\
\hline $\begin{array}{l}18 \text { Total number of participants with halluci- } \\
\text { nations by } 6 \text { weeks }\end{array}$ & 1 & 56 & $\begin{array}{l}\text { Odds Ratio (M-H, Fixed, } \\
95 \% \mathrm{Cl})\end{array}$ & $3.11[0.12,79.64]$ \\
\hline $\begin{array}{l}19 \text { Total number of participants with acci- } \\
\text { dental injury by } 6 \text { weeks }\end{array}$ & 2 & 325 & $\begin{array}{l}\text { Odds Ratio (M-H, Fixed, } \\
95 \% \mathrm{Cl})\end{array}$ & $1.45[0.84,2.50]$ \\
\hline $\begin{array}{l}20 \text { Total number of participants with } \\
\text { anorexia by } 6 \text { weeks }\end{array}$ & 1 & 172 & $\begin{array}{l}\text { Odds Ratio (M-H, Fixed, } \\
95 \% \mathrm{Cl})\end{array}$ & $2.53[0.92,6.92]$ \\
\hline $\begin{array}{l}21 \text { Total number of participants with weight } \\
\text { loss by } 6 \text { weeks }\end{array}$ & 1 & 172 & $\begin{array}{l}\text { Odds Ratio (M-H, Fixed, } \\
95 \% \mathrm{Cl})\end{array}$ & $2.77[0.71,10.81]$ \\
\hline $\begin{array}{l}22 \text { Total number of participants with dehy- } \\
\text { dration by } 6 \text { weeks }\end{array}$ & 1 & 172 & $\begin{array}{l}\text { Odds Ratio (M-H, Fixed, } \\
95 \% \mathrm{Cl})\end{array}$ & $3.63[0.73,18.01]$ \\
\hline $\begin{array}{l}23 \text { Total number of participants with metab- } \\
\text { olism and nutritional disorders by } 6 \text { weeks }\end{array}$ & 1 & 153 & $\begin{array}{l}\text { Odds Ratio (M-H, Fixed, } \\
95 \% \mathrm{Cl})\end{array}$ & $3.30[0.65,16.92]$ \\
\hline $\begin{array}{l}24 \text { Total number of participants with psychi- } \\
\text { atric disorders by } 6 \text { weeks }\end{array}$ & 1 & 153 & $\begin{array}{l}\text { Odds Ratio (M-H, Fixed, } \\
95 \% \mathrm{Cl})\end{array}$ & $1.61[0.71,3.66]$ \\
\hline $\begin{array}{l}25 \text { Total number of participants with other } \\
\text { gastrointestinal problem by } 6 \text { weeks }\end{array}$ & 2 & 208 & $\begin{array}{l}\text { Odds Ratio (M-H, Fixed, } \\
95 \% \mathrm{Cl})\end{array}$ & $1.44[0.70,2.97]$ \\
\hline $\begin{array}{l}26 \text { Total numbers of participants with ner- } \\
\text { vous system disorders by } 6 \text { weeks }\end{array}$ & 1 & 153 & $\begin{array}{l}\text { Odds Ratio (M-H, Fixed, } \\
95 \% \mathrm{Cl})\end{array}$ & $2.42[1.01,5.80]$ \\
\hline $\begin{array}{l}27 \text { Total number of participants with any ad- } \\
\text { verse event by } 6 \text { weeks }\end{array}$ & 3 & 381 & $\begin{array}{l}\text { Odds Ratio (M-H, Fixed, } \\
95 \% \mathrm{Cl})\end{array}$ & $2.02[1.30,3.14]$ \\
\hline $\begin{array}{l}28 \text { Total number of participants with serious } \\
\text { adverse events by } 6 \text { weeks }\end{array}$ & 2 & 228 & $\begin{array}{l}\text { Odds Ratio (M-H, Fixed, } \\
95 \% \mathrm{Cl})\end{array}$ & $4.77[1.00,22.74]$ \\
\hline
\end{tabular}


Analysis 2.1. Comparison 2 Divalproex versus placebo, Outcome 1 Total number of participants with sedation at 6 weeks.

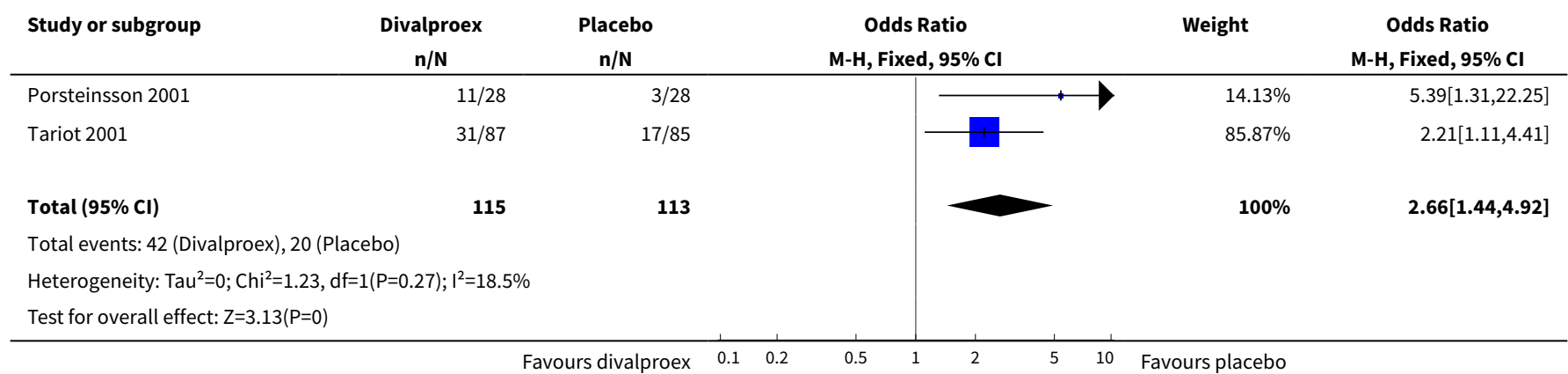

Analysis 2.2. Comparison 2 Divalproex versus placebo, Outcome 2 Total number of participants with nausea, vomiting, or diarrhoea at 6 weeks.

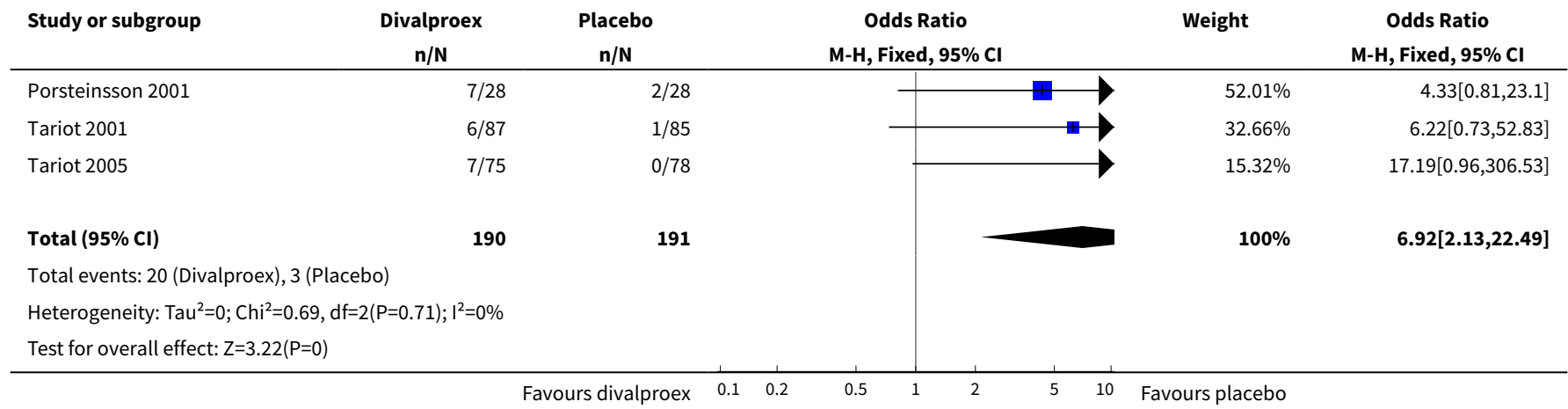

Analysis 2.3. Comparison 2 Divalproex versus placebo, Outcome 3 Total number of participants with a urinary tract infection by 6 weeks.

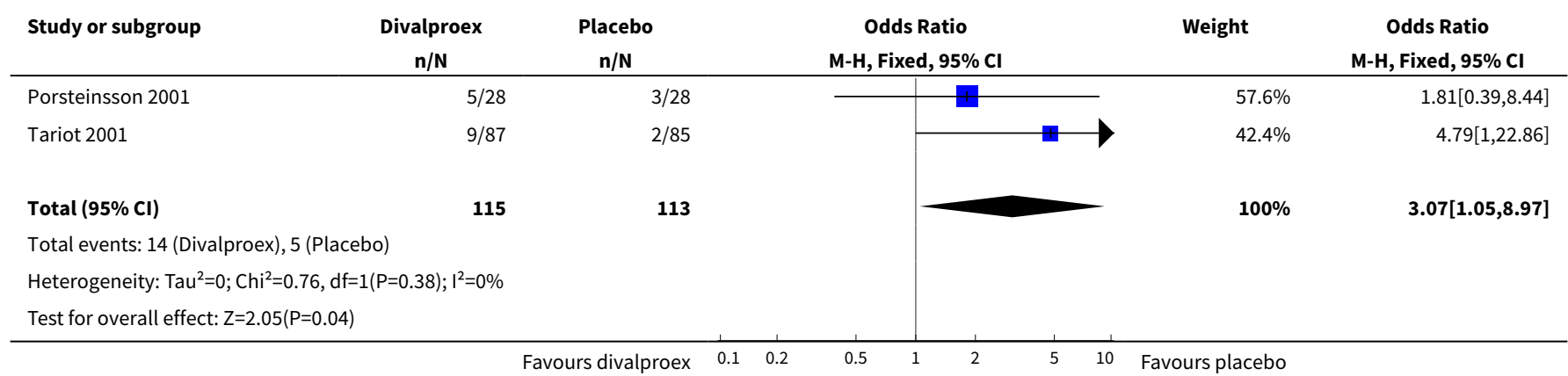


Analysis 2.4. Comparison 2 Divalproex versus placebo, Outcome 4 Total number of participants who had falls by 6 weeks.

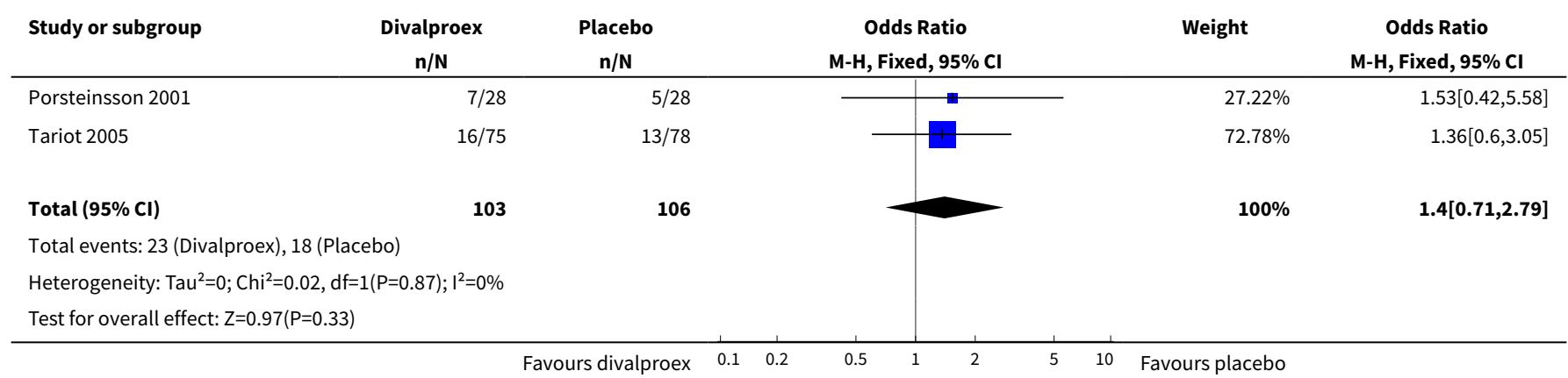

Analysis 2.5. Comparison 2 Divalproex versus placebo, Outcome 5 Total number of participants with general disorders by 6 weeks.

\begin{tabular}{|c|c|c|c|c|c|}
\hline Study or subgroup & $\begin{array}{c}\text { Divalproex } \\
\mathrm{n} / \mathrm{N}\end{array}$ & $\begin{array}{c}\text { Control } \\
n / N\end{array}$ & $\begin{array}{c}\text { Odds Ratio } \\
\text { M-H, Fixed, } 95 \% \mathrm{CI}\end{array}$ & Weight & $\begin{array}{c}\text { Odds Ratio } \\
\text { M-H, Fixed, } 95 \% \mathrm{Cl}\end{array}$ \\
\hline Tariot 2005 & $28 / 75$ & $17 / 78$ & & $100 \%$ & $2.14[1.05,4.36]$ \\
\hline Total $(95 \% \mathrm{Cl})$ & 75 & 78 & & $100 \%$ & $2.14[1.05,4.36]$ \\
\hline \multicolumn{6}{|c|}{ Total events: 28 (Divalproex), 17 (Control) } \\
\hline \multicolumn{6}{|c|}{ Heterogeneity: Not applicable } \\
\hline
\end{tabular}

Analysis 2.6. Comparison 2 Divalproex versus placebo, Outcome 6 Total number of participants with postural instability by 6 weeks.

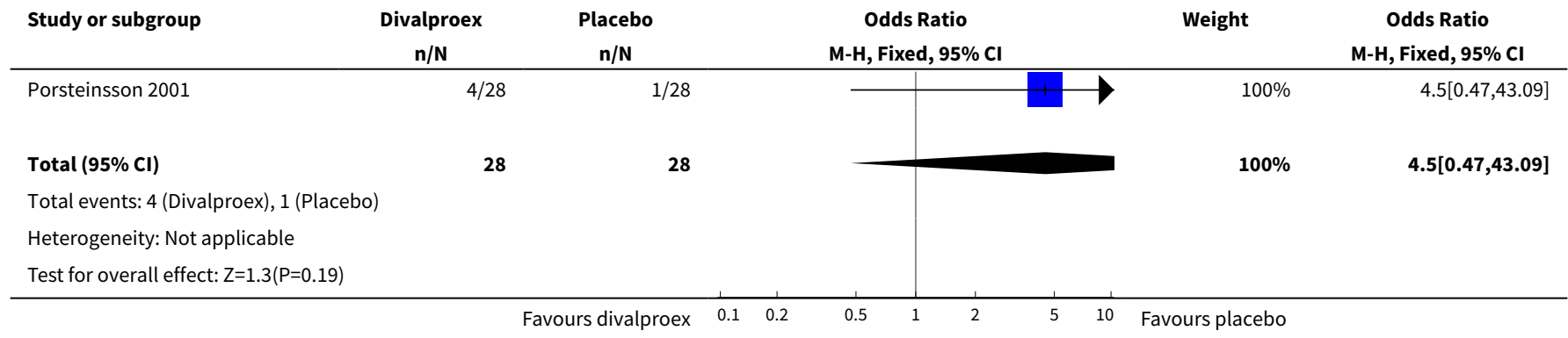

Analysis 2.7. Comparison 2 Divalproex versus placebo, Outcome 7 Total number of participants with weakness by 6 weeks.

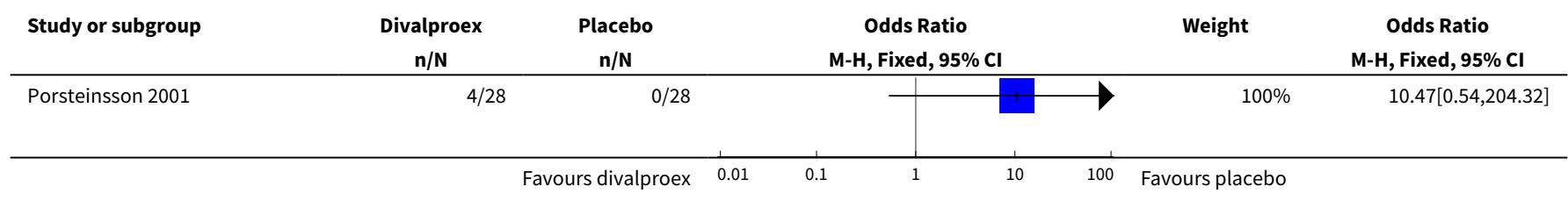




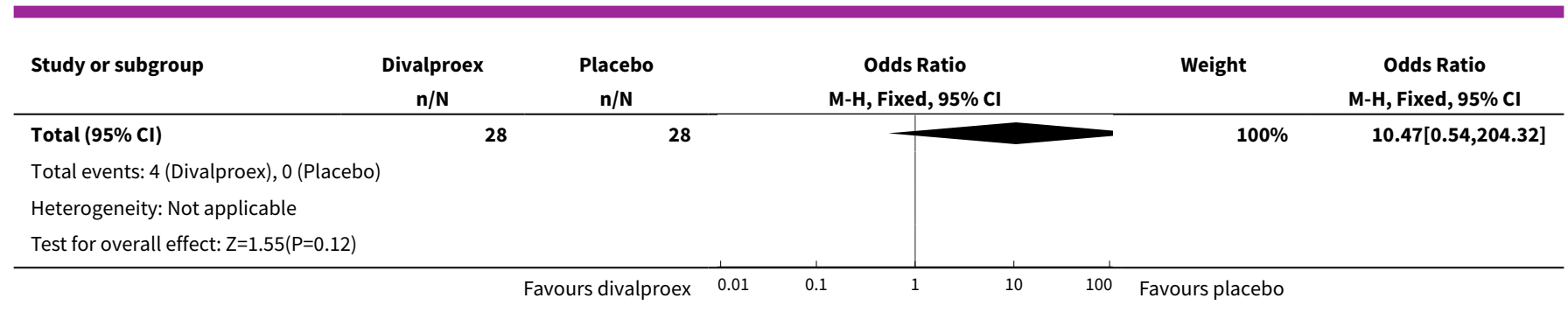

Analysis 2.8. Comparison 2 Divalproex versus placebo, Outcome 8 Total number of participants with cardiovascular problems by 6 weeks.

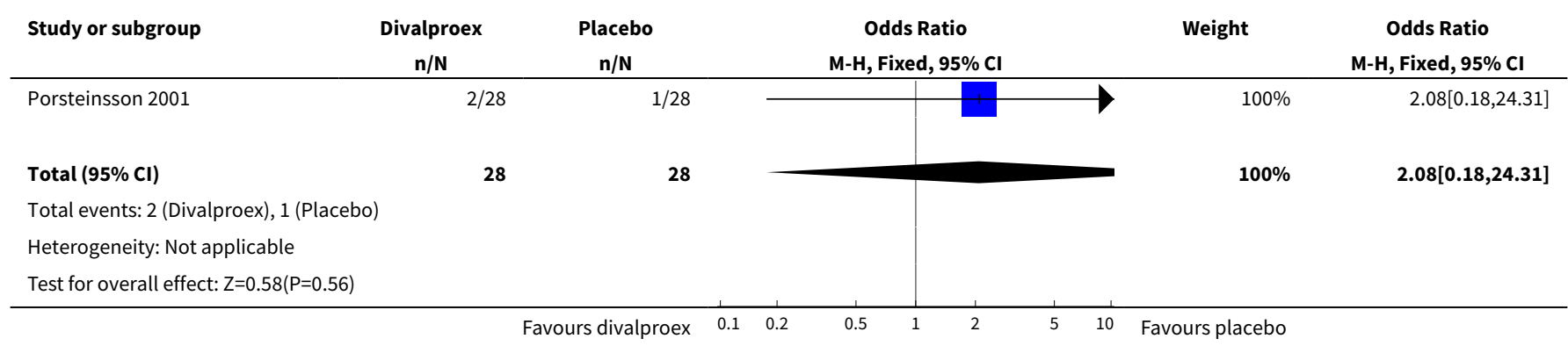

Analysis 2.9. Comparison 2 Divalproex versus placebo, Outcome 9 Total number of participants with oedema by 6 weeks.

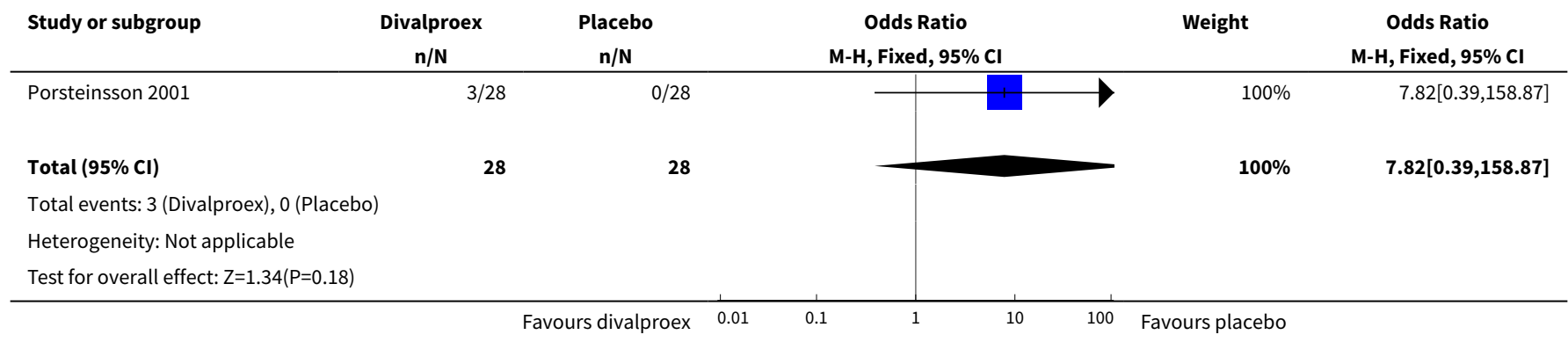

Analysis 2.10. Comparison 2 Divalproex versus placebo, Outcome 10 Total number of participants with a fever by 6 weeks.

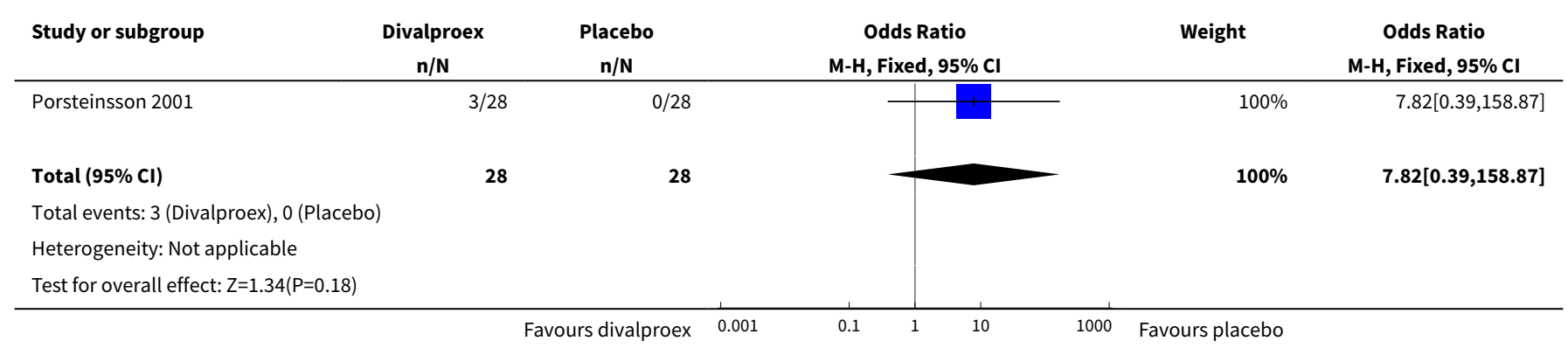


Analysis 2.11. Comparison 2 Divalproex versus placebo, Outcome 11

Total number of participants with a respiratory problem by 6 weeks.

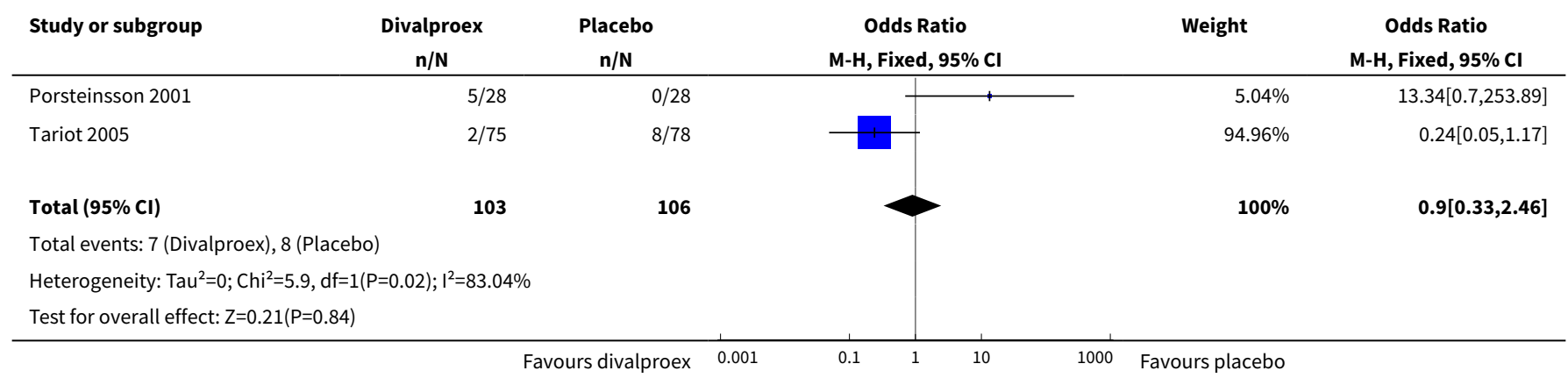

Analysis 2.12. Comparison 2 Divalproex versus placebo, Outcome 12 Total number of participants with ataxia at 6 weeks.

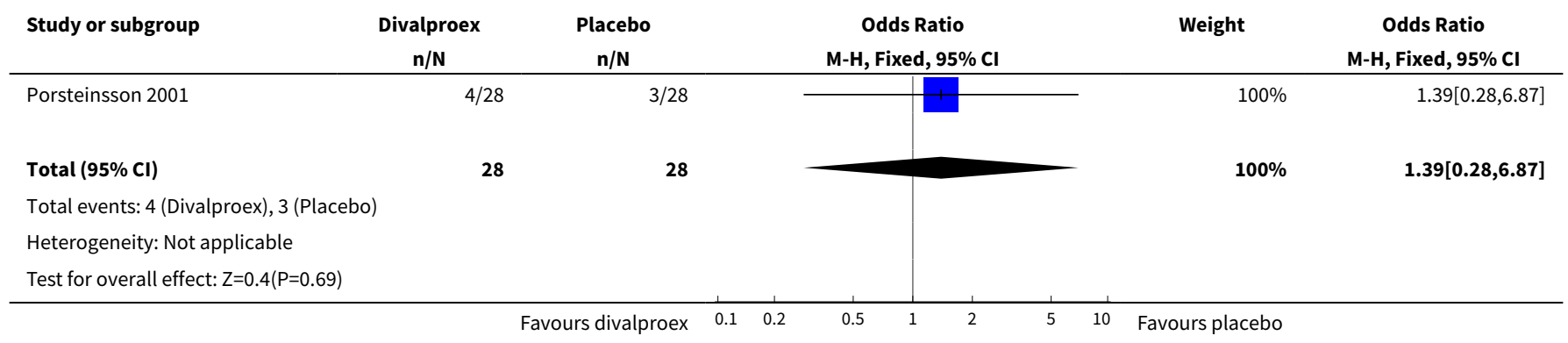

\section{Analysis 2.13. Comparison 2 Divalproex versus placebo, Outcome} 13 Total number of participants with a skin problem at 6 weeks.

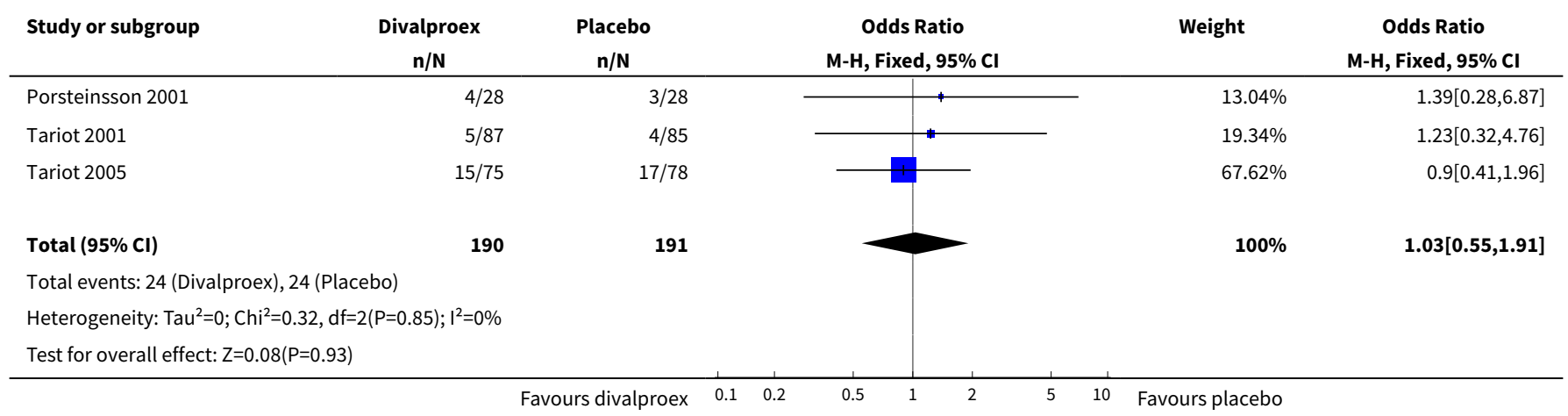


Analysis 2.14. Comparison 2 Divalproex versus placebo, Outcome 14

Total number of participants with trauma (other than falls) by 6 weeks.

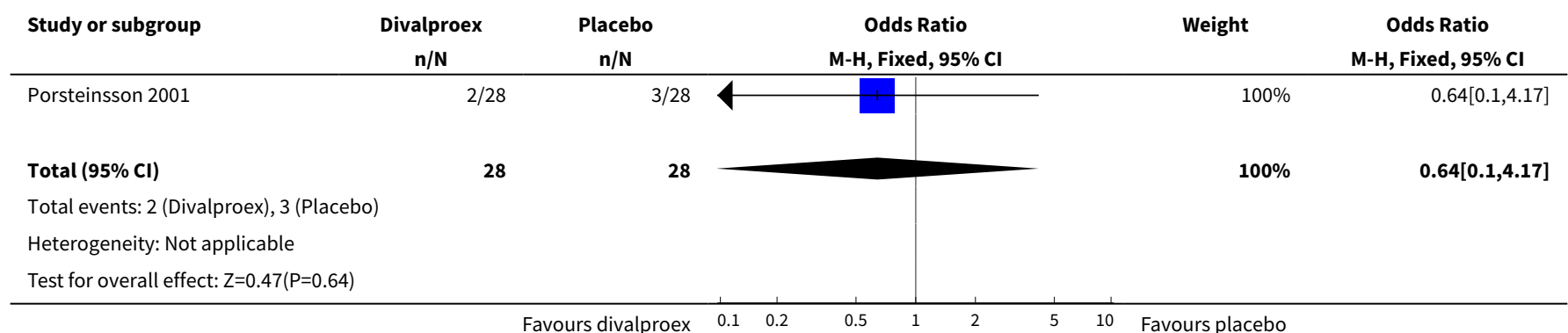

Analysis 2.15. Comparison 2 Divalproex versus placebo, Outcome 15 Total number of participants with thrombocytopenia by 6 weeks.

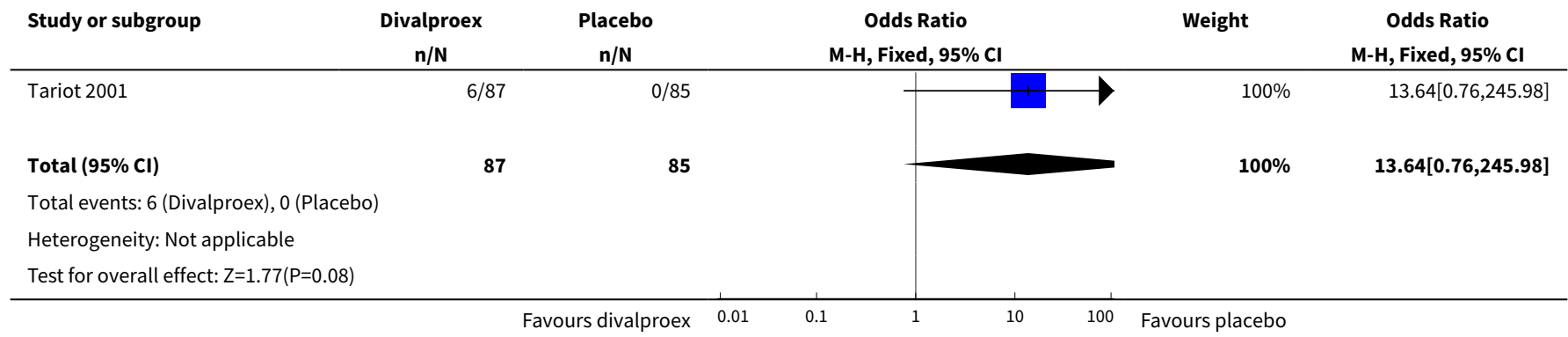

Analysis 2.16. Comparison 2 Divalproex versus placebo, Outcome 16 Total number of participants with joint problems by 6 weeks.

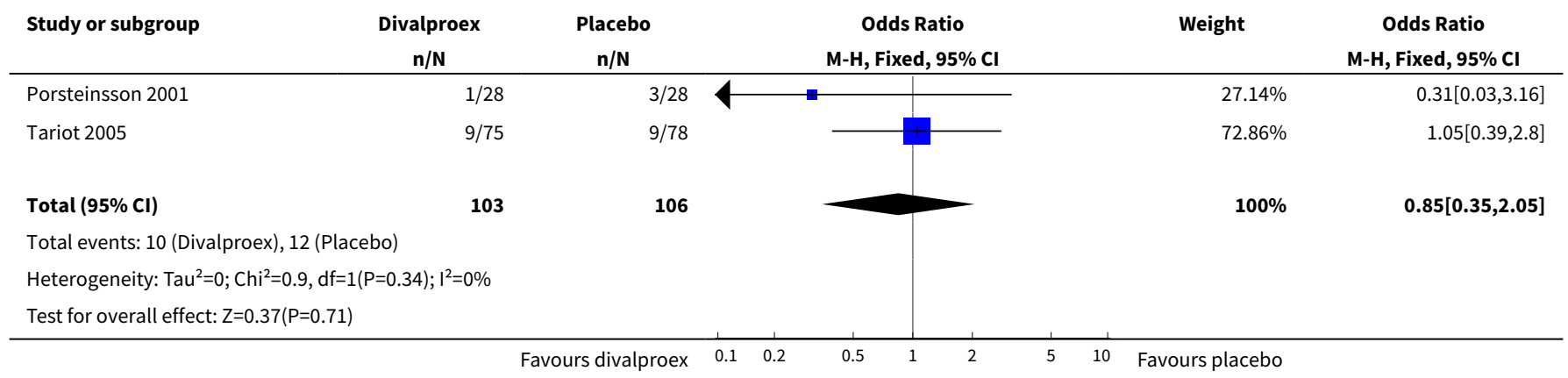

Analysis 2.17. Comparison 2 Divalproex versus placebo, Outcome 17 Total number of participants with other infection by 6 weeks.

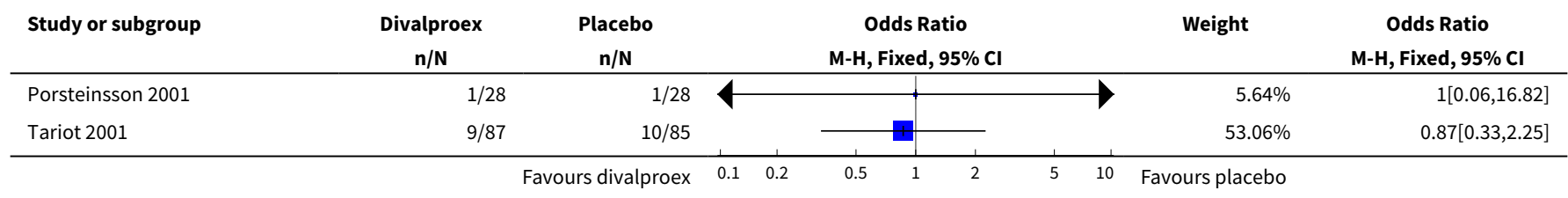




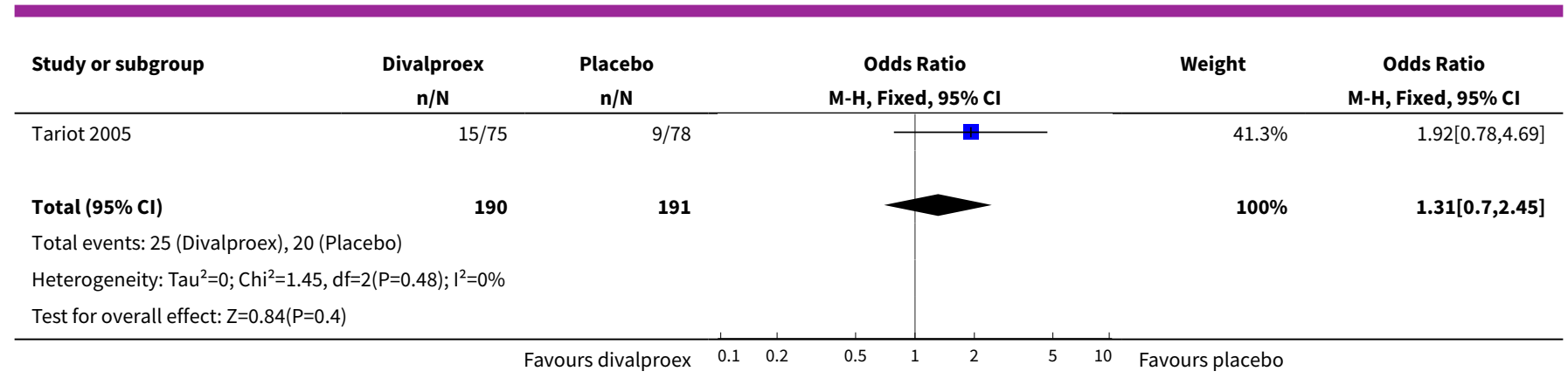

Analysis 2.18. Comparison 2 Divalproex versus placebo, Outcome

18 Total number of participants with hallucinations by 6 weeks.

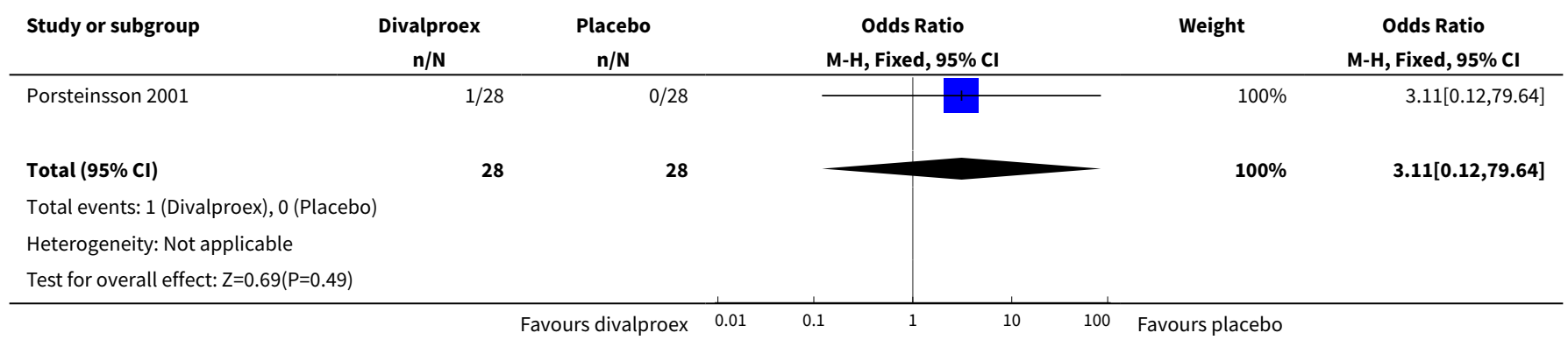

Analysis 2.19. Comparison 2 Divalproex versus placebo, Outcome

19 Total number of participants with accidental injury by 6 weeks.

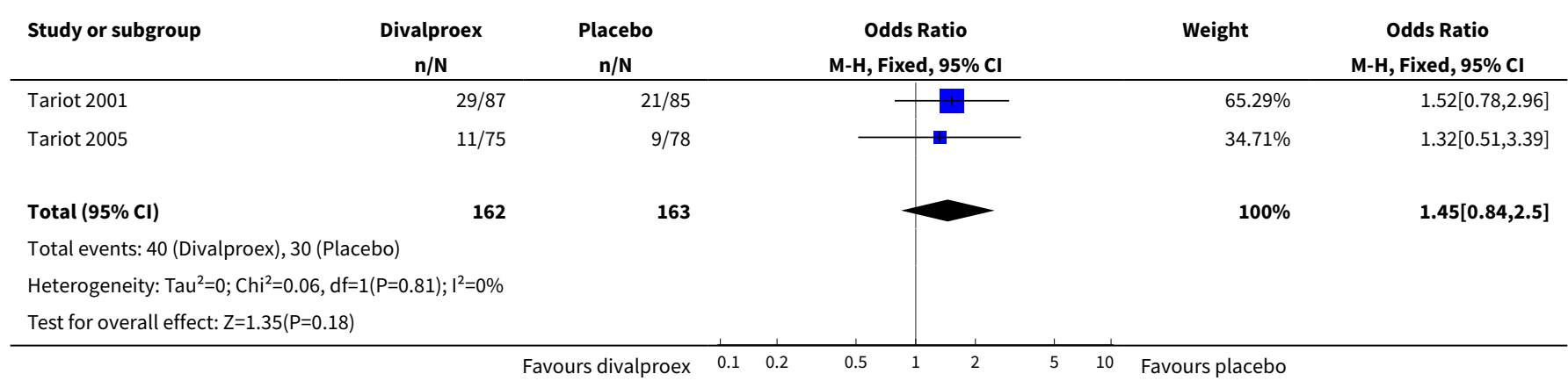

Analysis 2.20. Comparison 2 Divalproex versus placebo, Outcome 20 Total number of participants with anorexia by 6 weeks.

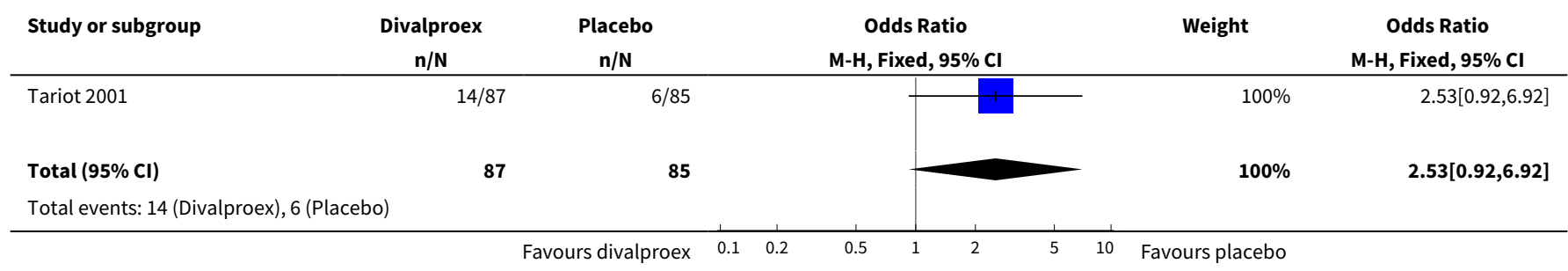




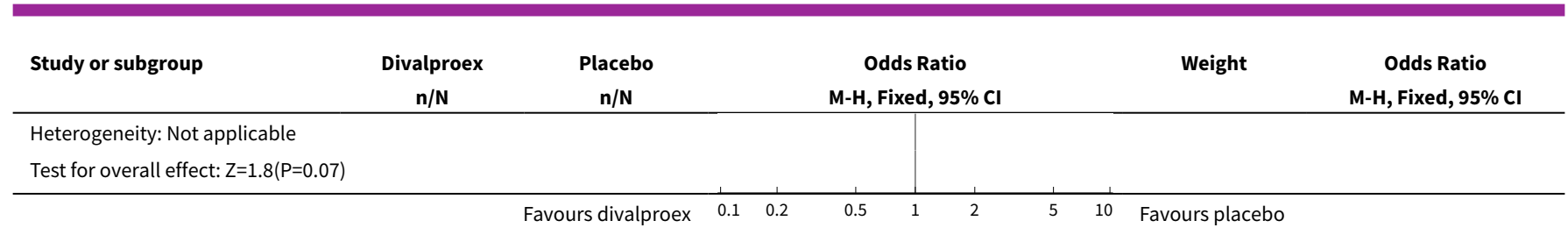

Analysis 2.21. Comparison 2 Divalproex versus placebo, Outcome 21 Total number of participants with weight loss by 6 weeks.

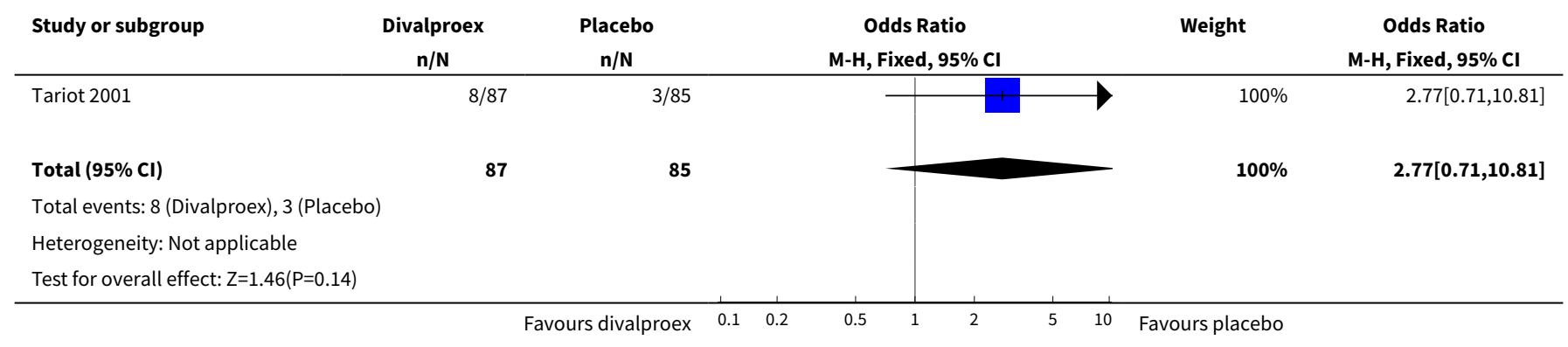

\section{Analysis 2.22. Comparison 2 Divalproex versus placebo, Outcome} 22 Total number of participants with dehydration by 6 weeks.

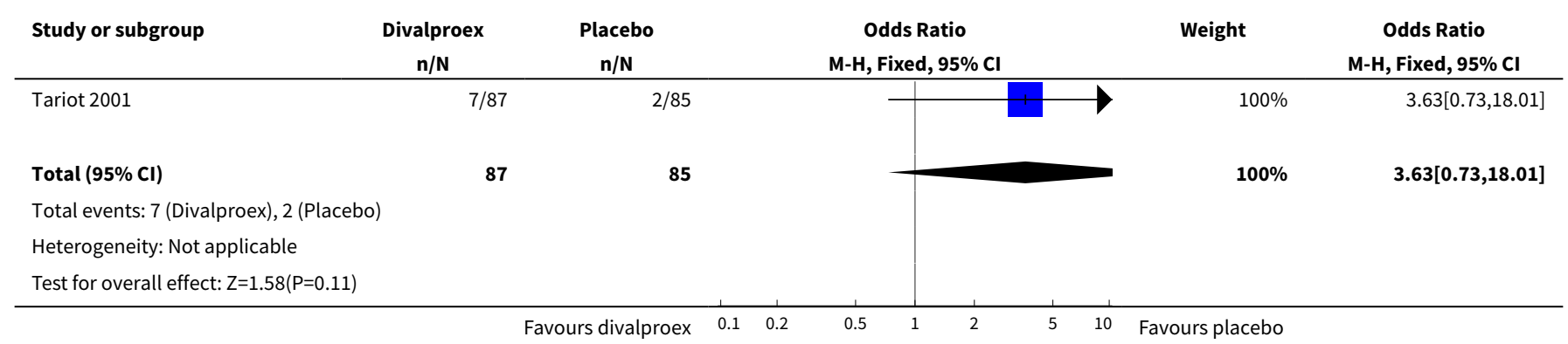

Analysis 2.23. Comparison 2 Divalproex versus placebo, Outcome 23 Total number of participants with metabolism and nutritional disorders by 6 weeks.

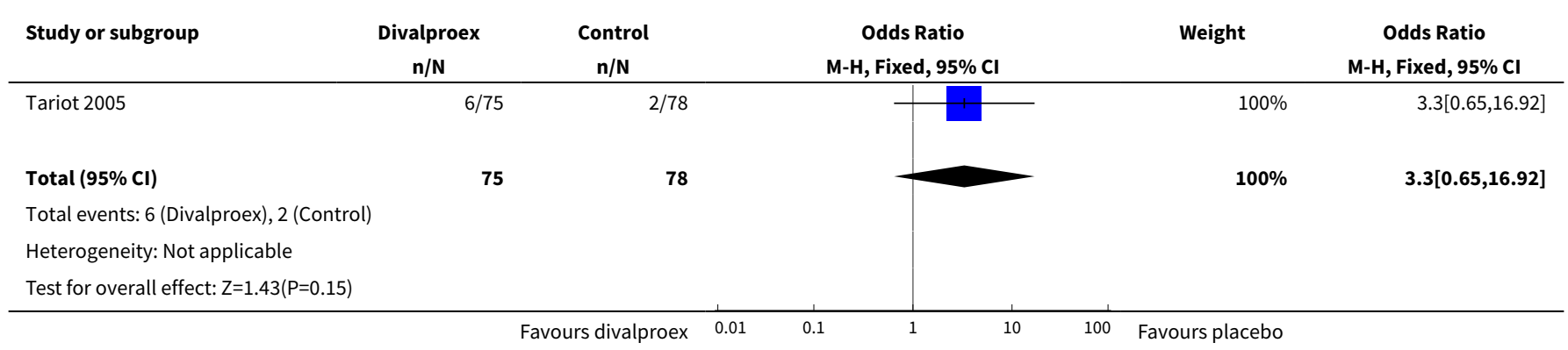


Analysis 2.24. Comparison 2 Divalproex versus placebo, Outcome 24

Total number of participants with psychiatric disorders by 6 weeks.

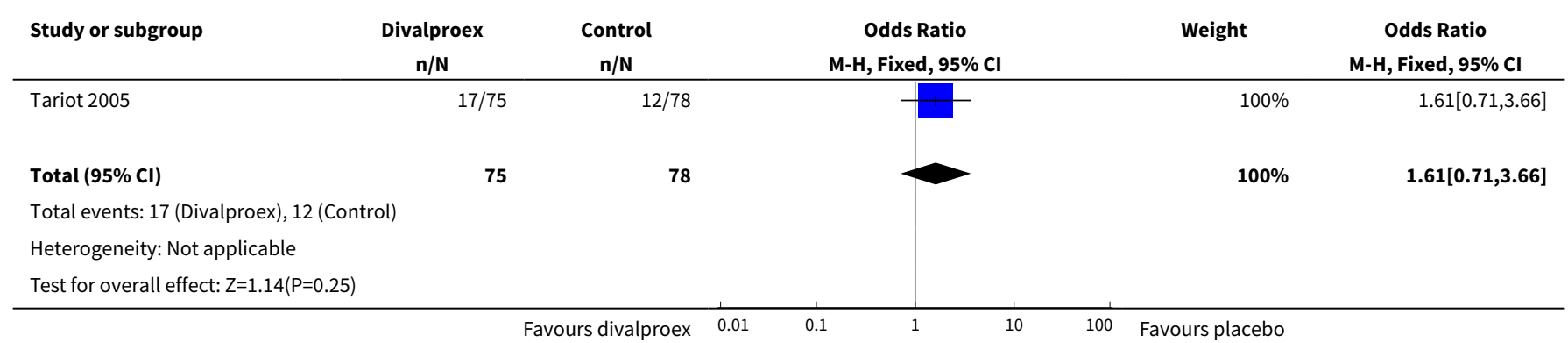

Analysis 2.25. Comparison 2 Divalproex versus placebo, Outcome 25 Total number of participants with other gastrointestinal problem by 6 weeks.

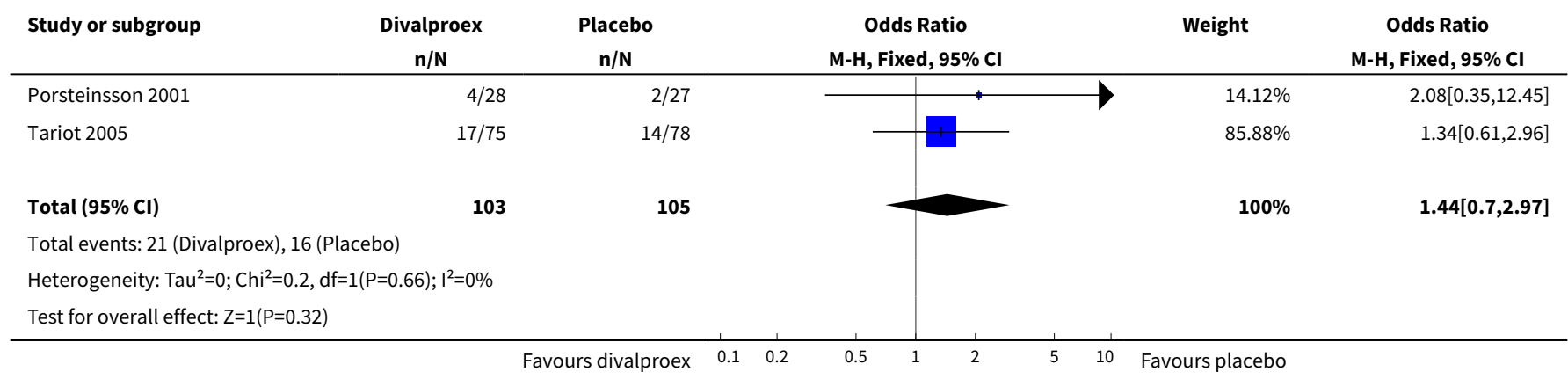

Analysis 2.26. Comparison 2 Divalproex versus placebo, Outcome 26 Total numbers of participants with nervous system disorders by 6 weeks.

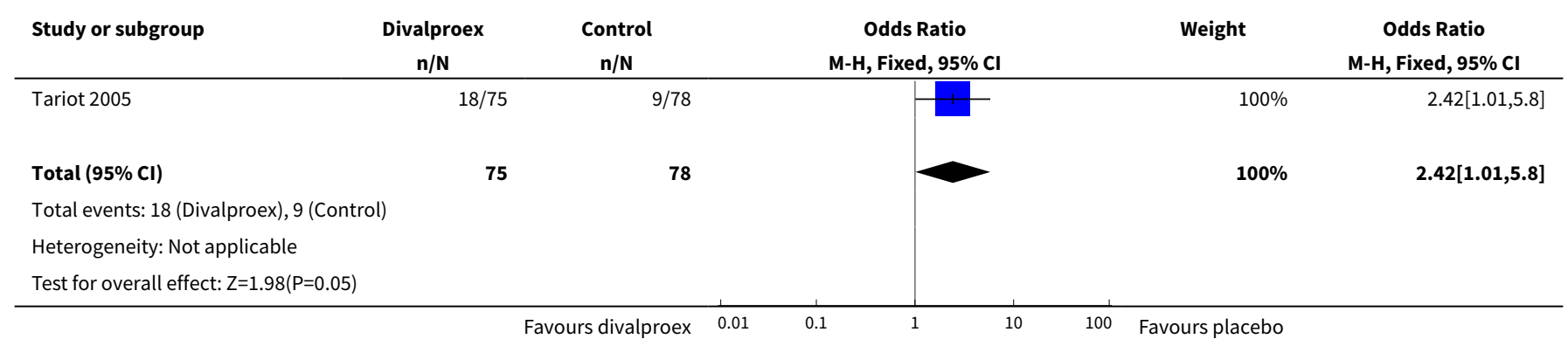

Analysis 2.27. Comparison 2 Divalproex versus placebo, Outcome 27 Total number of participants with any adverse event by 6 weeks.

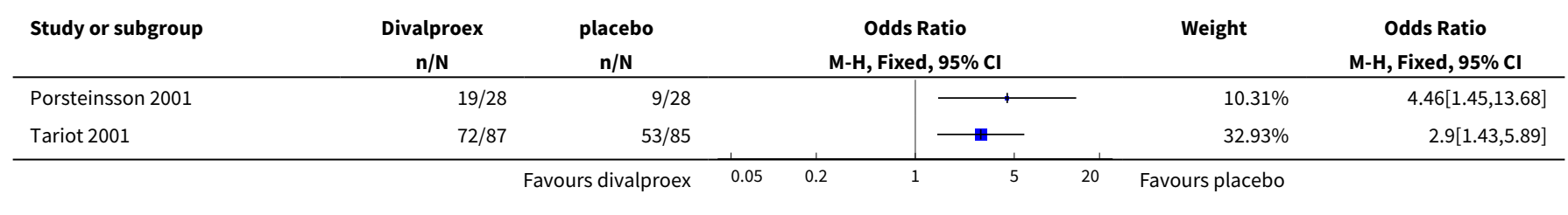




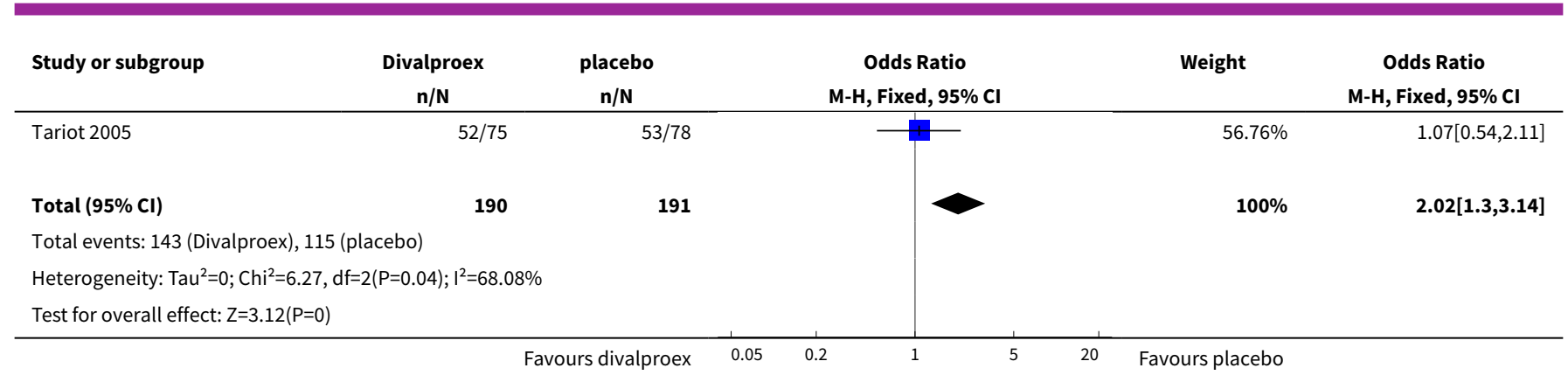

Analysis 2.28. Comparison 2 Divalproex versus placebo, Outcome 28

Total number of participants with serious adverse events by 6 weeks.

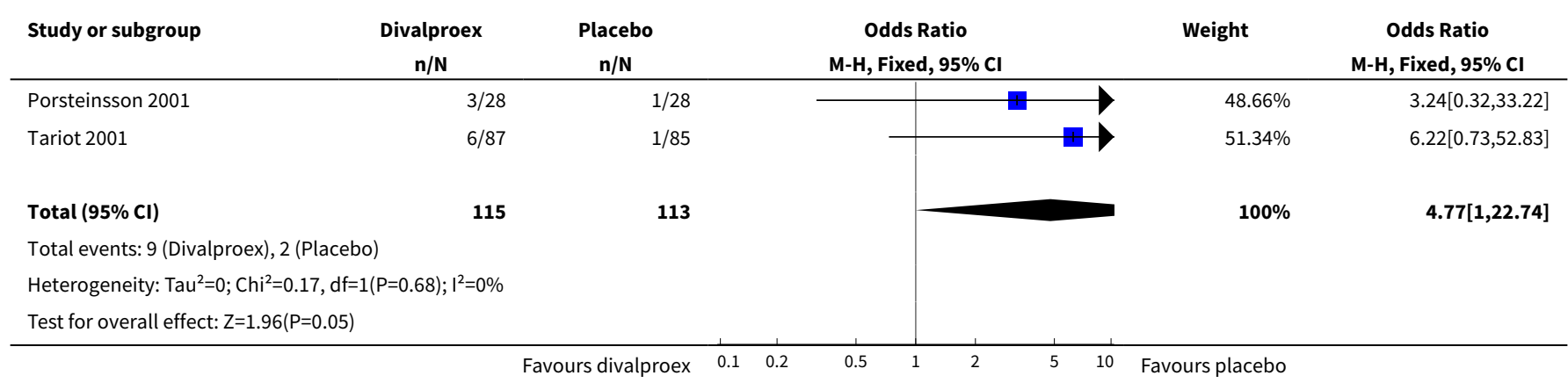




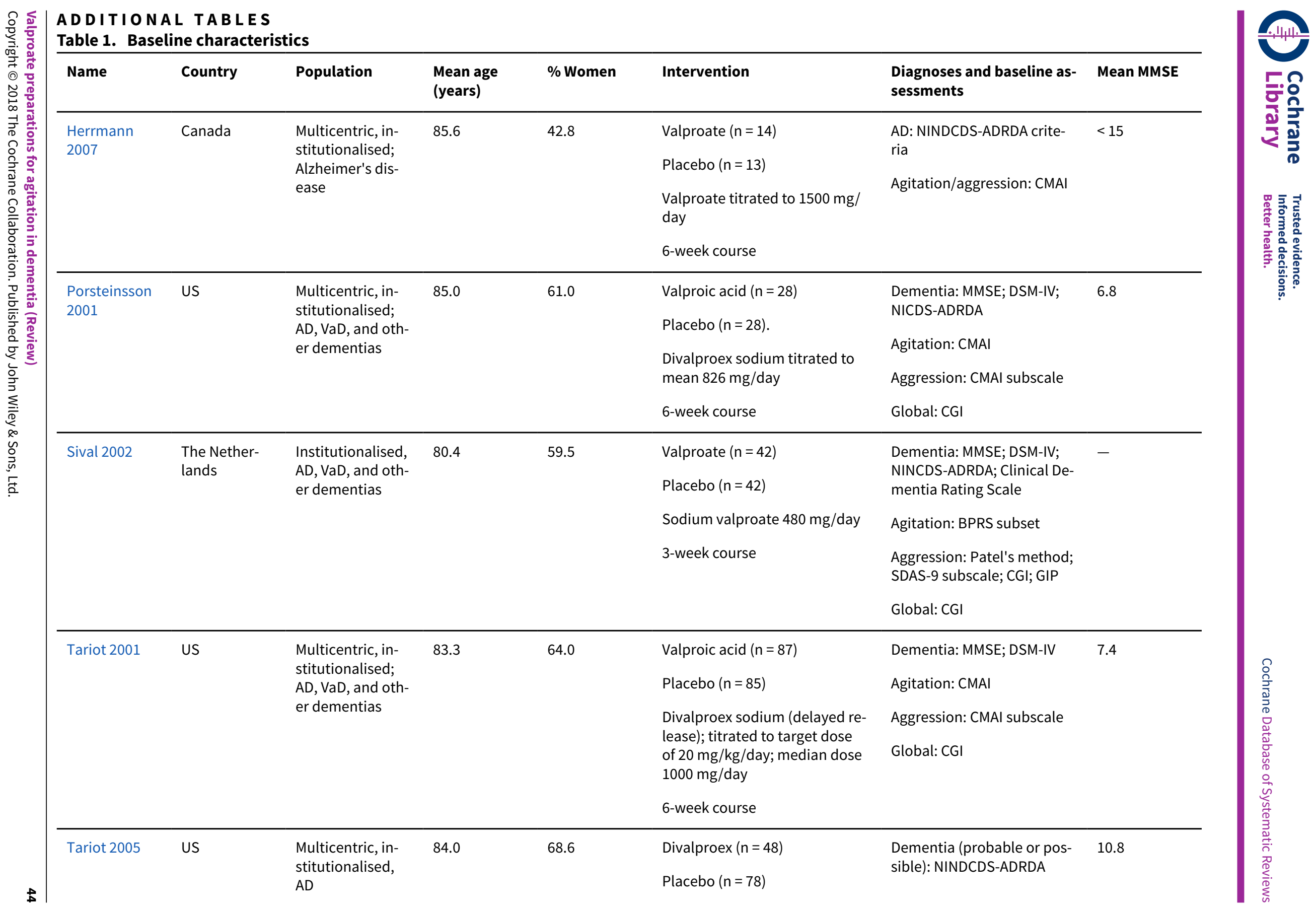




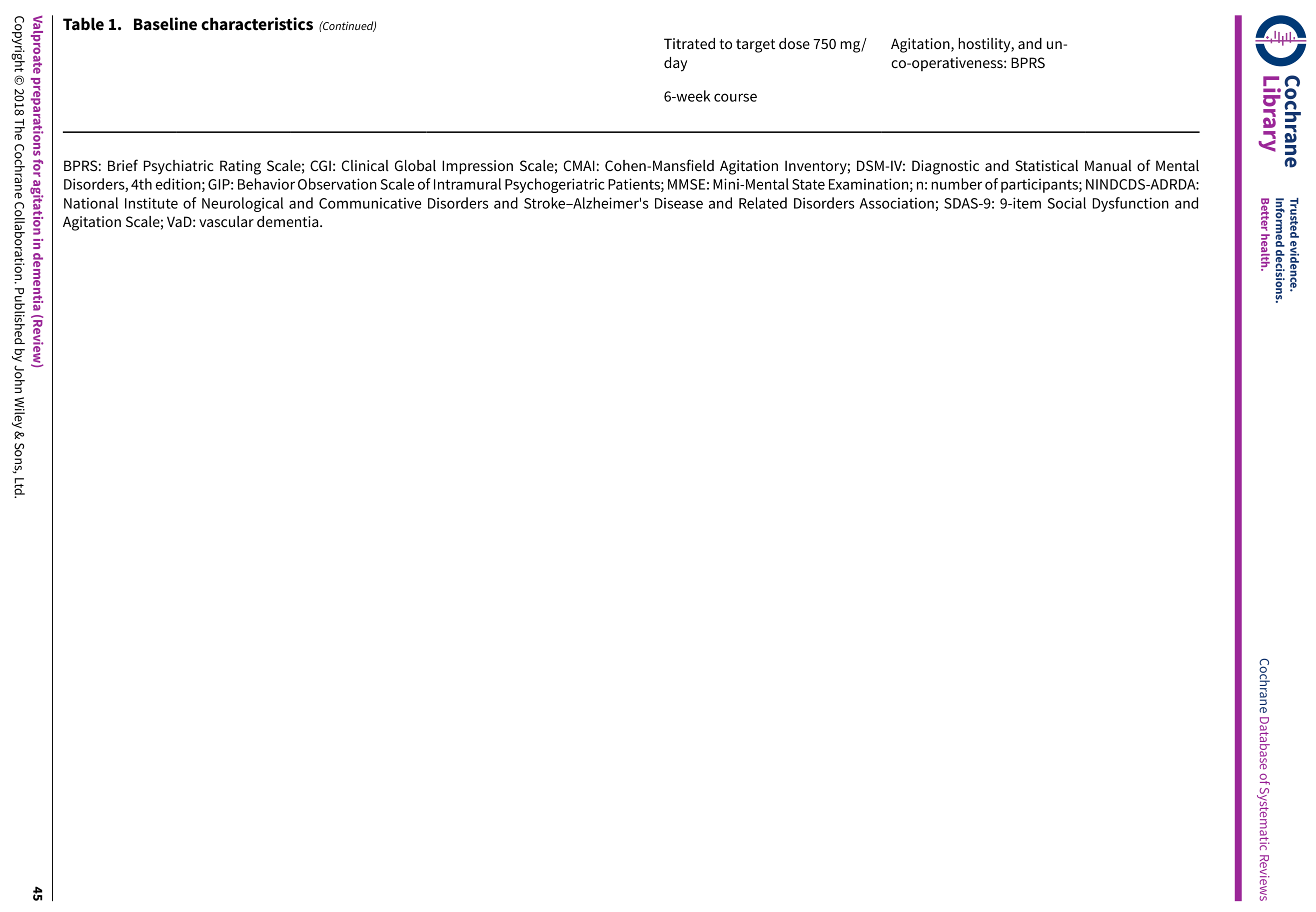


Table 2. Outcomes, instruments, and studies

\begin{tabular}{|c|c|c|}
\hline Outcomes & Instruments & Studies \\
\hline \multirow[t]{9}{*}{$\begin{array}{l}\text { Agitation and aggres- } \\
\text { sion }\end{array}$} & CMAI & $\begin{array}{l}\text { Herrmann 2007; Porsteinsson 2001; Tariot } \\
\text { 2001; Tariot } 2005\end{array}$ \\
\hline & BPRS or agitation and hostility subscale, or both & Porsteinsson 2001 \\
\hline & BPRS & Tariot 2001; Tariot 2005 \\
\hline & Neuropsychiatric Inventory (NPI) & Herrmann 2007 \\
\hline & Social Dysfunction and Aggression-9 Scale (SDAS-9) & Sival 2002 \\
\hline & Clinical Global Impression Scale (CGI) & Sival 2002 \\
\hline & Nurse Observation Scale & Sival 2002 \\
\hline & Patel's Method & Sival 2002 \\
\hline & Overt Aggression Scale & Porsteinsson 2001 \\
\hline $\begin{array}{l}\text { Other types of dis- } \\
\text { turbed behaviour }\end{array}$ & $\begin{array}{l}\text { Behavior Scale for Intramural Psychogeriatric Patients } \\
\text { (GIP) }\end{array}$ & Sival 2002 \\
\hline Cognition & MMSE & Herrmann 2007; Porsteinsson 2001; Tariot 2005 \\
\hline \multirow{2}{*}{$\begin{array}{l}\text { Functional perfor- } \\
\text { mance }\end{array}$} & PSMS & Porsteinsson 2001 \\
\hline & & Tariot 2005 \\
\hline $\begin{array}{l}\text { Overall clinical impres- } \\
\text { sion }\end{array}$ & CGI & Porsteinsson 2001; Tariot 2001; Tariot 2005 \\
\hline \multirow[t]{2}{*}{ Adverse effects } & Number of Adverse Reactions (checklist) & $\begin{array}{l}\text { Herrmann 2007; Porsteinsson 2001; Sival 2002; } \\
\text { Tariot } 2005\end{array}$ \\
\hline & $\begin{array}{l}\text { Coding Symbols for Thesaurus of Adverse Reaction } \\
\text { Terms (COSTART 1989) }\end{array}$ & Tariot 2001 \\
\hline
\end{tabular}

BPRS: Brief Psychiatric Rating Scale; CMAI: Cohen-Mansfield Agitation Inventory; MMSE: Mini-Mental State Examination; PSMS: Physical Self-Maintenance Scale.

\section{APPENDICES}

\section{Appendix 1. Sources searched and search strategies}

\begin{tabular}{lll}
\hline Source & Search strategy & Hits \\
\hline MEDLINE (OvidSP) & 1. exp Dementia/ & July 2010: 44 \\
$\begin{array}{l}\text { [Most recent search: } 7 \\
\text { December 2017] }\end{array}$ & 2. Delirium/ & October 2016: 14 \\
\hline
\end{tabular}


4. Delirium, Dementia, Amnestic, Cognitive Disorders/

5. dement ${ }^{\star} \cdot \mathrm{mp}$.

6. alzheimer*.mp.

7. (lewy ${ }^{\star}$ adj2 bod*).mp.

8. deliri`.mp.

9. (chronic adj2 cerebrovascular).mp.

10. ("organic brain disease" or "organic brain syndrome").mp.

11. ("normal pressure hydrocephalus" and "shunt*").mp.

12. "benign senescent forgetfulness".mp.

13. (cerebr ${ }^{\star}$ adj2 deteriorat $\left.{ }^{\star}\right) \cdot \mathrm{mp}$.

14. (cerebral ${ }^{\star}$ adj2 insufficient $\left.{ }^{\star}\right) \cdot m p$.

15. (pick ${ }^{\star}$ adj2 disease).mp.

16. (creutzfeldt or jcd or cjd).mp.

17. huntington ${ }^{\star} . \mathrm{mp}$.

18. binswanger ${ }^{\star} \cdot \mathrm{mp}$.

19. korsako*.mp.

20. or/1-19

21. Valproic Acid/

22. valproic ${ }^{\star}$.ti,ab.

23. valproate.ti,ab.

24. divalproex*.ti,ab.

25. or/21-24

26. 20 and 25

27. randomised controlled trial.pt.

28. controlled clinical trial.pt.

29. randomized.ab.

30. placebo.ab.

31. drug therapy.fs.

32. randomly.ab.

33. trial.ab.

34. groups.ab

35. or/27-34

36. (animals not (humans and animals)).sh . 
(Continued)
37.35 not 36
38.26 and 37
39. $\left(2008^{\star}\right.$ or $2009^{\star}$ or $\left.2010^{\star}\right)$.ed.
40.38 and 39

\section{Embase (OvidSP)}

[Most recent search: 7 December 2017]

\section{1. exp dementia/}

2. Lewy body/

3. delirium/

4. Wernicke encephalopathy/

5. cognitive defect/

6. dement*.mp.

7. alzheimer ${ }^{\star} . \mathrm{mp}$.

8. (lewy ${ }^{\star}$ adj2 bod*).mp.

9. deliri*.mp.

10. (chronic adj2 cerebrovascular).mp.

11. ("organic brain disease" or "organic brain syndrome").mp.

12. "supranuclear palsy".mp.

13. ("normal pressure hydrocephalus" and "shunt*").mp.

14. "benign senescent forgetfulness".mp.

15. $\left(\right.$ cerebr $^{\star}$ adj2 deteriorat $\left.{ }^{\star}\right) \cdot \mathrm{mp}$.

16. (cerebral $^{\star}$ adj2 insufficient $\left.{ }^{\star}\right) \cdot \mathrm{mp}$.

17. (pick* adj2 disease).mp.

18. (creutzfeldt or jcd or cjd).mp.

19. huntington ${ }^{\star} \cdot \mathrm{mp}$.

20. binswanger ${ }^{\star} \cdot \mathrm{mp}$.

21. korsako*.mp.

22. CADASIL.mp.

23. or/1-22

24. valproic acid/

25. valproic*.ti,ab.

26. valproate.ti,ab.

27. divalproex ${ }^{\star} \cdot \mathrm{ti}, \mathrm{ab}$.

28. or/24-27

29. 23 and 28

30. randomised controlled trial/
July 2010: 128

October 2016: 32

December 2017: 76 
(Continued)
31. controlled clinical trial/
32. randomi?ed.ab.
33. placebo.ab.
34. randomly.ab.
35. trial.ab.
36. groups.ab.
37. or/30-36
38. 29 and 37
39. $\left(2008^{\star}\right.$ or $2009^{\star}$ or $\left.2010^{\star}\right)$.em.
40. 38 and 39

\begin{tabular}{|c|c|c|}
\hline \multirow{24}{*}{$\begin{array}{l}\text { PsycINFO (OvidSP) } \\
\text { [Most recent search: } 7 \\
\text { December 2017] }\end{array}$} & 1. exp Dementia/ & July 2010: 37 \\
\hline & 2. exp Delirium/ & October 2016: 11 \\
\hline & 3. exp Huntingtons Disease/ & December 2017: 21 \\
\hline & 4. exp Kluver Bucy Syndrome/ & \\
\hline & 5. exp Wernickes Syndrome/ & \\
\hline & 6. exp Cognitive Impairment/ & \\
\hline & 7. dement ${ }^{\star} . m p$. & \\
\hline & 8. alzheimer ${ }^{\star} \cdot \mathrm{mp}$. & \\
\hline & 9. (lewy* adj2 bod*).mp. & \\
\hline & 10. deliri ${ }^{\star} . \mathrm{mp}$. & \\
\hline & 11. (chronic adj2 cerebrovascular).mp. & \\
\hline & 12. ("organic brain disease" or "organic brain syndrome").mp. & \\
\hline & 13. "supranuclear palsy".mp. & \\
\hline & 14. ("normal pressure hydrocephalus" and "shunt" ).mp. & \\
\hline & 15. "benign senescent forgetfulness".mp. & \\
\hline & 16. (cerebr ${ }^{\star}$ adj2 deteriorat $\left.{ }^{\star}\right) \cdot m p$. & \\
\hline & 17. (cerebral $^{*}$ adj2 insufficient $\left.{ }^{\star}\right) \cdot m p$. & \\
\hline & 18. (pick* adj2 disease).mp. & \\
\hline & 19. (creutzfeldt or jcd or cjd).mp. & \\
\hline & 20. huntington ${ }^{\star} . \mathrm{mp}$. & \\
\hline & 21. binswanger ${ }^{\star} . \mathrm{mp}$. & \\
\hline & 22. korsako*.mp. & \\
\hline & 23. ("parkinson* disease dementia" or PDD or "parkinson* dementia").mp. & \\
\hline & 24. or/1-23 & \\
\hline
\end{tabular}


(Continued)
25. Valproic Acid/
26. valproic*.ti,ab.
27. valproate.ti,ab.
28. divalproex ${ }^{\star} . t i, a b$.
29. or $/ 25-28$
30.24 and 29
31. $\left(2008^{\star}\right.$ or $2009^{\star}$ or $\left.2010^{\star}\right)$.up.
32.30 and 31

\section{CINAHL (EBSCOhost)}

[Most recent search: 7 December 2017]

\section{S1 (MH "Dementia+")}

S2 (MH "Delirium") or (MH "Delirium, Dementia, Amnestic, Cognitive Disorders")

S3 (MH "Wernicke's Encephalopathy")

S4 TX dement*

S5 TX alzheimer*

S6 TX lewy* N2 bod*

S7 TX deliri ${ }^{\star}$

S8 TX chronic N2 cerebrovascular

S9 TX "organic brain disease" or "organic brain syndrome"

S10 TX "normal pressure hydrocephalus" and "shunt ${ }^{\star}$

S11 TX "benign senescent forgetfulness"

S12 TX cerebr ${ }^{*}$ N2 deteriorat*

S13 TX cerebral ${ }^{\star}$ N2 insufficient ${ }^{\star}$

S14 TX pick* N2 disease

S15 TX creutzfeldt or jcd or cjd

S16 TX huntington*

S17 TX binswanger*

S18 TX korsako*

$\mathrm{S} 19 \mathrm{~S} 1$ or $\mathrm{S} 2$ or $\mathrm{S} 3$ or $\mathrm{S} 4$ or $\mathrm{S} 5$ or $\mathrm{S} 6$ or $\mathrm{S} 7$ or $\mathrm{S} 8$ or $\mathrm{S} 9$ or $\mathrm{S} 10$ or $\mathrm{S} 11$ or $\mathrm{S} 12$ or $\mathrm{S} 13$ or $\mathrm{S} 14$ or $\mathrm{S} 15$ or $\mathrm{S} 16$ or $\mathrm{S} 17$ or $\mathrm{S} 18$

S20 (MH "Valproic Acid")

S21 TX valproic*

S22 TX valproate

S23 TX divalproex*

S24 S20 or S21 or S22 or S23

S25 S19 and S24

\section{July 2010: 15}

October 2016: 2

December 2017: 8 
(Continued)

\section{S26 EM 2008}

S27 EM 2009

S28 EM 2010

S29 S26 or S27 or S28

S30 S25 and S29

\begin{tabular}{|c|c|c|}
\hline $\begin{array}{l}\text { Web of Knowledge (all } \\
\text { databases) } \\
\text { [Most recent search: } 7 \\
\text { December 2017] }\end{array}$ & $\begin{array}{l}\text { Topic=(dement* OR alzheimer* OR AD OR lewy) AND Topic=(valproic* OR val- } \\
\text { proate OR divalproex*) AND Topic=(random* OR trial OR placebo OR "double } \\
\left.\text { blind }{ }^{\star} " \text { OR "blinded" OR "single blind*" OR "control group }{ }^{\star "}\right) \\
\text { Timespan=Latest } 5 \text { years. }\end{array}$ & $\begin{array}{l}\text { July 2010: } 51 \\
\text { October 2016: } 19 \\
\text { December 2017: } 21\end{array}$ \\
\hline $\begin{array}{l}\text { LILACS (BIREME) } \\
\text { [Most recent search: } 7 \\
\text { December 2017] }\end{array}$ & $\begin{array}{l}\text { vaproate OR valpric\$ OR divalproex\$ [Words] and demenc\$ OR dement\$ OR } \\
\text { alzheimer\$ OR lewy [Words] }\end{array}$ & $\begin{array}{l}\text { July 2010: } 3 \\
\text { October 2016: } 0 \\
\text { December 2017: } 0\end{array}$ \\
\hline $\begin{array}{l}\text { ALOIS (www.medi- } \\
\text { cine.ox.ac.uk/alois) } \\
\text { [Most recent search: } 7 \\
\text { December 2017] }\end{array}$ & Keyword search: Valproate OR valproic OR divalproex & $\begin{array}{l}\text { July 2010: } 13 \\
\text { October 2016: } 0 \\
\text { December 2017: } 0\end{array}$ \\
\hline
\end{tabular}

CENTRAL (the Cochrane Library)

[Most recent search: 7 December 2017]
\#1 MeSH descriptor Dementia explode all trees

\#2 MeSH descriptor Delirium, this term only

\#3 MeSH descriptor Wernicke Encephalopathy, this term only

\#4 MeSH descriptor Delirium, Dementia, Amnestic, Cognitive Disorders, this term only

\#5 dement ${ }^{\star}$

\#6 alzheimer*

\#7 "lewy* bod*"

\#8 deliri*

\#9 "chronic cerebrovascular"

\#10 "organic brain disease" or "organic brain syndrome"

\#11 "normal pressure hydrocephalus" and "shunt*"

\#12 "benign senescent forgetfulness"

\#13 "cerebr ${ }^{\star}$ deteriorat ${ }^{\star} "$

\#14 "cerebral* insufficient*"

\#15 "pick* disease"

\#16 creutzfeldt or jcd or cjd

\#17 huntington*

\#18 binswanger ${ }^{\star}$

\#19 korsako*
July 2010: 2

October 2016: 0

December 2017: 15 
(Continued)

\section{\#20 (\#1 OR \#2 OR \#3 OR \#4 OR \#5 OR \#6 OR \#7 OR \#8 OR \#9 OR \#10 OR \#11 OR \#12 OR \#13 OR \#14 OR \#15 OR \#16 OR \#17 OR \#18 OR \#19)}

\#21 MeSH descriptor Valproic Acid, this term only

\#22 valproic

\#23 valproate

\#24 divalproex*

\#25 (\#21 OR \#22 OR \#23 OR \#24)

\#26 (\#20 AND \#25), from 2008 to 2010

\begin{tabular}{lll}
\hline ClinicalTrials.gov & Interventional Studies | dementia OR alzhiemer OR alzheimers OR alzheimer's & July 2010: 7 \\
& OR agitation | valproate OR valproic OR divalproex &
\end{tabular}

[Most recent search: 7 OR agitation / valproate OR valproic OR divalproex

October 2016: 0

December 2017]

December 2017: 1

ICTRP (The WHO portal) Interventional Studies | dementia OR alzhiemer OR alzheimers OR alzheimer's OR agitation | valproate OR valproic OR divalproex AND date rec: 01/01/2008 ? $30 / 07 / 2010$
July 2010: 4

October 2016: 0

December 2017: 1

February 2008: 109

July 2010: 304

October 2016: 78

December 2017: 148

TOTAL: 639

February 2008: 11

July 2010: 12

October 2016: 4

December 2017: 14

TOTAL: 41

WHAT'S NEW

\begin{tabular}{lll}
\hline Date & Event & Description \\
\hline 7 December 2017 & New search has been performed & $\begin{array}{l}\text { A top-up search was performed for this review on 7 December } \\
2017 .\end{array}$ \\
\hline 7 December 2017 & $\begin{array}{l}\text { New citation required but conclusions } \\
\text { have not changed }\end{array}$ & $\begin{array}{l}\text { No new studies added. Conclusions unchanged. Review revised } \\
\text { in line with MECIR standards. New authors added }\end{array}$ \\
\hline
\end{tabular}




\section{HISTORY}

Protocol first published: Issue 4, 2002

Review first published: Issue 2, 2004

\begin{tabular}{lll}
\hline Date & Event & Description \\
\hline 4 November 2016 & New search has been performed & $\begin{array}{l}\text { An updated search was performed for this review on 04 Novem- } \\
\text { ber 2016. No new studies were identified for either inclusion or } \\
\text { exclusion within the review. }\end{array}$ \\
& & \\
\hline
\end{tabular}

2 October $2014 \quad$ New search has been performed

An update search was performed for this review on 30 July 2010. No new studies were identified for either inclusion or exclusion within the review.

An update search was performed for this review on 02 October 2015. No new studies were identified for either inclusion or exclusion within the review.

31 October $2008 \quad$ New search has been performed

31 October $2008 \quad$ New citation required but conclusions have not changed
February 2008: A new update search for the review was run. Some possible new studies for inclusion or exclusion were retrieved.

October 2008: Two new controlled studies were reviewed (Tariot, 2005; Herrman, 2007).These studies were incorporated into a meta analysis that examined the effect of valproate preparations on agitation as measured by the Cohen-Mansfield Agitation Index score and by the Brief Psychiatric Rating Scale. In addition, meta analysis was uses to examine the frequency of adverse events in valproate patients compared with placebo treated patients.

Both studies confirmed the Cochrane report of 2004 (Lonergan, 2004) that valproate preparations showed no effect on agitation as compared with placebo controls. Further meta analysis also demonstrated among valproate patients increased adverse events, especially falls, infection, gastrointestinal disorders, and decreased platelet counts compared with placebo treated patients.

At this time valproate preparations cannot be recommended for the control of agitation in demented patients)

12 August $2005 \quad$ New search has been performed

Minor update: 12 August 2005. In a new controlled study of the effect of divalproex sodium on agitation in demented patients, reported in abstract form, Tariot and associates (Tariot 2004) were unable to demonstrate any significant difference in agitation among treated patients (target dose of divalproex, 750 $\mathrm{mg}$ per day), compared with placebo controls. This study will be reviewed in greater detail when the published article becomes available.

\begin{tabular}{ll}
\hline 1 February 2004 & $\begin{array}{l}\text { New citation required and conclusions } \\
\text { have changed }\end{array}$
\end{tabular}

\section{CONTRIBUTIONS OF AUTHORS}

SB: drafting of updated review; selection of recent trials; extraction of data; interpretation of data analyses; updated review 2018. 
UN: drafting of updated review; selection of recent trials; extraction of data; interpretation of data analyses; updated review 2018.

$\mathrm{JL}$ : drafting of review versions; selection of trials; extraction of data; interpretation of data analyses; original review 2004, updated review 2009, and updated review 2018.

AC: drafting of updated review; correspondence; selection of recent trials; extraction of data; interpretation of data analyses; updated review 2018.

E Lonergan (previous review author): drafting of review versions; correspondence; selection of trials; extraction of data; entry of data; interpretation of data analyses original review 2004 and updated review 2009.

Ann Ludvik: consumer editor.

This review was peer reviewed anonymously in April 2004.

\section{DECLARATIONSOF INTEREST}

SB: none known.

UN: none known.

JL: none known.

AC: none known.

\section{SOURCES OF SUPPORT}

\section{Internal sources}

- Department of Health Sciences, University of Leicester, UK.

Employing institution for S Baillon

- Leicestershire Partnership NHS Trust, UK.

Salary support for S Baillon

- Faculty Health \& Life Sciences, De Montfort University, Leicester, UK.

Employing institute of A Clifton

\section{External sources}

- NIHR, UK.

This update was supported by the National Institute for Health Research (NIHR), via Cochrane Infrastructure funding to the Cochrane Dementia and Cognitive Improvement group. The views and opinions expressed therein are those of the authors and do not necessarily reflect those of the Systematic Reviews Programme, NIHR, National Health Service, or the Department of Health

\section{DIFFERENCES BETWEEN PROTOCOL AND REVIEW}

In many of the studies that the searches identified, the reporting of baseline clinical evaluation was not always specific or detailed. We took a pragmatic approach to avoid risking the loss of relevant evidence and included studies despite this information not being explicitly reported.

If an included study was discontinued due to a high level of dropout and adverse effects experienced by the treatment group, we decided that this presented a high risk of attrition bias and so excluded data from the pooled analysis from the outcome measures.

One of the aims stated in the protocol was to examine the effect of valproate preparations on carer burden. All of the included studies were carried out in long-term care settings and not in the community; consequently, none of the studies attempted to assess carer burden, and so analysis of such effects was not possible.

The original protocol proposed analysis treatment efficacy by type of dementia, degree of dementia, age, and sex if number of participants was sufficient. The low number of included studies meant that the number of participants were not sufficient for such subgroup analysis.

The original protocol stated participants receiving more than one psychopharmacological agent at the time of the study would be excluded from the report. In this 2018 updated review, we excluded participants receiving chronic therapy with other psychoactive medications from the review except for those studies where treatment with an additional psychotropic medication was permitted in the study 
protocol. Participants receiving treatment for dementia with cholinesterase inhibitors or memantine or receiving long-term unchanged antidepressant treatment were not excluded from the review. Often clear information regarding concomitant medication was not reported.

The original protocol proposed analysis of effect of treatment on one or more specific aspects of agitation. The low number of included studies meant that the number of participants were not sufficient for such analysis.

The original protocol proposed analysis of effect of treatment of different forms of valproic acid (e.g. divalproex versus sodium valproate). The number of included studies was too low to enable such analysis. It was also proposed to determine if the response to treatment was influenced by the dose or duration of treatment. Four of the five included studies involved the same duration of treatment preventing assessment of the impact of duration of treatment, and all studies varied in terms of the medication and dose used. The number of studies included was too low to enable any analysis of these aspects of the treatment.

\section{INDEX TERMS}

\section{Medical Subject Headings (MeSH)}

Aggression [drug effects]; Antimanic Agents [adverse effects] [*therapeutic use]; Cognition [drug effects]; Dementia [ ${ }^{*}$ complications]; Psychomotor Agitation [ ${ }^{*}$ drug therapy] [etiology]; Randomized Controlled Trials as Topic; Treatment Outcome; Valproic Acid [adverse effects] [*therapeutic use]

\section{MeSH check words}

Aged; Humans 